$$
\begin{aligned}
& \text { RECEIVEC } \\
& \text { JUL } 02 \text { 1999 } \\
& \text { OSTI }
\end{aligned}
$$

\title{
Study of the Neutron Flux and Dpa Attenuation in the Reactor Pressure-Vessel Wall
}

\author{
I. Remec
}

MANAGED AND OPERATED BY

LOCKHEED WARTIN ENERGY RESEARCH CORPORATION FOR THE UNTEO STATES

DEPARTUENT OF ENERGY 

ORNL/NRC/LTR-99/5

Contract Program or Title:

Subject of this Document:

Type of Document:

Author:

Date of Document:

Responsible NRC Individual and NRC Office or Division:
Embrittlement Data Base and Dosimetry Evaluation Program

Study of the Neutron Flux and Dpa Attenuation in the Reactor PressureVessel Wall

Letter Report

I. Remec

June 1999

C. Fairbanks (301-415-6014)

Division of Engineering, U.S. Nuclear Regulatory Commission

Prepared for the

U.S. Nuclear Regulatory Commission

Washington, DC 20555

under Interagency Agreement DOE 1886-N616-4W

NRC JCN No. W6164

OAK RIDGE NATIONAL LABORATORY

Oak Ridge, TN 37831-6363

managed by

LOCKHEED MARTIN ENERGY RESEARCH CORP.

for the

U.S. Department of Energy

under contract DE-AC05-96OR22464. 
ORNL/NRC/LTR-99/5

Study of the Neutron Flux and Dpa Attenuation in the Reactor Pressure-Vessel Wall

I. Remec

Manuscript Completed - May 1999

Date Published - June 1999

Prepared for the

U.S. Nuclear Regulatory Commission

Washington, DC 20555

under Interagency Agreement DOE 1886-N616-4W

NRC JCN No. W6164

Prepared by the

OAK RIDGE NATIONAL LABORATORY

Oak Ridge, TN 37831-6363

managed by

LOCKHEED MARTIN ENERGY RESEARCH CORP.

for the

U.S. Department of Energy

under contract DE-AC05-96OR22464 


\section{DISCLAIMER}

This report was prepared as an account of work sponsored by an agency of the United States Government. Neither the United States Government nor any agency thereof, nor any of their employees, make any warranty, express or implied, or assumes any legal liability or responsibility for the accuracy, completeness, or usefulness of any information, apparatus, product, or process disclosed, or represents that its use would not infringe privately owned rights. Reference herein to any specific commercial product, process, or service by trade name, trademark, manufacturer, or otherwise does not necessarily constitute or imply its endorsement, recommendation, or favoring by the United States Government or any agency thereof. The views and opinions of authors expressed herein do not necessarily state or reflect those of the United States Government or any agency thereof. 


\section{DISCLAIMER}

Portions of this document may be illegible in electronic image products. Images are produced from the best available original document. 


\begin{abstract}
The study of the neutron flux and dpa attenuation in the reactor pressure vessel (PV) wall presented in this work was performed with state-of-the art methods currently used to determine PV fluxes, the BUGLE-96 cross-section library, and the iron displacement cross sections derived from ENDF/B-VI data.
\end{abstract}

The calculations showed that the RG 1.99, Rev. 2, extrapolation formula predicts slower-and therefore conservative-attenuation of the neutron flux $(\mathrm{E}>1 \mathrm{MeV})$ in the PV wall. More importantly, the calculations gave slower attenuation of the dpa rate in the PV wall than the attenuation predicted by the formula. The slower dpa rate attenuation was observed for all the cases considered, which included two different PWRs, and several configurations obtained by varying the PV wall thickness and thermal shield thickness. For example, for a PV wall thickness of $\sim 24 \mathrm{~cm}$, the calculated ratio of the dpa rate at $1 / 4$ and $3 / 4$ of the PV wall thickness to the dpa value on the inner PV surface is $\sim 14 \%$ and $19 \%$ higher, respectively, than predicted by the RG 1.99 , Rev. 2 , formula.

An investigation into the causes of these relatively large differences was performed through the comparison of a series of calculations with the SAILOR cross section library, based on ENDF/B-IV data, and the BUGLE-96 cross-section library. This approach was used because the dpa rate attenuation in the PV wall, calculated with the SAILOR cross section, $\mathrm{P}_{1}$ approximation to the angular dependence of scattering cross sections, and dpa cross sections from ASTM standard E 693, comes relatively close (within $\sim 5 \%$ ) to the RG 1.99, Rev. 2, formula prediction. It was found that approximately $40-45 \%$ of the differences are caused by the change in cross sections (from SAILOR, $P_{1}$ to BUGLE-96, $\left.P_{1}\right), \sim 35-40 \%$ of the differences are due to the change from $P_{1}$ to $P_{3}$, and $\sim 15-20 \%$ of the differences are induced by the change from the ENDF/B-IV to the ENDF/B-VI dpa cross sections. Near the PV surfaces the calculated attenuation of the dpa rate also deviates from the simple exponential attenuation used in the RG 1.99, Rev. 2, formula, which contributes to the larger differences, especially near the PV outer surface.

Calculations for various thermal shield thicknesses showed that thicker thermal shield typically results in slower dpa attenuation in the PV wall. However, increasing the thermal shield thickness ten'ds to decrease the dpa rate at the PV inner wall by $3.5 \%$ per $1 \mathrm{~cm}$ of the thermal shield thickness increase $(1 \mathrm{~cm}$ of water replaced by $1 \mathrm{~cm}$ of steel). The thickness of the PV wall has a negligible effect on the dpa rate at the PV inner wall; however, the thicker the PV is, the slower is the dpa decrease inside the wall. The effect is small in the region near the PV inner surface but becomes quite important at larger distances from the PV inner wall.

The dpa rate attenuation calculated for the two-loop PWR was found in good agreement with the results for the three-loop PWR with similar PV wall thickness. This agreement indicates that performing a few additional parametric studies with the models used in this study, for different thermal shield, PV, and downcomer thicknesses, may be sufficient to generate the data base for an update of the RG 1.99, Rev. 2, attenuation formula. A more rigorous, but also more time-consuming approach, would require the calculations of the dpa attenuation in the PV wall for several different reactor designs, similar to Guthrie's work, which considered six types of commercial PWRs. 



\section{CONTENTS}

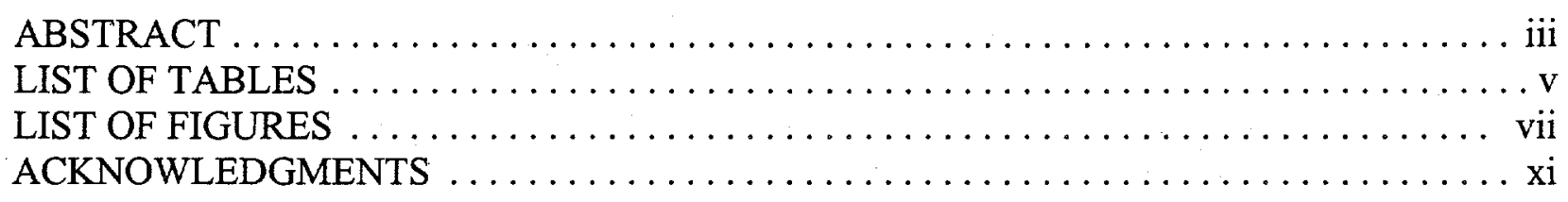

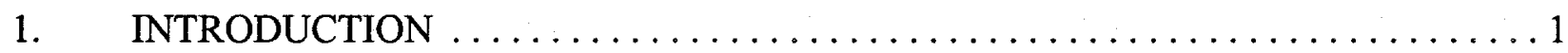

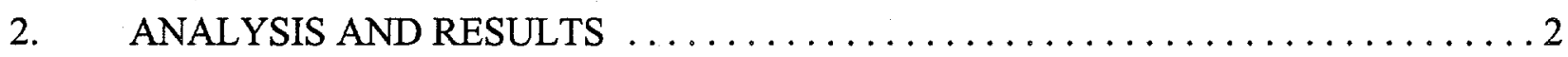

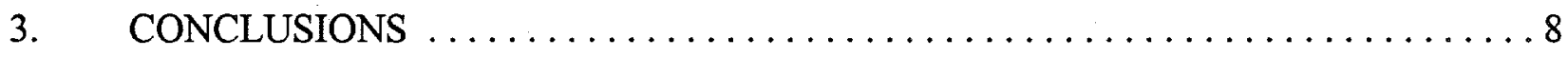

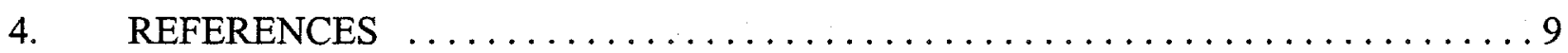

\section{TABLES}

Table 1 Flux $(E>1 \mathrm{MeV})$, flux $(\mathrm{E}>0.1 \mathrm{MeV})$, and dpa rate at the PV inner surface, versus the thickness of the thermal shield $\ldots \ldots \ldots \ldots \ldots \ldots \ldots \ldots \ldots \ldots \ldots$

Table 2 Flux $(E>1 \mathrm{MeV})$ attenuation in the PV wall, for different thermal shield thicknesses

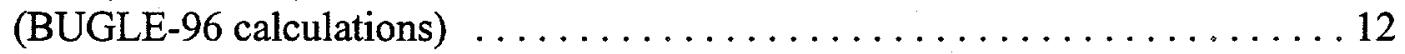

Table 3 Attenuation of the dpa rate in the PV wall for different thermal shield (TS) thicknesses. Absolute dpa rate values are given as well as the values relative to the dpa rate at the PV inner wall. Neutron fluxes are from the calculations with BUGLE-96. ENDF/B-VI dpa cross sections were used $\ldots \ldots \ldots \ldots \ldots$

Table 4 Attenuation of the dpa rate in the PV wall for different thermal shield (TS) thicknesses. Absolute dpa rate values are given as well as the values relative to the dpa rate at the PV inner wall. Neutron fluxes are from the calculations with BUGLE96. ASTM dpa cross sections were used $\ldots \ldots \ldots \ldots \ldots \ldots \ldots \ldots \ldots \ldots$

Table 5 Attenuation of the flux $(\mathrm{E}>0.1 \mathrm{MeV})$ through the PV wall for different thermal

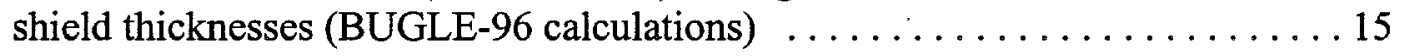

Table 6 Flux $(\mathrm{E}>1 \mathrm{MeV})$ attenuation in the PV wall for different wall thicknesses. (PV inner radius was $197.49 \mathrm{~cm}$ in all the cases; calculations with BUGLE-96) . . 16

Table 7 Dpa rate attenuation in the PV wall for different wall thicknesses. (Calculated with BUGLE-96 cross sections and ENDF/B-VI dpa cross sections) . . . . . . . 17

Table 8 Dpa rate attenuation in the PV wall for different wall thicknesses. (Calculated with BUGLE-96 cross sections and ASTM dpa cross sections) $\ldots \ldots \ldots \ldots \ldots 18$ 
Table 9 Flux $(\mathrm{E}>0.1 \mathrm{MeV})$ attenuation in the PV wall for different wall thicknesses. PV inner radius was $197.49 \mathrm{~cm}$ in all the cases. (Calculations with BUGLE-96) . . 19

Table 10 Flux $(\mathrm{E}>1 \mathrm{MeV})$ attenuation in the PV wall, calculated with the BUGLE-96 and the SAILOR cross-section libraries. The HBR-2 nominal geometry was used in both calculations. SAILOR calculation used the ENDF/B-IV fission spectra . . . . . 20

Table 11 Attenuation of the dpa rate in the PV wall. The ENDF/B-VI dpa cross section was used with BUGLE-96 and SAILOR calculations $\ldots \ldots \ldots \ldots \ldots \ldots \ldots \ldots \ldots$

Table 12 Flux $(\mathrm{E}>1 \mathrm{MeV})$ and dpa rate attenuation in the PV wall. To determine the dpa rates the ENDF/B-VI dpa cross sections were used with BUGLE-96, while ASTM dpa cross sections were used with SAILOR. All calculations are for the HBR-2 geometry $\ldots \ldots \ldots \ldots \ldots \ldots \ldots \ldots \ldots \ldots \ldots \ldots \ldots \ldots \ldots \ldots \ldots \ldots \ldots \ldots \ldots, 22$

Table 13 Flux $(\mathrm{E}>1 \mathrm{MeV})$ attenuation in the PV, calculated with the BUGLE-96 crosssection library and the $P_{1}$ to $P_{3}$ approximations for the anisotropic scattering ..23

Table 14 The attenuation of the dpa rate in the PV wall, calculated with the BUGLE-96 cross sections, the $\mathrm{P}_{1}$ to $\mathrm{P}_{3}$ approximations for anisotropic scattering, and with the ASTM

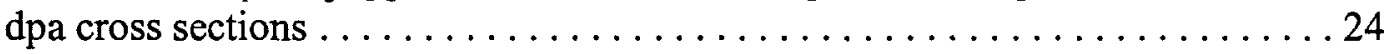

Table 15 Comparison of dpa rate attenuation in the PV wall, calculated with SAILOR library, $\mathrm{P}_{1}$ approximation, and ASTM dpa cross sections with the dpa rate attenuation obtained with BUGLE-96 library, $\mathrm{P}_{3}$ approximation, and ENDF/B-VI dpa cross sections. (Comparison with the RG 1.99, Rev. 2, attenuation formula is also

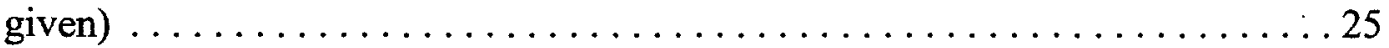

Table 16 Comparison of the dpa rate attenuation in the PV wall, calculated with ENDF/B-VI and ASTM dpa cross sections. Neutron fluxes are from the BUGLE-96 calculation. The HBR-2 "nominal" geometry was used. . . . . . . . . . . . . . 26

Table 17 Summary of the changes in dpa attenuation at $\sim 5 \mathrm{~cm}$ and $15 \mathrm{~cm}$ from the PV inner surface, for a 24.20 -cm-thick PV wall ..................... 27

Table 18 Flux $(\mathrm{E}>1 \mathrm{MeV})$ attenuation in the PV wall. The ratios of the fast flux at a given depth to the fast flux at the PV inner radius are given. The column "average" gives the ratio, at the depth, "d," in the vessel wall, calculated as the arithmetic average over all azimuthal intervals. The columns "maximum" and "minimum" give the maximum and minimum ratio, respectively, over all azimuthal intervals. The deviations (in percent) of the maximum and minimum from the average are also

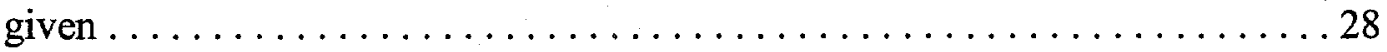


Table 19 Dpa rate (ASTM) attenuation in the PV wall. The ratios of the dpa rate at a given depth to the dpa rate at the PV inner radius are given. The column "average" gives the ratio, at the given depth, "d," in the vessel wall, calculated as the arithmetic average over all azimuthal intervals. The columns "maximum" and "minimum" give the maximum and minimum ratio over all azimuthal intervals, respectively. The deviations of the maximum and minimum from the average are also given . . . 29

Table 20 The attenuation of the flux $(E>1 \mathrm{MeV})$, flux $(\mathrm{E}>0.1 \mathrm{MeV})$, and dpa rate calculated with the ASTM and ENDF/B-VI dpa cross sections, respectively, inside the PV wall. The calculations were done with the BUGLE-96 library. A two-loop plant of Westinghouse design with a $17.16-\mathrm{cm}$-thick PV wall was analyzed . . . . . 30

Table 21 The attenuation of the flux $(E>1 \mathrm{MeV})$, flux $(\mathrm{E}>0.1 \mathrm{MeV})$, and dpa rate calculated with the ASTM and the ENDF/B-VI dpa cross sections, respectively, inside the PV wall. The calculations were done with the SAILOR library. A two-loop plant of Westinghouse design with a $17.16 \mathrm{~cm}$ thick PV wall was analyzed ....... 31

\section{FIGURES}

Figure 1 Flux $(\mathrm{E}>1 \mathrm{MeV})$, flux $(\mathrm{E}>0.1 \mathrm{MeV})$, and dpa rate (ENDF/B-VI dpa) at the PV inner wall as a function of the thermal shield thickness $\ldots \ldots \ldots \ldots \ldots 32$

Figure 2 Flux (E $>1 \mathrm{MeV}$ ) attenuation in the PV wall for different thermal shield thicknesses. (Calculations were done with BUGLE-96 library) $\ldots \ldots \ldots \ldots \ldots \ldots$

Figure 3 Dpa rate attenuation in the PV wall for different thicknesses of the thermal shield (TS). All values are normalized to 1.000 at the PV inner wall (wetted surface). Neutron fluxes are from the calculations with BUGLE-96. ENDF/B-VI dpa cross

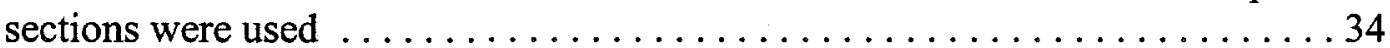

Figure $4 \quad$ Flux $(\mathrm{E}>0.1 \mathrm{MeV}$ ) attenuation in the PV wall for different thermal shield thicknesses. (Calculations were done with the BUGLE-96 library) . . . . . . 35

Figure 5 Flux $(\mathrm{E}>1 \mathrm{MeV})$ attenuation in the PV wall for different $\mathrm{PV}$ wall thicknesses. The curve derived from the RG 1.99 , Rev. 2 , formula is also shown . . . . . . 36

Figure 6 Dpa rate attenuation in the PV wall for different PV wall thicknesses. Calculations were done with the BUGLE-96 cross-section library and ENDF/B-VI dpa cross sections. The curve derived from the RG 1.99, Rev. 2, formula is also shown . . 37

Figure $7 \quad$ Flux $(E>0.1 \mathrm{MeV})$ attenuation in the PV wall for different PV wall thicknesses. Calculations were done with the BUGLE-96 cross-section library. The curve derived from the RG 1.99 , Rev. 2 , formula is also shown . . . . . . . . . . . 38 
Figure $8 \quad$ Flux $(\mathrm{E}>0.1 \mathrm{MeV})$ attenuation in the PV wall for different PV wall thicknesses. Calculations were done with the BUGLE-96 cross-section library. The curve derived from the RG 1.99 , Rev. 2 , formula is also shown . . . . . . . . . . . 39

Figure 9 Flux $(E>1 \mathrm{MeV})$ and dpa rate attenuation in the PV wall for different PV wall thicknesses. Calculations were done with the BUGLE-96 cross-section library and ENDF/B-VI dpa cross sections. The curve derived from the RG 1.99, Rev. 2, formula

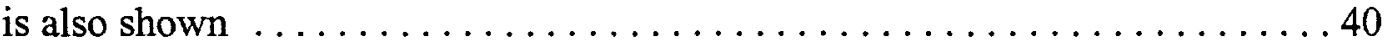

Figure 10 Flux $(E>1 \mathrm{MeV}$ ) attenuation in the PV wall calculated with BUGLE-96 and SAILOR cross-section libraries. SAILOR calculation used ENDF/B-IV fission spectra. The curve derived from the RG 1.99, Rev. 2, formula is also shown . . 41

Figure 11 Comparison of dpa rate attenuation in the PV wall. The ENDF/B-VI dpa cross sections were used with both the BUGLE-96 and the SAILOR calculations. The curve derived from the RG 1.99 , Rev. 2, attenuation formula is also shown . . 42

Figure 12 Flux $(E>1 \mathrm{MeV})$ and dpa rate attenuation in the PV wall calculated with BUGLE-96 and SAILOR cross-section libraries. SAILOR calculation used ENDF/B-IV fission spectra and ASTM dpa cross sections. The ENDF/B-VI dpa cross sections were used with BUGLE-96 calculations. The curve derived from the RG 1.99, Rev. 2, formula

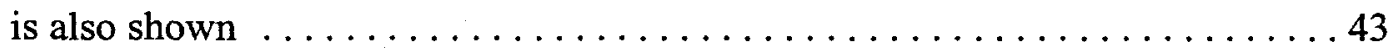

Figure 13 Comparison of dpa rate attenuation in the PV wall. The BUGLE-96 calculation with ENDF/B-VI dpa cross sections, and the SAILOR calculation with ASTM dpa cross sections are compared between themselves and with the RG 1.99, Rev. 2, attenuation

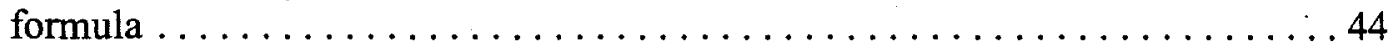

Figure 14 Flux $(E>1 \mathrm{MeV})$ attenuation in the PV wall, calculated with BUGLE-96 crosssection library, and the $P_{1}$ to $P_{3}$ approximations for the anisotropic scattering. Calculations were done for HBR-2 "nominal" dimensions . . . . . . . . . . 45

Figure 15 Dpa rate attenuation in the PV wall, calculated with the BUGLE-96 cross-section library, the $P_{1}$ to $P_{3}$ approximations for anisotropic scattering, and ASTM dpa cross sections. Calculations were done for HBR-2 "nominal" dimensions . . . . . .46

Figure 16 Dpa rate attenuation in the PV wall, calculated with the BUGLE-96 cross-section library, the $P_{1}$ to $P_{3}$ approximations for anisotropic scattering, and ASTM dpa cross sections. The results from the SAILOR calculation with $P_{1}$ and $P_{3}$ approximations, ENDF/B-IV fission spectra, and ASTM dpa cross sections are also shown. Calculations were done for HBR-2 "nominal" dimensions $\ldots \ldots \ldots \ldots \ldots \ldots 7$ 
Figure 17 Comparison of the attenuation in the PV wall, as obtained from the BUGLE-96 calculation with $\mathrm{P}_{3}$ approximation, and ENDF/B-VI dpa cross-section; and SAILOR calculation with $\mathrm{P}_{1}$ approximation and ASTM dpa cross sections. The curve derived from RG 1.99 , Rev. 2 , formula is also given $\ldots \ldots \ldots \ldots \ldots \ldots \ldots \ldots 48$

Figure 18 Comparison of the dpa rate attenuation in the PV wall, calculated with ENDF/B-VI and ASTM dpa cross sections. Neutron fluxes are from the BUGLE-96 calculation. HBR-2 "nominal" geometry was used . . . . . . . . . . . . . . . . 49

Figure 19 Flux $(\mathrm{E}>1 \mathrm{MeV})$ versus azimuthal angle, at the PV inner radius, and at the $1 / 4$ and $3 / 4$ of the PV wall thickness from the PV inner surface. Calculations were done with BUGLE-96 cross-section library for "nominal" HBR-2 geometry . . . . . . . 50

Figure 20 Dpa rate versus azimuthal angle, at the PV inner radius, and at the $1 / 4$ and $3 / 4$ of the PV wall thickness from the PV inner surface. Calculations were done with BUGLE96 cross-section library and ASTM dpa cross sections, for "nominal" HBR-2

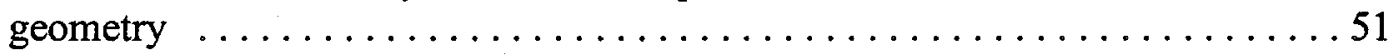

Figure 21 Flux $(\mathrm{E}>1 \mathrm{MeV})$ attenuation in the PV wall. The curve labeled "average" gives the ratio of the flux at the given depth, "d," from the inner surface to the flux at the PV inner surface, averaged (arithmetic average) over all the azimuthal intervals. Curves labeled "maximum" and "minimum" give the maximum and minimum ratios over all the azimuthal intervals, respectively $\ldots \ldots \ldots \ldots \ldots \ldots \ldots \ldots \ldots .52$

Figure 22 Dpa rate attenuation in the PV wall. The curve labeled "average" gives the ratio of the dpa rate at the given depth, "d," from the inner surface to the dpa rate at the PV inner surface, averaged (arithmetic average) over all the azimuthal intervals. The curves labeled "maximum" and "minimum" give the maximum and minimum ratios over all the azimuthal intervals, respectively. Dpa rates were obtained from the calculations with BUGLE-96 and ASTM dpa cross sections $\ldots \ldots \ldots \ldots 53$

Figure 23 Flux $(\mathrm{E}>1 \mathrm{MeV})$ attenuation in the PV wall, calculated with BUGLE-96 library, for different PV wall thicknesses. The calculations for the PV thickness of $17.16 \mathrm{~cm}$ were done for a two-loop plant. The other curves are those from Figure $5 \ldots . .54$

Figure 24 Flux $(E>0.1 \mathrm{MeV})$ attenuation in the PV wall, calculated with BUGLE-96 library, for different PV wall thcknesses. Calculations for the PV thickness of $17.16 \mathrm{~cm}$ were done for a two-loop plant. The other curves are those from Figure $8 \ldots \ldots \ldots 5$

Figure 25 Dpa rate attenuation in the PV wall, calculated with BUGLE-96 library and the ASTM dpa cross sections, for different PV wall thicknesses. Calculations for the PV thickness of $17.16 \mathrm{~cm}$ were done for a two-loop plant. Other curves show data from

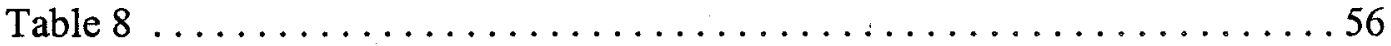


Figure 26 Dpa rate attenuation in the PV wall, calculated with BUGLE-96 library and ENDF/B-VI dpa cross sections, for different PV wall thicknesses. Calculations for the PV thickness of $17.16 \mathrm{~cm}$ were done for a two-loop plant. Other curves are from

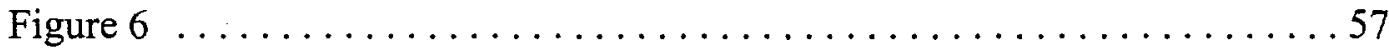




\section{ACKNOWLEDGMENTS}

The author wishes to express his appreciation to the reviewers, J. V. Pace III and R. E. Stoller of the Oak Ridge National Laboratory. Special thanks go to C. H. Shappert for providing the editorial review and to $M$. $R$. Whittenbarger for the preparation of this report. The work was performed as a part of the "Embrittlement Data Base and Dosimetry Evaluation Program" (FIN W6164) sponsored by the Nuclear Regulatory Commission and managed by Carolyn Fairbanks of the Nuclear Regulatory Commission. 


\section{INTRODUCTION}

The current methodology for the determination of the fast flux $(E>1 \mathrm{MeV})$ inside the reactor pressure vessel (PV) wall, acceptable to the U.S. Nuclear Regulatory Commission (NRC) is described in Regulatory Guide 1.99, Revision 2 (Ref. 1). The regulatory guide states that "The neutron fluence at any depth in the vessel wall, $\mathrm{f}\left(10^{19} \mathrm{n} / \mathrm{cm}^{2}, \mathrm{E}>1 \mathrm{MeV}\right)$, is determined as follows:

$$
\mathrm{f}=\mathrm{f}_{\text {surf }} \times \mathrm{e}^{-0.24 x}
$$

where $f_{\text {surf }}\left(10^{19} \mathrm{n} / \mathrm{cm}^{2}, E>1 \mathrm{MeV}\right)$ is the calculated value of the neutron fluence at the inner wetted surface of the vessel at the location of the postulated defect, and $x$ (in inches) is the depth into the vessel wall measured from the vessel inner (wetted) surface. Alternatively, if dpa calculations are made as part of the fluence analysis, the ratio of the dpa at the depth in question to the dpa at the inner surface may be substituted for the exponential attenuation factor in Equation 3." The RG 1.99 Equation 3 is the (Eq. 1) shown above.

The basis for the RG 1.99, Rev. 2, attenuation formula is discussed in Randall's paper (Ref. 2) and can be summarized as follows: Prior to the RG 1.99, Rev. 2, the fast-flux attenuation in the wall was estimated by the formula given in (Eq. 1), but with the coefficient in the exponent of 0.33 . This older attenuation formula came from U.S. NRC staff reviews of the surveillance reports. During the preparation of RG 1.99, Rev. 2, it was realized that the changes in neutron spectra with depth of penetration in the wall are significant. To take this into account it was decided to use a "dpa equivalent" (displacements per atom) attenuation formula. To convert the "fluence attenuation" formula to the "dpa attenuation" formula, the calculations reported in Guthrie's paper (Ref. 3) were used. Guthrie and coworkers showed that the dpa attenuation through the vessel wall was less than the attenuation of fast fluence $(E>1 \mathrm{MeV})$ by a factor of $\sim 2.06$, which was the average of six calculations (one calculation for each of six different PWR reactors). As explained in Reference 2, to achieve a 2.06-times slower flux attenuation through an 8-in.-thick PV wall, the exponent in the flux attenuation formula was changed from 0.33 to 0.24 , which is given in RG 1.99, Rev. 2. (See Eq. $1)^{*}$

The transport calculations by Guthrie and coworkers were performed as fixed neutron source calculations with the Westinghouse version of the DOT-3 neutron transport code (Ref. 4), and $\mathrm{S}_{8}$ angular quadrature. The GAMBIT-1T cross-section library (Ref. 5), based on an early version of ENDF/B evaluated data files, was used. The angular dependence of the scattering cross sections was

"The factor of 2.06, which is the average of the factors calculated for six different reactors, reported in Reference 3, was used with the PV wall thickness of 8 in. However, Reference 3 does not give the thicknesses of the PV wall of the six reactors considered. It is quite possible that calculations for different reactors, from which the average factor 2.06 was derived, were actually done for different PV wall thicknesses. The relatively large spread of the factors reported in Reference 3 (minimum 1.62, maximum 2.23) seems to indicate that different PV thicknesses were used for the different reactor types analyzed. 
described with a $P_{1}$ approximation. The spectrum of the fission neutron source was the Cranberg fission spectrum.

Since Guthrie's analysis the cross sections were updated several times. $\mathrm{A}_{3}$ expansion is routinely used in the transport calculations, and the cross-section libraries typically use a refined energy-group structure (e.g., 8 groups above $1 \mathrm{MeV}$ were used in GAMBIT-1T, compared with 19 groups in BUGLE-96). Given all these changes, it appears necessary to revisit the fast flux and dpa attenuation in the PV wall, which is the purpose of the work presented here. The in-vessel-wall gradients are calculated using (1) the BUGLE-96 multigroup cross-section library (based on ENDF/B-VI), (2) the current methodology of the transport calculations, and (3) the displacement cross sections for iron derived from ENDF/B-VI data. The comparisons with RG 1.99, Rev. 2, attenuation formula are presented. The results from this study will contribute to the data needed for an update of the RG 1.99, Rev. 2, fluence attenuation formula.

\section{ANALYSIS AND RESULTS}

The calculational method used in this analysis is consistent with state-of-the art methods currently used to determine PV fluxes. The same calculational method has been used, for example, in the analysis of the PCA and HBR-2 benchmarks (Ref. 6 and 7). The neutron transport calculations were performed with the DORT computer code (Ref. 8). The synthesis method, which combines one $r-\theta$, one $r-z$, and one one-dimensional (1-D) $r$-calculation to obtain the three-dimensional (3-D) flux distributions, was used throughout the analysis. More about the synthesis method can be found in References 6, 7, and 9. All transport calculations used a $P_{3}$ expansion of the scattering cross sections. The only exceptions were the calculations in which the effect of the order of scattering expansion was investigated. All calculations were performed as fixed neutron source calculations. The neutron source spatial distributions were prepared from the core power distributions available from the fuel cycle calculations, which were not part of this study, and were performed with codes used for core design calculations. Two neutron cross-section libraries were used: The BUGLE-96 library represents the currently recommended cross-section library based on ENDF/B-VI (Ref. 10) which was released in 1996. The SAILOR library (Ref. 11) represents older cross-section libraries, based on ENDF/B-IV data. The SAILOR library has been extensively used for PV flux calculations since it was released in 1984. Both cross-section libraries have the same neutron energy group structure of 47 groups (of which 19 groups cover the energy range above $1 \mathrm{MeV}$ ), which is of greatest interest in the PV flux calculations. The calculations with the SAILOR library were done to quantify the change in the flux and dpa rate attenuation in the PV wall due to the change in the cross sections.

Most of the calculations were done for the H. B. Robinson-2 (HBR-2), which is a three-loop pressurized-water reactor (PWR) of Westinghouse design, with a reactor thermal power of 2300 MW. The data on reactor core and out-of-core components, geometry, materials, and power distributions were taken from Reference 7. The HBR-2 dimensions, as given in Reference 7, are referred to in this report as the "nominal" dimensions. Starting from the nominal dimensions, the calculations were repeated for different thicknesses of the thermal shield and reactor PV wall, to quantify the effect of these parameters on the attenuation in the PV wall. Each change in geometry required a new set of transport calculations and flux synthesis. 
The effect of the change of the thermal shield (TS) thickness is presented in Tables 1-5 and Figures 1-4. Different thermal shield thicknesses were modeled by varying the thermal shield inner radius, and, consequently, the thickness of the water gap between the core barrel and the thermal shield. All other dimensions, in particular the core barrel outer radius, the thermal shield outer radius, and the PV inner radius were the same in all calculations. The flux $(E>1 \mathrm{MeV})$, flux $(\mathrm{E}>0.1 \mathrm{MeV})$, and the dpa rate, at the PV inner radius at the azimuthal location where they have maximal values, are listed for different TS thicknesses in Table 1 and are shown in Figure 1. Unless it is specified otherwise, all the irradiation parameters and their attenuation through the PV wall are given for the location at which they reach the maximum value at the PV inner wall. The flux (E>1 MeV) and dpa rate at the PV inner wall decrease monotonously as the TS thickness increases. The flux $(E>1 \mathrm{MeV}$ ) shows nearly a linear decrease of $\sim 3.5 \%$ per centimeter of the TS thickness increase. The decrease in the dpa rate is slower, while the flux $(E>0.1 \mathrm{MeV})$ has a minimum in the range of the TS thickness between 3 to $7 \mathrm{~cm}$. The flux $(E>1 \mathrm{MeV})$ versus the distance from the PV inner (wetted) surface, for different TS thicknesses, is listed in Table 2. The slowest attenuation of the flux $(\mathrm{E}>1 \mathrm{MeV}$ ) through the PV wall is observed for the configuration without the thermal shield (i. e., TS thickness $0 \mathrm{~cm})$. The ratio of the irradiation parameter [e.g., flux $(E>1 \mathrm{MeV})$ ], at the given distance from the PV inner (wetted) surface to the value at the PV inner surface, will be referred to as the extrapolation factor. For the TS thickness of $0 \mathrm{~cm}$ the flux $(\mathrm{E}>1 \mathrm{MeV})$ extrapolation factors at $\sim 5 \mathrm{~cm}$ and at $\sim 15 \mathrm{~cm}$ inside the PV wall are $\sim 3 \%$ and $\sim 6 \%$ higher, respectively, than the values for the TS thickness of $\sim 10 \mathrm{~cm}$. As shown in Figure 2, the RG 1.99, Rev. 2, formula predicts slower, therefore conservative, attenuation of the flux $(E>1 \mathrm{MeV})$, than the attenuations obtained from the transport calculations for all the TS thicknesses considered, except for the first few $(\sim 4 \mathrm{~cm})$ of the PV wall, where the calculated attenuation is slightly slower than the RG 1.99 prediction and gives up to $\sim 4.6 \%$ higher extrapolations factors.

The dpa rate attenuation in the PV wall is given in Table 3 for the iron atom displacement cross sections (dpa cross sections) generated from the ENDF/B-VI data, and in Table 4 for the irondisplacement cross sections from the ASTM standard E 693, which were derived from the ENDF/BIV data (Ref. 12). The dpa cross sections from ASTM E 693 will be referred to in the following as the "ASTM dpa." The thicker thermal shield typically causes slower dpa rate attenuation in the PV wall. For the TS thickness of $\sim 10 \mathrm{~cm}$, the extrapolation factors at $\sim 5 \mathrm{~cm}$ and at $\sim 15 \mathrm{~cm}$ from the PV inner wall are $\sim 3.6 \%$ and $11.5 \%$ higher, respectively, than the extrapolation factors for the configuration without the thermal shield. The dpa rate attenuation curves for different TS thicknesses are compared in Figure 3. The calculated attenuation of the dpa rate is slower than the attenuation predicted by RG 1.99, Rev. 2, for all TS thicknesses considered. For example, for the TS thickness $6.83 \mathrm{~cm}$, the extrapolation factors at $\sim 5 \mathrm{~cm}$ and $15 \mathrm{~cm}$ from the PV inner wall are $\sim 14 \%$ and $19 \%$ higher than the RG 1.99 formula prediction. The dpa rates calculated with the ENDF/B-VI dpa cross sections are typically slightly higher than the dpa rates calculated with the ASTM dpa cross sections, except at the PV inner surface and in a thin region of the PV close to the inner surface, for the configuration with a thin or no thermal shield. The effect of change from the ASTM to the ENDF/BVI dpa cross sections will be considered in more detail later. Table 5 gives the attenuation of the flux (E>0.1 Mev) through the PV for different TS thicknesses, and the attenuation curves are shown in Figure 4. Flux $(E>0.1 \mathrm{MeV})$ reaches maximum value within the first few centimeters of the PV wall and then decreases monotonically. In Figure 4 the attenuation curve derived from RG 1.99 is also shown. It predicts much faster attenuation than the calculated curves for the flux $(\mathrm{E}>0.1 \mathrm{MeV})$; 
however, this comparison must be viewed from the perspective that the RG 1.99 formula is intended to predict the attenuation of the dpa rate and not the flux $(E>0.1 \mathrm{MeV})$.

Next, the effect of PV wall thickness on the flux and dpa rate attenuation in the PV wall was investigated. Different PV wall thicknesses were modeled by changing the PV outer radius, while the inner radius, the thermal shield $(6.83 \mathrm{~cm}$ thick), and all the rest of the geometry were kept unchanged. Besides the nominal HBR-2 PV thickness of $24.2 \mathrm{~cm}$, the calculations were done for an $\sim 25 \%$ thinner and $\sim 25 \%$ thicker $P V$ wall. The calculated fluxes $(E>1 \mathrm{MeV})$ are listed in Table 6 and are shown in Figure 5. The PV wall thickness has a negligible effect on the flux $(\mathrm{E}>1 \mathrm{MeV})$ on the PV inner surface and throughout most of the PV wall. Only in approximately the last quarter of the PV wall the differences start to show, and the flux ( $E>1 \mathrm{MeV}$ ) in the thinner PV decreases faster towards the PV outer surface than it decreases in the PV with the thicker wall. The results for the dpa rate attenuation are given in Tables 7 and 8 for the ENDF/B-VI and ASTM dpa cross sections, respectively. Figure 6 shows the dpa rate attenuation curves calculated with the ENDF/BVI dpa cross sections. The dpa rate attenuation is more affected by the PV wall thickness than the flux $(\mathrm{E}>1 \mathrm{MeV})$ attenuation. A thicker PV wall results in slower dpa rate attenuation. For example, at $\sim 5 \mathrm{~cm}$ from the PV inner surface, the dpa extrapolation factor for the 30 -cm-thick PV is $\sim 3.4 \%$ higher than the corresponding factor for the PV with an 18.8-cm-thick wall. The differences increase through the PV wall and are in the range of $45 \%-60 \%$ in the vicinity of the PV outer surface. The RG 1.99 attenuation formula predicts faster attenuation than the calculated dpa curves for all three PV thicknesses considered. The only exception is the $\sim 3-\mathrm{cm}$-thick region near the PV outer surface, for the PV with an 18.75-cm-thick wall, as can be seen in Figure 6. The flux $(\mathrm{E}>0.1 \mathrm{MeV})$ attenuation in the PV wall is significantly affected by the PV wall thickness and is illustrated in Figures 7 (Lin-Lin plot) and 8 (Log-Lin plot). The flux $(\mathrm{E}>0.1 \mathrm{MeV})$ values and extrapolation factors are listed in Table 9. The dpa rate and flux $(\mathrm{E}>1 \mathrm{MeV})$ attenuation curves for different $\mathrm{PV}$ wall thicknesses are shown, together with the RG 1.99, Rev. 2, attenuation curve, on Figure 9.

Finally, the impact of the change from the SAILOR (ENDF/B-IV) to the BUGLE-96 cross-section library on the attenuation profiles in the PV were examined. The flux ( $E>1 \mathrm{MeV}$ ) attenuation in the PV, calculated with the two cross-section libraries, was compared in Table 10. The calculations were performed for the nominal HBR-2 geometry. The calculations with the SAILOR library used the ENDF/B-IV fission spectra for ${ }^{235} \mathrm{U}$ and ${ }^{239} \mathrm{Pu}$, while the BUGLE-96 calculation used the corresponding spectra from ENDF/B-VI data. The BUGLE-96 calculation results in slower flux $(E>1 \mathrm{MeV}$ ) attenuation. The extrapolation factor for the BUGLE-96 calculation is $\sim 3 \%$ higher at $\sim 5 \mathrm{~cm}$ from the PV inner wall, and the differences increase towards the PV outer surface, where they reach $\sim 17 \%$. The flux ( $\mathrm{E}>1 \mathrm{MeV}$ ) attenuation curves, calculated with SAILOR and BUGLE96 cross sections, are shown in Figure 10. The dpa rates, calculated with ENDF/B-VI dpa cross sections and fluxes from the SAILOR and BUGLE-96 calculations, are compared in Table 11 and in Figure 11. The differences in the dpa rates, calculated with the two libraries, are similar to the differences observed in flux $(E>1 \mathrm{MeV})$. Again, the BUGLE-96 calculation gives higher extrapolation factors: $\sim 3.7 \%$ higher at $\sim 5 \mathrm{~cm}$ from the inner PV surface, and $\sim 17 \%$ higher near the PV outer surface. Both calculations give considerably slower attenuation of dpa rate than the RG 1.99 formula, except for the region within a few centimeters from the PV outer surface. In most, if not all previous analyses performed with the SAILOR library, the ASTM dpa cross sections were used to determine dpa rates and attenuation in the PV wall. The dpa rates, therefore, were calculated 
also with neutron fluxes from the SAILOR calculation and the ASTM dpa cross sections. The comparison of the dpa rate attenuation profile with the one obtained with BUGLE-96 and ENDF/BVI dpa cross sections is given in Table 12, and in Figure 12. The dpa rate profiles are also compared with the BUGLE-96 flux (E $>1 \mathrm{MeV}$ ) profile and RG 1.99 attenuation formula. When SAILOR fluxes are combined with ASTM dpa cross sections, the dpa attenuation in the PV wall is slightly faster than the dpa attenuation calculated with the ENDF/B-VI dpa cross sections. The dpa attenuation factor, determined with "BUGLE-96 and ENDF/B-VI dpa cross sections," is $\sim 5.5 \%$ higher than the "SAILOR with ASTM dpa cross-sections" attenuation factor at $\sim 5 \mathrm{~cm}$ from the PV inner wall, and more than $20 \%$ higher near the PV outer surface. The dpa attenuation obtained with the "SAILOR with ASTM dpa cross sections" is also slower than the attenuation predicted with RG 1.99 formula throughout the PV wall, except in the region within approximately one quarter of the PV wall thickness from the PV outer wall. The differences between the calculated dpa rate attenuation in the PV wall and RG 1.99 formula are illustrated further in Figure 13, which shows the difference in percent between the extrapolation factors. For the $24.20-\mathrm{cm}$-thick PV wall, the maximal differences in predicted attenuation between the "BUGLE-96 with ENDF/B-VI dpa cross sections" and RG 1.99 formula is almost $20 \%$, at approximately $15 \mathrm{~cm}$ from the PV inner wall; the RG 1.99 formula predicts faster attenuation. Maximal differences between "SAILOR with ASTM dpa cross sections" and RG 1.99 formula are about $8 \%$ at $\sim 5 \mathrm{~cm}$ from the PV inner wall. The differences between dpa attenuation obtained from "BUGLE-96 with ENDF/B-VI dpa cross sections" to the "SAILOR with ASTM dpa cross sections" increase monotonically through the PV wall and exceed $20 \%$ near the PV outer surface.

Even though it was expected that the attenuation in the PV wall, calculated with the BUGLE-96 library, would be considerably slower than the attenuation described with the RG 1.99 formula, it is somewhat surprising that the attenuation obtained from "SAILOR with ASTM dpa cross sections" is also considerably slower than the RG 1.99 formula prediction. To investigate these differences, attention is turned to the effect of the approximation used for the description of angular dependence of the scattering cross sections. The transport calculations by Guthrie and coworkers, which furnished data for the RG 1.99, Rev. 2, attenuation formula update, were performed with a $\mathrm{P}_{1}$ approximation, while all the calculations reported so far in this work used a more accurate $\mathrm{P}_{3}$ approximation. To quantify the effect of the "P-order" approximation on the flux and dpa rate attenuation in the PV wall, a series of calculations with the $P_{1}, P_{2}$, and $P_{3}$ expansion of scattering cross sections was performed. All calculations were done for the "nominal" HBR-2 geometry. The results, obtained with the BUGLE-96 library, are given in Table 13 for the flux $(E>1 \mathrm{MeV})$ and in Table 14 for the dpa rate, calculated with ASTM dpa cross sections. The change from $P_{1}$ to $P_{3}$ results in slower attenuation of the flux $(\mathrm{E}>1 \mathrm{MeV})$ and the dpa rate through the PV wall. The flux $\left(\mathrm{E}>1 \mathrm{MeV}\right.$ ) extrapolation factor, determined with the $\mathrm{P}_{3}$ approximation, is $\sim 5 \%$ higher at $\sim 5 \mathrm{~cm}$ from the PV inner wall, $\sim 12 \%$ higher at $\sim 15 \mathrm{~cm}$, and $\sim 17 \%$ higher near the PV outer surface. The corresponding effect on the dpa rate attenuation is somewhat smaller: the extrapolation factor is $\sim 3.7 \%$ and $6.6 \%$ higher at $\sim 5 \mathrm{~cm}$, and $\sim 15 \mathrm{~cm}$ from the PV inner wall, respectively, when $\mathrm{P}_{3}$ approximation is used instead of the $\mathrm{P}_{1}$ approximation, and the maximum differences near the PV outer surface are $\sim 8 \%$. Figures 14 and 15 show the flux $(E>1 \mathrm{MeV})$ and the dpa rate attenuation in the PV wall, calculated with the BUGLE-96 library and $P_{1}$ to $P_{3}$ approximations. It can be seen that the effect of the change from $\mathrm{P}_{2}$ to $\mathrm{P}_{3}$ is practically negligible; however, the differences in the attenuation curves between the $P_{1}$ and $P_{3}$ calculations are important. Even the dpa rate attenuation 
curve obtained with the $\mathrm{P}_{1}$ approximation, the BUGLE-96 library, and the ASTM dpa cross sections, shows slower attenuation in the PV wall than predicted by the RG 1.99 formula. The calculations were repeated with the SAILOR library and the $P_{1}$ and $P_{3}$ approximations. The results are shown, in Figure 16, together with those for the BUGLE-96 library. Detailed comparisons are given in Table 15 and in Figure 17. The calculation with the SAILOR library, $\mathrm{P}_{1}$ approximation, and the ASTM dpa cross sections gives the fastest dpa rate attenuation in the PV wall and comes close to the RG 1.99, Rev. 2, attenuation formula: maximum differences do not exceed $5 \%$ over most of the PV wall thickness. However the "SAILOR, $\mathrm{P}_{1}$, ASTM dpa" calculation still gives slower attenuation of the dpa rate than the RG 1.99 formula. The exception is again in the region near the PV surface, where the formula gives slower attenuation. The reason for this is that in the region near the vessel outer surface the flux $(E>1 \mathrm{MeV})$ and the dpa rate decrease faster than in the region closer to the inner wall, because of the effect of the "free" PV outer surface: because of a low density of air in the cavity (compared with the density of PV steel) very few neutrons are scattered back from the cavity into the PV wall. These conditions are reflected in the calculated attenuation curves, but not in the RG 1.99, Rev. 2, formula, which assumes uniform exponential attenuation throughout the PV wall. Besides, as mentioned before (see also Reference 2), the exponent in the RG 1.99, Rev. 2, formula was derived for the PV wall thickness of $\sim 20 \mathrm{~cm}(8-\mathrm{in}$.), and larger deviations from the actual (calculated) attenuation in the region near PV outer surface, for a PV thicker than $\sim 20 \mathrm{~cm}$ is not surprising.

The effect of changing from the ASTM dpa cross sections, based on ENDF/B-IV data (Ref. 12) to the new dpa cross sections, derived from the ENDF/B-VI data, is analyzed in Table 16 and in Figure 18. The ENDF/B-VI dpa cross sections result in slightly slower attenuation of the dpa rate through the PV wall. The dpa extrapolation factors obtained with ENDF/B-VI dpa cross sections are $\sim 1.6 \%$ and $\sim 4 \%$ higher at the $\sim 5 \mathrm{~cm}$ and $\sim 15 \mathrm{~cm}$ from the PV inner wall, respectively, than the values obtained with ASTM dpa cross sections. The differences increase monotonically through the PV wall and reach $\sim 4.6 \%$ near the PV outer surface.

The contributions to the changes in the dpa attenuation through the PV wall are summarized in Table 17. The dpa extrapolation factor, calculated with the BUGLE-96 library, $P_{3}$ approximation, and ENDF/B-VI dpa cross sections is higher than the extrapolation factor obtained with the SAILOR library, $\mathrm{P}_{1}$ approximation, and ASTM dpa cross sections by $\sim 10 \%$ at $\sim 5 \mathrm{~cm}$ from the PV inner wall, and by $\sim 20 \%$ at $\sim 15 \mathrm{~cm}$ from the PV inner wall. Most of these changes are caused by the changes in the cross sections: the differences in extrapolation factors obtained with SAILOR and BUGLE-96 are $4.2 \%$ and $8.9 \%$, at $\sim 5 \mathrm{~cm}$ and $\sim 15 \mathrm{~cm}$ from the $\mathrm{PV}$ outer wall, when the $\mathrm{P}_{1}$ approximation for the angular dependence of the scattering cross sections is used. The next biggest contribution comes form the change from the $\mathrm{P}_{1}$ to $\mathrm{P}_{3}$ approximation, and hence better description of the anisotropic scattering. This change results in $\sim 3.7 \%$ and $6.6 \%$ increase in the extrapolation factor, calculated with the BUGLE-96 library. The last contribution is due to the change from ENDF/B-IV dpa cross sections (ASTM, Reference 12) to the new ENDF/B-VI dpa cross sections. This change introduces a modest increase in extrapolation factors of $\sim 1.6 \%$ and $3.8 \%$ at the $\sim 5 \mathrm{~cm}$ and $\sim 15 \mathrm{~cm}$ from the PV inner surface. The difference between the dpa extrapolation factors from the calculation with the "BUGLE-96, $\mathrm{P}_{3}$ approximation, and ENDF/B-VI dpa cross sections," and the RG 1.99 formula are $\sim 14 \%$ and $20 \%$ at $\sim 5 \mathrm{~cm}$ and $\sim 15 \mathrm{~cm}$ from the PV inner wall. These differences are composed primarily of the contributions discussed above. The differences exceeding these contributions are 
most probably caused by the simplifications necessary to describe the dpa attenuation with a simple exponential formula given in RG 1.99, Rev. 2, and by the averaging of results for different power plants, done in the derivation of the formula (see Reference 2).

So far all discussions of the attenuation of the flux and dpa rate through the PV wall were limited to the location of the PV wall, where the flux (and dpa) reached the maximal value on the PV inner surface. However, due to the staircase-shape of the core boundary, the thickness of the water layer between the core baffle and the core barrel varies around the core and causes a variation of neutron flux around the PV circumference. These "azimuthal" variations of the flux (E>1 MeV) and the dpa rate are shown in Figures 19 and 20. The variations are relatively large: the ratio of maximum-tominimum of the flux $(E>1 \mathrm{MeV})$ and of the dpa rate at the PV inner surface are in the range 2.5-3. Therefore, it appeared of interest to investigate the changes in the attenuation in the PV wall with the azimuthal location as well. In the transport calculation, one octant (i.e., a $45^{\circ}$ section) of the reactor horizontal cross section was covered with 74 azimuthal intervals, and the flux and dpa rate attenuation curves were calculated for all the azimuthal intervals. Then, for any depth, " $\mathrm{d}$," from the PV inner surface, the average, maximum, and minimum extrapolation factors were determined. The average value was determined as an arithmetic average over all the azimuthal intervals. The results for the flux $(E>1 \mathrm{MeV})$ and the dpa rate are listed in Tables 18 and 19, respectively, and are illustrated in Figures 21 and 22. The maximum and minimum flux $(E>1 \mathrm{MeV})$ extrapolation factors differ from the average by $2 \%$ and $5 \%$, at $\sim 5 \mathrm{~cm}$ and $\sim 15 \mathrm{~cm}$ from the PV inner wall. The corresponding differences for the dpa extrapolation factors are slightly larger: $\sim 3 \%$ and $8 \%$. The spread of the minimum-to-maximum values for the flux $(E>1 \mathrm{MeV})$ and the dpa rate extrapolation factors increase through the PV wall. However, even the curve for the minimum dpa extrapolation factors indicates slower dpa attenuation than the $\mathrm{RG} 1.99$, Rev. 2, formula, as can be seen from Figure 22. These variations of the extrapolation factors with azimuthal location give an estimation of the uncertainty introduced if only one attenuation formula is used at all azimuthal locations.

The final part of this study consists of an analysis of another power plant, which was a 1876-MW (thermal power) two-loop PWR of Westinghouse design, with a PV inner radius of $167.64 \mathrm{~cm}$, a 17.16-cm-thick PV wall - the PV wall thickness includes $0.32-\mathrm{cm}$ cladding on the inner surface - and a 9.05-cm-thick thermal shield. The same modeling approximations and calculational procedure, as described previously in this report, were used. The transport calculations were performed with the BUGLE-96 and the SAILOR cross-section libraries, with the $\mathrm{P}_{3}$ approximation for the angular dependence of the scattering cross sections. The flux ( $\mathrm{E}>1 \mathrm{MeV})$, flux $(\mathrm{E}>0.1 \mathrm{MeV})$, and the dpa rate (calculated with ASTM and ENDF/B-VI dpa cross sections) attenuation profiles through the PV wall are listed in Table 20 for the calculations with BUGLE-96 library and in Table 21 for the calculations with the SAILOR library. The absolute values, as well as the extrapolation factors, are given; extrapolation factors, determined from RG 1.99, Rev. 2, formula, are listed for comparison. The flux $(\mathrm{E}>1 \mathrm{MeV})$, flux $(\mathrm{E}>0.1 \mathrm{MeV})$, dpa (ASTM) rate, and dpa (ENDF/B-VI) attenuation curves in the PV wall are compared with the results obtained for the three-loop plant in the Figures 23-26. For all the irradiation parameters considered, the attenuation curves for the two-loop plant (with a PV wall thickness of $17.16 \mathrm{~cm}$ ) closely agree with the results for the three-loop plant with a PV thickness of $18.75 \mathrm{~cm}$. Therefore, from the point of view of RG 1.99, Rev. 2, extrapolation formula update, the analysis of the two-loop plant does not contribute any significantly new information. 


\section{CONCLUSIONS}

The attenuation of the dpa rate in the PV wall calculated with the BUGLE-96 cross-section library, $\mathrm{P}_{3}$ approximation to the angular dependence of the scattering cross sections, and dpa cross sections derived from ENDF/B-VI data is significantly slower than the attenuation predicted by the RG 1.99 , Rev. 2, formula. For a PV wall thickness of $\sim 24 \mathrm{~cm}$, the calculated ratio of the dpa rate at $1 / 4$ and $3 / 4$ of the PV wall thickness, to the dpa value on the inner PV surface is $\sim 14 \%$, and $19 \%$ higher, respectively, than predicted by the RG 1.99 , Rev. 2, formula.

The dpa rate attenuation in the PV wall, calculated with the SAILOR (ENDF/B-VI) cross-section library, $\mathrm{P}_{1}$ approximation to angular dependence of scattering cross sections, and dpa cross sections from ASTM standard E 693, comes relatively close to the RG 1.99, Rev. 2, formula prediction. The calculation still predicts up to $\sim 5 \%$ slower dpa attenuation in the region close to the PV inner wall.

Insight into the causes of the large difference between the dpa attenuation in the PV wall obtained with "BUGLE-96, P3, ENDF/B-VI dpa" calculation and the RG 1.99, Rev. 2, formula was obtained from the comparisons of results with the BUGLE-96 and the SAILOR cross-section libraries, the $\mathrm{P}_{1}-\mathrm{P}_{3}$ approximations for angular distribution of scattering cross section, and the ASTM and the ENDF/B-VI dpa cross sections. Approximately $40-45 \%$ of the difference is caused by the change in cross sections (from SAILOR, $\mathrm{P}_{1}$ to BUGLE-96, $\mathrm{P}_{1}$ ), $\sim 35-40 \%$ of the difference is due to the change from $\mathrm{P}_{1}$ to $\mathrm{P}_{3}$, and $\sim 15-20 \%$ of the difference is caused by the change from the ENDF/B-IV to the ENDF/B-VI dpa cross sections. Near the PV surfaces the calculated attenuation of the dpa rate also deviates from the simple exponential attenuation used in RG 1.99, Rev. 2, formula, which contributes to the larger differences, especially near the PV outer surface.

Calculations for varied thermal shield thicknesses showed that a thicker thermal shield typically results in slower dpa attenuation in the PV wall. However, increasing the thermal shield thickness tends to decrease the dpa rate at the PV inner wall by $\sim 3.5 \%$ per $1 \mathrm{~cm}$ of the thermal shield thickness increase $(1 \mathrm{~cm}$ of water replaced by $1 \mathrm{~cm}$ of steel).

The thickness of the PV has a negligible effect on the dpa rate at the PV inner wall; however, the thicker the PV, the slower is the dpa decrease inside the PV wall.The effect is small in the region near the PV inner surface but becomes quite important at larger distances from the PV inner wall.

The dpa rate attenuation curves calculated for the two-loop PWR were found in good agreement with the results for the three-loop PWR with similar PV wall thickness. This agreement indicates that performing a few additional parametric studies with the models used in this study, for different thermal-shield, PV, and downcomer thicknesses, may be sufficient to generate the data base for the update of RG 1.99, Rev. 2, attenuation formula. A more rigorous, but also more time-consuming approach, would require calculations of the dpa attenuation in the PV wall for several different reactor designs, similar to Guthrie's work, which considered six types of commercial PWRs. 


\section{REFERENCES}

1. U.S. Nuclear Regulatory Commission Regulatory Guide 1.99, Revision 2, "Radiation Embrittlement of Reactor Vessel Materials," May 1988.

2. P. N. Randall, "Basis for Revision 2 of the U.S. Nuclear Regulatory Commission's Regulatory Guide 1.99," Radiation Embrittlement of Nuclear Reactor Pressure Vessel Steels: An International Review (Second Volume), ASTM STP 909, L. E. Steele, Ed., American Society for Testing and Materials, Philadelphia, 1986, pp. 149-162.

3. G. L. Guthrie, W. N. McElroy, and S. L. Anderson, "A Preliminary Study of the Use of Fuel Management Techniques for Slowing Pressure Vessel Embrittlement," pp. 111-120 in Proc. Of the Fourth ASTM-EURATOM Symposium on Reactor Dosimetry, Gaithersburg, Maryland, March 1982.

4. G. Collier et al., Second Version of the GAMBIT Code, WANL-TME-1969, Westinghouse Astronuclear Laboratory, Pittsburgh, November 1969.

5. R. G. Soltesz et al., "Two-Dimensional Discrete Ordinates Transport Technique," Nuclear Rocket Shielding Methods, Modification, Updating, and Input Data Preparation, WANL-PR(LL)034, Vol. 5, Westinghouse Astronuclear Laboratory, Pittsburgh, August 1970.

6. I. Remec and F. B. K. Kam, Pool Critical Assembly Pressure Vessel Facility Benchmark, NUREG/CR-6454, ORNL/TM-13205, U.S. Nuclear Regulatory Commission, 1997.

7. I. Remec and F. B. K. Kam, H. B. Robinson-2 Pressure Vessel Benchmark, NUREG/CR-6453, ORNL/TM-13204, U.S. Nuclear Regulatory Commission, February 1998.

8. W. A. Rhoades et al., "TORT-DORT Two- and Three-Dimensional Discrete Ordinates Transport, Version 2.8.14," CCC-543, Radiation Shielding Information Center, Oak Ridge National Laboratory, 1994; (DORT version 3.2, dated October 1, 1997, was used.)

9. R. E. Maerker, "LEPRICON Analysis of the Pressure Vessel Surveillance Dosimetry Inserted into H. B. Robinson-2 During Cycle 9," Nuc. Sci. Eng. 96:263 (1987).

10. J. E. White et al., "BUGLE-96: Coupled 47 Neutron, 20 Gamma-Ray Group Cross Section Library Derived from ENDF/B-VI for LWR Shielding and Pressure Vessel Dosimetry Applications," RSICC Data Library Collection, DLC-185, Oak Ridge National Laboratory, March 1996.

11. G. L. Simmons et al., "Analysis of the Browns Ferry Unit 3 Irradiation Experiments," EPRI NP-3719 (November 1984), RSICC Data Library Collection, DLC-076/SAILOR; (Sailor, Coupled Self-Shielded, 47-Neutron, 20-Gamma-Ray, P3, Cross-Section Library for Light Water Reactors), Oak Ridge National Laboratory, 1984. 
12. E 693 Standard Practice for Characterizing Neutron Exposures in Iron and Low Alloy Steels in Terms of Displacement Per Atom (DPA), E 706(ID), Annual Book of ASTM Standards, Sect. 12, Nuclear, Solar, and Geothermal Energy, 1998. 
Table 1 Flux $(\mathrm{E}>1 \mathrm{MeV})$, flux $(\mathrm{E}>0.1 \mathrm{MeV})$, and dpa rate at the $\mathrm{PV}$ inner surface, versus the thickness of the thermal shield

\begin{tabular}{|c|c|c|c|c|c|c|c|c|}
\hline \multirow{2}{*}{$\begin{array}{c}\text { Thermal } \\
\text { shield } \\
\text { thickness }\end{array}$} & \multicolumn{2}{|c|}{$\begin{array}{c}\text { Flux } \\
(\mathrm{E}>0.1 \mathrm{MeV})\end{array}$} & \multicolumn{2}{c|}{$\begin{array}{c}\text { Flux } \\
\text { Value }\end{array}$} & Ratio $1 \mathrm{MeV})$ & \multicolumn{2}{c|}{$\begin{array}{c}\text { dpa rate } \\
\text { ASTM }\end{array}$} & \multicolumn{3}{c|}{ dpa rate } \\
Ealue & Ratio & Value & Ratio & Value & Ratio \\
\hline $\mathrm{cm}$ & $\mathrm{cm}^{-2} \mathrm{~s}^{-1}$ & & $\mathrm{~cm}^{-2} \mathrm{~s}^{-1}$ & & & $\mathrm{~s}^{-1}$ & & \\
\hline 0.000 & $8.82 \mathrm{E}+10$ & 1.00 & $4.17 \mathrm{E}+10$ & 1.00 & $6.22 \mathrm{E}-11$ & 1.00 & $6.14 \mathrm{E}-11$ & 1.00 \\
3.413 & $8.16 \mathrm{E}+10$ & 0.93 & $3.53 \mathrm{E}+10$ & 0.85 & $5.36 \mathrm{E}-11$ & 0.86 & $5.31 \mathrm{E}-11$ & 0.86 \\
6.830 & $8.05 \mathrm{E}+10$ & 0.91 & $3.04 \mathrm{E}+10$ & 0.73 & $4.82 \mathrm{E}-11$ & 0.78 & $4.80 \mathrm{E}-11$ & 0.78 \\
10.238 & $8.63 \mathrm{E}+10$ & 0.98 & $2.69 \mathrm{E}+10$ & 0.65 & $4.63 \mathrm{E}-11$ & 0.74 & $4.64 \mathrm{E}-11$ & 0.76 \\
\hline
\end{tabular}


Table 2 Flux ( $\mathrm{E}>1 \mathrm{MeV}$ ) attenuation in the PV wall, for different thermal shield thicknesses (BUGLE-96 calculations)

\begin{tabular}{|c|c|c|c|c|c|c|c|c|c|}
\hline \multicolumn{2}{|c|}{} & \multicolumn{2}{c|}{$\begin{array}{c}\text { Thermal shield } \\
\text { thickness } 0 \mathrm{~cm}\end{array}$} & \multicolumn{2}{c|}{$\begin{array}{c}\text { Thermal shield } \\
\text { thickness } 3.413 \mathrm{~cm}\end{array}$} & \multicolumn{2}{c|}{$\begin{array}{c}\text { Thermal shield } \\
\text { thickness } 6.83 \mathrm{~cm}\end{array}$} & \multicolumn{2}{c|}{$\begin{array}{c}\text { Thermal shield } \\
\text { thickness } 10.238 \mathrm{~cm}\end{array}$} \\
\hline $\mathrm{d}^{*}$ & $\mathrm{r}^{*}$ & Value & Ratio & Value & Ratio & Value & Ratio & Value & Ratio \\
\hline $\mathrm{cm}$ & $\mathrm{cm}$ & $\mathrm{cm}^{-2} \mathrm{~s}^{-1}$ & & $\mathrm{~cm}^{-2} \mathrm{~s}^{-1}$ & & $\mathrm{~cm}^{-2} \mathrm{~s}^{-1}$ & & $\mathrm{~cm}^{-2} \mathrm{~s}^{-1}$ & \\
\hline 0.000 & 197.49 & $4.173 \mathrm{E}+10$ & 1.0000 & $3.530 \mathrm{E}+10$ & 1.0000 & $3.042 \mathrm{E}+10$ & 1.0000 & $2.692 \mathrm{E}+10$ & 1.0000 \\
0.285 & 197.77 & $4.147 \mathrm{E}+10$ & 0.9939 & $3.502 \mathrm{E}+10$ & 0.9920 & $3.014 \mathrm{E}+10$ & 0.9908 & $2.663 \mathrm{E}+10$ & 0.9893 \\
1.474 & 198.959 & $3.800 \mathrm{E}+10$ & 0.9105 & $3.196 \mathrm{E}+10$ & 0.9055 & $2.745 \mathrm{E}+10$ & 0.9023 & $2.423 \mathrm{E}+10$ & 0.9000 \\
3.293 & 200.778 & $3.172 \mathrm{E}+10$ & 0.7601 & $2.655 \mathrm{E}+10$ & 0.7522 & $2.273 \mathrm{E}+10$ & 0.7472 & $2.004 \mathrm{E}+10$ & 0.7443 \\
5.111 & 202.596 & $2.545 \mathrm{E}+10$ & 0.6100 & $2.121 \mathrm{E}+10$ & 0.6008 & $1.811 \mathrm{E}+10$ & 0.5953 & $1.593 \mathrm{E}+10$ & 0.5916 \\
6.930 & 204.415 & $2.010 \mathrm{E}+10$ & 0.4818 & $1.669 \mathrm{E}+10$ & 0.4727 & $1.421 \mathrm{E}+10$ & 0.4673 & $1.248 \mathrm{E}+10$ & 0.4637 \\
8.748 & 206.233 & $1.579 \mathrm{E}+10$ & 0.3783 & $1.308 \mathrm{E}+10$ & 0.3704 & $1.111 \mathrm{E}+10$ & 0.3653 & $9.745 \mathrm{E}+09$ & 0.3620 \\
10.567 & 208.052 & $1.235 \mathrm{E}+10$ & 0.2959 & $1.020 \mathrm{E}+10$ & 0.2889 & $8.657 \mathrm{E}+09$ & 0.2846 & $7.583 \mathrm{E}+09$ & 0.2817 \\
12.385 & 209.87 & $9.575 \mathrm{E}+09$ & 0.2295 & $7.895 \mathrm{E}+09$ & 0.2236 & $6.691 \mathrm{E}+09$ & 0.2200 & $5.855 \mathrm{E}+09$ & 0.2175 \\
14.203 & 211.688 & $7.428 \mathrm{E}+09$ & 0.1780 & $6.120 \mathrm{E}+09$ & 0.1734 & $5.180 \mathrm{E}+09$ & 0.1703 & $4.529 \mathrm{E}+09$ & 0.1682 \\
16.022 & 213.507 & $5.719 \mathrm{E}+09$ & 0.1371 & $4.703 \mathrm{E}+09$ & 0.1332 & $3.977 \mathrm{E}+09$ & 0.1307 & $3.475 \mathrm{E}+09$ & 0.1291 \\
17.840 & 215.325 & $4.385 \mathrm{E}+09$ & 0.1051 & $3.602 \mathrm{E}+09$ & 0.1020 & $3.044 \mathrm{E}+09$ & 0.1001 & $2.658 \mathrm{E}+09$ & 0.0987 \\
19.659 & 217.144 & $3.333 \mathrm{E}+09$ & 0.0799 & $2.737 \mathrm{E}+09$ & 0.0775 & $2.311 \mathrm{E}+09$ & 0.0760 & $2.018 \mathrm{E}+09$ & 0.0750 \\
21.477 & 218.962 & $2.487 \mathrm{E}+09$ & 0.0596 & $2.040 \mathrm{E}+09$ & 0.0578 & $1.721 \mathrm{E}+09$ & 0.0566 & $1.501 \mathrm{E}+09$ & 0.0557 \\
23.296 & 220.781 & $1.774 \mathrm{E}+09$ & 0.0425 & $1.455 \mathrm{E}+09$ & 0.0412 & $1.227 \mathrm{E}+09$ & 0.0403 & $1.071 \mathrm{E}+09$ & 0.0398 \\
\hline
\end{tabular}

${ }^{*} \mathrm{~d}=$ distance from PV inner (wetted) surface.

${ }^{* *} \mathrm{r}=$ distance from core vertical axis. 
Table 3 Attenuation of the dpa rate in the PV wall for different thermal shield (TS) thicknesses. Absolute dpa rate values are given as well as the values relative to the dpa rate at the PV inner wall. Neutron fluxes are from the calculations with BUGLE-96.

ENDF/B-VI dpa cross sections were used

\begin{tabular}{|c|c|c|c|c|c|c|c|c|c|c|}
\hline & & \multicolumn{2}{|c|}{$\begin{array}{c}\text { TS thickness } \\
0 \mathrm{~cm}\end{array}$} & \multicolumn{2}{c|}{$\begin{array}{c}\text { TS thickness } \\
3.413 \mathrm{~cm}\end{array}$} & \multicolumn{2}{c|}{$\begin{array}{c}\text { TS thickness } \\
6.83 \mathrm{~cm}\end{array}$} & \multicolumn{2}{c|}{$\begin{array}{c}\text { TS thickness } \\
10.238 \mathrm{~cm}\end{array}$} & \\
\cline { 3 - 9 } $\mathrm{d}^{*}$ & \multirow{2}{*}{$\mathrm{r}^{* *}$} & dpa rate & Ratio & dpa rate & Ratio & dpa rate & Ratio & Ra rate & Ratio & $\begin{array}{c}\text { RG } 1.99 \\
\text { Rev. } 2\end{array}$ \\
\hline $\mathrm{cm}$ & $\mathrm{cm}$ & $\mathrm{s}^{-1}$ & & $\mathrm{~s}^{-1}$ & & $\mathrm{~s}^{-1}$ & & $\mathrm{~s}^{-1}$ & & \\
\hline 0.000 & 197.485 & $6.14 \mathrm{E}-11$ & 1.0000 & $5.31 \mathrm{E}-11$ & 1.0000 & $4.80 \mathrm{E}-11$ & 1.0000 & $4.64 \mathrm{E}-11$ & 1.0000 & 1.0000 \\
0.285 & 197.770 & $6.13 \mathrm{E}-11$ & 0.9977 & $5.30 \mathrm{E}-11$ & 0.9971 & $4.79 \mathrm{E}-11$ & 0.9970 & $4.62 \mathrm{E}-11$ & 0.9965 & 0.9734 \\
1.474 & 198.959 & $5.72 \mathrm{E}-11$ & 0.9318 & $4.95 \mathrm{E}-11$ & 0.9313 & $4.48 \mathrm{E}-11$ & 0.9338 & $4.35 \mathrm{E}-11$ & 0.9372 & 0.8700 \\
3.293 & 200.778 & $4.99 \mathrm{E}-11$ & 0.8119 & $4.32 \mathrm{E}-11$ & 0.8130 & $3.93 \mathrm{E}-11$ & 0.8192 & $3.84 \mathrm{E}-11$ & 0.8285 & 0.7326 \\
5.111 & 202.596 & $4.24 \mathrm{E}-11$ & 0.6906 & $3.68 \mathrm{E}-11$ & 0.6930 & $3.37 \mathrm{E}-11$ & 0.7023 & $3.32 \mathrm{E}-11$ & 0.7155 & 0.6170 \\
6.930 & 204.415 & $3.58 \mathrm{E}-11$ & 0.5834 & $3.12 \mathrm{E}-11$ & 0.5871 & $2.87 \mathrm{E}-11$ & 0.5983 & $2.85 \mathrm{E}-11$ & 0.6143 & 0.5195 \\
8.748 & 206.233 & $3.03 \mathrm{E}-11$ & 0.4930 & $2.65 \mathrm{E}-11$ & 0.4979 & $2.45 \mathrm{E}-11$ & 0.5100 & $2.44 \mathrm{E}-11$ & 0.5271 & 0.4375 \\
10.567 & 208.052 & $2.56 \mathrm{E}-11$ & 0.4165 & $2.24 \mathrm{E}-11$ & 0.4220 & $2.09 \mathrm{E}-11$ & 0.4344 & $2.09 \mathrm{E}-11$ & 0.4516 & 0.3684 \\
12.385 & 209.870 & $2.15 \mathrm{E}-11$ & 0.3506 & $1.89 \mathrm{E}-11$ & 0.3563 & $1.77 \mathrm{E}-11$ & 0.3685 & $1.79 \mathrm{E}-11$ & 0.3851 & 0.3103 \\
14.203 & 211.688 & $1.81 \mathrm{E}-11$ & 0.2950 & $1.60 \mathrm{E}-11$ & 0.3008 & $1.50 \mathrm{E}-11$ & 0.3122 & $1.52 \mathrm{E}-11$ & 0.3277 & 0.2613 \\
16.022 & 213.507 & $1.51 \mathrm{E}-11$ & 0.2462 & $1.34 \mathrm{E}-11$ & 0.2516 & $1.26 \mathrm{E}-11$ & 0.2620 & $1.28 \mathrm{E}-11$ & 0.2761 & 0.2201 \\
17.840 & 215.325 & $1.25 \mathrm{E}-11$ & 0.2037 & $1.11 \mathrm{E}-11$ & 0.2086 & $1.05 \mathrm{E}-11$ & 0.2178 & $1.07 \mathrm{E}-11$ & 0.2301 & 0.1853 \\
19.659 & 217.144 & $1.02 \mathrm{E}-11$ & 0.1659 & $9.05 \mathrm{E}-12$ & 0.1702 & $8.55 \mathrm{E}-12$ & 0.1781 & $8.75 \mathrm{E}-12$ & 0.1886 & 0.1561 \\
21.477 & 218.962 & $8.04 \mathrm{E}-12$ & 0.1309 & $7.14 \mathrm{E}-12$ & 0.1343 & $6.75 \mathrm{E}-12$ & 0.1406 & $6.91 \mathrm{E}-12$ & 0.1490 & 0.1314 \\
23.296 & 220.781 & $5.98 \mathrm{E}-12$ & 0.0973 & $5.31 \mathrm{E}-12$ & 0.0998 & $5.02 \mathrm{E}-12$ & 0.1045 & $5.14 \mathrm{E}-12$ & 0.1108 & 0.1107 \\
\hline
\end{tabular}

* $\mathrm{d}=$ distance from PV inner (wetted) surface.

${ }^{* *} \mathrm{r}=$ distance from core vertical axis. 
Table 4 Attenuation of the dpa rate in the PV wall for different thermal shield (TS) thicknesses. Absolute dpa rate values are given as well as the values relative to the dpa rate at the PV inner wall. Neutron fluxes are from the calculations with BUGLE-96. ASTM dpa cross sections were used

\begin{tabular}{|c|c|c|c|c|c|c|c|c|c|c|}
\hline \multirow{2}{*}{} & & \multicolumn{2}{|c|}{$\begin{array}{c}\text { TS thickness } \\
0 \mathrm{~cm}\end{array}$} & \multicolumn{2}{c|}{$\begin{array}{c}\text { TS thickness } \\
3.413 \mathrm{~cm}\end{array}$} & \multicolumn{2}{c|}{$\begin{array}{c}\text { TS thickness } \\
6.83 \mathrm{~cm}\end{array}$} & \multicolumn{2}{c|}{$\begin{array}{c}\text { TS thickness } \\
10.238 \mathrm{~cm}\end{array}$} & \multirow{2}{*}{$\begin{array}{c}\text { RG 1.99 } \\
\text { Rev. } 2\end{array}$} \\
\cline { 3 - 10 } $\mathrm{d}^{*}$ & $\mathrm{r}^{* *}$ & Value & Ratio & Value & Ratio & Value & Ratio & Value & Ratio & \\
\hline $\mathrm{cm}$ & $\mathrm{cm}$ & $\mathrm{s}^{-1}$ & & $\mathrm{~s}^{-1}$ & & $\mathrm{~s}^{-1}$ & & $\mathrm{~s}^{-1}$ & & \\
\hline 0.000 & 197.485 & $6.217 \mathrm{E}-11$ & 1.0000 & $5.361 \mathrm{E}-11$ & 1.0000 & $4.819 \mathrm{E}-11$ & 1.0000 & $4.626 \mathrm{E}-11$ & 1.0000 & 1.0000 \\
0.285 & 197.770 & $6.196 \mathrm{E}-11$ & 0.9967 & $5.339 \mathrm{E}-11$ & 0.9959 & $4.799 \mathrm{E}-11$ & 0.9958 & $4.604 \mathrm{E}-11$ & 0.9953 & 0.9734 \\
1.474 & 198.959 & $5.766 \mathrm{E}-11$ & 0.9275 & $4.969 \mathrm{E}-11$ & 0.9268 & $4.477 \mathrm{E}-11$ & 0.9290 & $4.313 \mathrm{E}-11$ & 0.9322 & 0.8700 \\
3.293 & 200.778 & $4.998 \mathrm{E}-11$ & 0.8039 & $4.314 \mathrm{E}-11$ & 0.8047 & $3.906 \mathrm{E}-11$ & 0.8105 & $3.791 \mathrm{E}-11$ & 0.8195 & 0.7326 \\
5.111 & 202.596 & $4.229 \mathrm{E}-11$ & 0.6802 & $3.657 \mathrm{E}-11$ & 0.6822 & $3.331 \mathrm{E}-11$ & 0.6912 & $3.259 \mathrm{E}-11$ & 0.7044 & 0.6170 \\
6.930 & 204.415 & $3.554 \mathrm{E}-11$ & 0.5717 & $3.083 \mathrm{E}-11$ & 0.5751 & $2.825 \mathrm{E}-11$ & 0.5861 & $2.785 \mathrm{E}-11$ & 0.6020 & 0.5195 \\
8.748 & 206.233 & $2.989 \mathrm{E}-11$ & 0.4808 & $2.603 \mathrm{E}-11$ & 0.4855 & $2.397 \mathrm{E}-11$ & 0.4974 & $2.380 \mathrm{E}-11$ & 0.5145 & 0.4375 \\
10.567 & 208.052 & $2.514 \mathrm{E}-11$ & 0.4044 & $2.196 \mathrm{E}-11$ & 0.4097 & $2.034 \mathrm{E}-11$ & 0.4220 & $2.032 \mathrm{E}-11$ & 0.4393 & 0.3684 \\
12.385 & 209.870 & $2.108 \mathrm{E}-11$ & 0.3391 & $1.847 \mathrm{E}-11$ & 0.3446 & $1.719 \mathrm{E}-11$ & 0.3566 & $1.728 \mathrm{E}-11$ & 0.3735 & 0.3103 \\
14.203 & 211.688 & $1.767 \mathrm{E}-11$ & 0.2842 & $1.554 \mathrm{E}-11$ & 0.2899 & $1.452 \mathrm{E}-11$ & 0.3012 & $1.466 \mathrm{E}-11$ & 0.3170 & 0.2613 \\
16.022 & 213.507 & $1.470 \mathrm{E}-11$ & 0.2365 & $1.296 \mathrm{E}-11$ & 0.2418 & $1.215 \mathrm{E}-11$ & 0.2521 & $1.233 \mathrm{E}-11$ & 0.2664 & 0.2201 \\
17.840 & 215.325 & $1.213 \mathrm{E}-11$ & 0.1951 & $1.072 \mathrm{E}-11$ & 0.1999 & $1.008 \mathrm{E}-11$ & 0.2091 & $1.025 \mathrm{E}-11$ & 0.2217 & 0.1853 \\
19.659 & 217.144 & $9.856 \mathrm{E}-12$ & 0.1585 & $8.726 \mathrm{E}-12$ & 0.1628 & $8.223 \mathrm{E}-12$ & 0.1706 & $8.391 \mathrm{E}-12$ & 0.1814 & 0.1561 \\
21.477 & 218.962 & $7.760 \mathrm{E}-12$ & 0.1248 & $6.876 \mathrm{E}-12$ & 0.1283 & $6.485 \mathrm{E}-12$ & 0.1346 & $6.621 \mathrm{E}-12$ & 0.1431 & 0.1314 \\
23.296 & 220.781 & $5.764 \mathrm{E}-12$ & 0.0927 & $5.107 \mathrm{E}-12$ & 0.0953 & $4.818 \mathrm{E}-12$ & 0.1000 & $4.919 \mathrm{E}-12$ & 0.1063 & 0.1107 \\
\hline
\end{tabular}

* $\mathrm{d}=$ distance from PV inner (wetted) surface.

${ }^{* * *} \mathrm{r}=$ distance from core vertical axis. 
Table 5 Attenuation of the flux $(\mathrm{E}>0.1 \mathrm{MeV})$ through the PV wall for different thermal shield thicknesses (BUGLE-96 calculations)

\begin{tabular}{|c|c|c|c|c|c|c|c|c|}
\hline \multirow{2}{*}{$\mathrm{d}^{*}$} & \multicolumn{2}{|c|}{$\begin{array}{c}\text { Thermal shield } \\
\text { thicknes } 0 \mathrm{~cm}\end{array}$} & \multicolumn{2}{c|}{$\begin{array}{c}\text { Thermal shield } \\
\text { thickness } 3.413 \mathrm{~cm}\end{array}$} & \multicolumn{2}{c|}{$\begin{array}{c}\text { Thermal shield } \\
\text { thickness } 6.83 \mathrm{~cm}\end{array}$} & \multicolumn{2}{c|}{$\begin{array}{c}\text { Thermal shield } \\
\text { thickness 10.238 cm }\end{array}$} \\
\cline { 2 - 9 } & Flux & Ratio & Flux & Ratio & Flux & Ratio & Flux & Ratio \\
\hline $\mathrm{cm}$ & $\mathrm{cm}^{-2} \mathrm{~s}^{-1}$ & & $\mathrm{~cm}^{-2} \mathrm{~s}^{-1}$ & & $\mathrm{~cm}^{-2} \mathrm{~s}^{-1}$ & & $\mathrm{~cm}^{-2} \mathrm{~s}^{-1}$ & \\
\hline 0.000 & $8.818 \mathrm{E}+10$ & 1.0000 & $8.163 \mathrm{E}+10$ & 1.0000 & $8.055 \mathrm{E}+10$ & 1.0000 & $8.631 \mathrm{E}+10$ & 1.0000 \\
0.285 & $8.993 \mathrm{E}+10$ & 1.0199 & $8.310 \mathrm{E}+10$ & 1.0180 & $8.188 \mathrm{E}+10$ & 1.0165 & $8.761 \mathrm{E}+10$ & 1.0150 \\
1.474 & $9.012 \mathrm{E}+10$ & 1.0221 & $8.303 \mathrm{E}+10$ & 1.0173 & $8.168 \mathrm{E}+10$ & 1.0141 & $8.733 \mathrm{E}+10$ & 1.0118 \\
3.293 & $8.623 \mathrm{E}+10$ & 0.9780 & $7.922 \mathrm{E}+10$ & 0.9705 & $7.778 \mathrm{E}+10$ & 0.9657 & $8.309 \mathrm{E}+10$ & 0.9626 \\
5.111 & $7.964 \mathrm{E}+10$ & 0.9032 & $7.298 \mathrm{E}+10$ & 0.8941 & $7.156 \mathrm{E}+10$ & 0.8884 & $7.635 \mathrm{E}+10$ & 0.8846 \\
6.930 & $7.240 \mathrm{E}+10$ & 0.8211 & $6.624 \mathrm{E}+10$ & 0.8115 & $6.490 \mathrm{E}+10$ & 0.8058 & $6.922 \mathrm{E}+10$ & 0.8019 \\
8.748 & $6.527 \mathrm{E}+10$ & 0.7402 & $5.966 \mathrm{E}+10$ & 0.7309 & $5.840 \mathrm{E}+10$ & 0.7250 & $6.223 \mathrm{E}+10$ & 0.7210 \\
10.567 & $5.838 \mathrm{E}+10$ & 0.6621 & $5.332 \mathrm{E}+10$ & 0.6532 & $5.215 \mathrm{E}+10$ & 0.6475 & $5.554 \mathrm{E}+10$ & 0.6434 \\
12.385 & $5.169 \mathrm{E}+10$ & 0.5862 & $4.717 \mathrm{E}+10$ & 0.5778 & $4.611 \mathrm{E}+10$ & 0.5725 & $4.908 \mathrm{E}+10$ & 0.5686 \\
14.203 & $4.540 \mathrm{E}+10$ & 0.5149 & $4.142 \mathrm{E}+10$ & 0.5074 & $4.046 \mathrm{E}+10$ & 0.5024 & $4.304 \mathrm{E}+10$ & 0.4986 \\
16.022 & $3.931 \mathrm{E}+10$ & 0.4458 & $3.584 \mathrm{E}+10$ & 0.4390 & $3.499 \mathrm{E}+10$ & 0.4344 & $3.719 \mathrm{E}+10$ & 0.4309 \\
17.840 & $3.355 \mathrm{E}+10$ & 0.3805 & $3.057 \mathrm{E}+10$ & 0.3745 & $2.983 \mathrm{E}+10$ & 0.3704 & $3.168 \mathrm{E}+10$ & 0.3670 \\
19.659 & $2.802 \mathrm{E}+10$ & 0.3178 & $2.552 \mathrm{E}+10$ & 0.3127 & $2.489 \mathrm{E}+10$ & 0.3091 & $2.642 \mathrm{E}+10$ & 0.3061 \\
21.477 & $2.252 \mathrm{E}+10$ & 0.2554 & $2.049 \mathrm{E}+10$ & 0.2511 & $1.997 \mathrm{E}+10$ & 0.2479 & $2.116 \mathrm{E}+10$ & 0.2451 \\
23.296 & $1.693 \mathrm{E}+10$ & 0.1920 & $1.539 \mathrm{E}+10$ & 0.1886 & $1.498 \mathrm{E}+10$ & 0.1860 & $1.585 \mathrm{E}+10$ & 0.1836 \\
\hline
\end{tabular}

* $\mathrm{d}=$ distance from PV inner (wetted) surface. 
Table 6 Flux ( $\mathrm{E}>1 \mathrm{MeV}$ ) attenuation in the PV wall for different wall thicknesses. ( $P V$ inner radius was $197.49 \mathrm{~cm}$ in all the cases; calculations with BUGLE-96)

\begin{tabular}{|c|c|c|c|c|c|c|c|c|}
\hline \multirow[b]{2}{*}{$\mathrm{d}^{*}$} & \multirow[b]{2}{*}{$\mathrm{r}^{* *}$} & \multicolumn{2}{|c|}{$\begin{array}{l}\text { PV thickness } 18.75 \mathrm{~cm} \\
\text { PV outer radius } 216.235\end{array}$} & \multicolumn{2}{|c|}{\begin{tabular}{|l|} 
PV thickness $24.20 \mathrm{~cm}$ \\
PV outer radius $221.69 \mathrm{~cm}$
\end{tabular}} & \multicolumn{2}{|c|}{$\begin{array}{l}\text { PV thickness } 30.25 \mathrm{~cm} \\
\text { PV outer radius } 227.74 \mathrm{~cm}\end{array}$} & \multirow{2}{*}{$\begin{array}{l}\text { RG } 1.99 \\
\text { Rev. } 2\end{array}$} \\
\hline & & Flux & Ratio & Flux & Ratio & Flux & Ratio & \\
\hline $\mathrm{cm}$ & $\mathrm{cm}$ & $\mathrm{cm}^{-2} \mathrm{~s}^{-1}$ & & $\mathrm{~cm}^{-2} \mathrm{~s}^{-1}$ & & $\mathrm{~cm}^{-2} \mathrm{~s}^{-1}$ & & \\
\hline 0.000 & 197.49 & $3.0403 E+10$ & 1.0000 & $3.0420 \mathrm{E}+10$ & 1.0000 & $3.04237 \mathrm{E}+10$ & 1.0000 & 1.0000 \\
\hline 0.285 & 197.77 & $3.0123 \mathrm{E}+10$ & 0.9908 & $3.0142 \mathrm{E}+10$ & 0.9908 & $3.01455 \mathrm{E}+10$ & 0.9909 & 0.9734 \\
\hline 1.474 & 198.96 & $2.7424 \mathrm{E}+10$ & 0.9020 & $2.7449 \mathrm{E}+10$ & 0.9023 & $2.74540 \mathrm{E}+10$ & 0.9024 & 0.8700 \\
\hline 3.293 & 200.78 & $2.2696 \mathrm{E}+10$ & 0.7465 & $2.2731 E+10$ & 0.7472 & $2.27381 E+10$ & 0.7474 & 0.7326 \\
\hline 5.111 & 202.60 & $1.8061 \mathrm{E}+10$ & 0.5941 & $1.8108 \mathrm{E}+10$ & 0.5953 & $1.81170 \mathrm{E}+10$ & 0.5955 & 0.6170 \\
\hline 6.930 & 204.42 & $1.4152 \mathrm{E}+10$ & 0.4655 & $1.4215 \mathrm{E}+10$ & 0.4673 & $1.42272 \mathrm{E}+10$ & 0.4676 & 0.5195 \\
\hline 8.748 & 206.23 & $1.1030 \mathrm{E}+10$ & 0.3628 & $1.1113 \mathrm{E}+10$ & 0.3653 & $1.11288 \mathrm{E}+10$ & 0.3658 & 0.4375 \\
\hline 10.567 & 208.05 & $8.5473 \mathrm{E}+09$ & 0.2811 & $8.6568 \mathrm{E}+09$ & 0.2846 & $8.67818 \mathrm{E}+09$ & 0.2852 & 0.3684 \\
\hline 12.385 & 209.87 & $6.5458 \mathrm{E}+09$ & 0.2153 & $6.6911 \mathrm{E}+09$ & 0.2200 & $6.71955 \mathrm{E}+09$ & 0.2209 & 0.3103 \\
\hline 14.203 & 211.69 & $4.9856 \mathrm{E}+09$ & 0.1640 & $5.1802 \mathrm{E}+09$ & 0.1703 & $5.21709 \mathrm{E}+09$ & 0.1715 & 0.2613 \\
\hline 16.022 & 213.51 & $3.7056 \mathrm{E}+09$ & 0.1219 & $3.9774 \mathrm{E}+09$ & 0.1307 & $4.02652 \mathrm{E}+09$ & 0.1323 & 0.2201 \\
\hline 17.840 & 215.33 & $2.6229 \mathrm{E}+09$ & 0.0863 & $3.0436 \mathrm{E}+09$ & 0.1001 & $3.10774 \mathrm{E}+09$ & 0.1021 & 0.1853 \\
\hline 19.659 & 217.14 & & & $2.3115 \mathrm{E}+09$ & 0.0760 & $2.39520 \mathrm{E}+09$ & 0.0787 & 0.1561 \\
\hline 21.477 & 218.96 & & & $1.7209 \mathrm{E}+09$ & 0.0566 & $1.83834 \mathrm{E}+09$ & 0.0604 & 0.1314 \\
\hline 23.296 & 220.78 & & & $1.2274 \mathrm{E}+09$ & 0.0403 & $1.41107 E+09$ & 0.0464 & 0.1107 \\
\hline 24.840 & 222.33 & & & & & $1.10989 E+09$ & 0.0365 & \\
\hline 26.272 & 223.76 & & & & & $8.91255 \mathrm{E}+08$ & 0.0293 & \\
\hline 27.865 & 225.35 & & & & & $6.83200 \mathrm{E}+08$ & 0.0225 & \\
\hline 29.458 & 226.94 & & & & & $4.99693 E+08$ & 0.0164 & \\
\hline
\end{tabular}

${ }^{*} \mathrm{~d}=$ distance from PV inner (wetted) surface.

${ }^{* *} \mathrm{r}=$ distance from core vertical axis. 
Table 7 Dpa rate attenuation in the PV wall for different wall thicknesses. (Calculated with BUGLE-96 cross sections and ENDF/B-VI dpa cross sections)

\begin{tabular}{|c|c|c|c|c|c|c|c|c|}
\hline \multirow[b]{2}{*}{$\mathrm{d}^{*}$} & \multirow[b]{2}{*}{$\mathrm{r}^{* *}$} & \multicolumn{2}{|c|}{$\begin{array}{l}\text { PV thickness } 18.75 \mathrm{~cm} \\
\text { PV outer radius } 216.235 \mathrm{~cm}\end{array}$} & \multicolumn{2}{|c|}{$\begin{array}{l}\text { PV thickness } 24.20 \mathrm{~cm} \\
\text { PV outer radius } 221.69 \mathrm{~cm}\end{array}$} & \multicolumn{2}{|c|}{$\begin{array}{l}\text { PV thickness } 30.25 \mathrm{~cm} \mathrm{PV} \\
\text { outer radius } 227.74 \mathrm{~cm}\end{array}$} & \multirow{2}{*}{$\begin{array}{l}\text { RG } 1.99 \\
\text { Rev. } 2 \\
\end{array}$} \\
\hline & & $\mathrm{dpa} / \mathrm{s}$ & Ratio & $\mathrm{dpa} / \mathrm{s}$ & Ratio & $\mathrm{dpa} / \mathrm{s}$ & Ratio & \\
\hline $\mathrm{cm}$ & $\mathrm{cm}$ & $\mathrm{s}^{-1}$ & & $\mathrm{~s}^{-1}$ & & $\mathrm{~s}^{-1}$ & & \\
\hline 0.00 & 197.49 & $4.758 \mathrm{E}-11$ & 1.0000 & $4.800 \mathrm{E}-11$ & 1.0000 & $4.823 \mathrm{E}-11$ & 1.0000 & 1.0000 \\
\hline 0.28 & 197.77 & $4.739 \mathrm{E}-11$ & 0.9959 & $4.786 \mathrm{E}-11$ & 0.9970 & $4.811 \mathrm{E}-11$ & 0.9976 & 0.9734 \\
\hline 1.47 & 198.96 & $4.421 \mathrm{E}-11$ & 0.9291 & $4.482 \mathrm{E}-11$ & 0.9338 & $4.515 \mathrm{E}-11$ & 0.9363 & 0.8700 \\
\hline 3.29 & 200.78 & $3.851 \mathrm{E}-11$ & 0.8093 & $3.932 \mathrm{E}-11$ & 0.8192 & $3.976 \mathrm{E}-11$ & 0.8245 & 0.7326 \\
\hline 5.11 & 202.60 & $3.269 \mathrm{E}-11$ & 0.6872 & $3.371 \mathrm{E}-11$ & 0.7023 & $3.426 \mathrm{E}-11$ & 0.7104 & 0.6170 \\
\hline 6.93 & 204.42 & $2.750 \mathrm{E}-11$ & 0.5779 & $2.872 \mathrm{E}-11$ & 0.5983 & $2.938 \mathrm{E}-11$ & 0.6093 & 0.5195 \\
\hline 8.75 & 206.23 & $2.304 \mathrm{E}-11$ & 0.4842 & $2.448 \mathrm{E}-11$ & 0.5100 & $2.526 \mathrm{E}-11$ & 0.5238 & 0.4375 \\
\hline 10.57 & 208.05 & $1.917 \mathrm{E}-11$ & 0.4029 & $2.085 \mathrm{E}-11$ & 0.4344 & $2.176 \mathrm{E}-11$ & 0.4512 & 0.3684 \\
\hline 12.38 & 209.87 & $1.574 \mathrm{E}-11$ & 0.3309 & $1.769 \mathrm{E}-11$ & 0.3685 & $1.873 \mathrm{E}-11$ & 0.3884 & 0.3103 \\
\hline 14.20 & 211.69 & $1.275 \mathrm{E}-11$ & 0.2680 & $1.499 \mathrm{E}-11$ & 0.3122 & $1.617 \mathrm{E}-11$ & 0.3353 & 0.2613 \\
\hline 16.02 & 213.51 & $9.977 \mathrm{E}-12$ & 0.2097 & $1.258 \mathrm{E}-11$ & 0.2620 & $1.393 \mathrm{E}-11$ & 0.2887 & 0.2201 \\
\hline 17.84 & 215.33 & $7.339 \mathrm{E}-12$ & 0.1543 & $1.045 \mathrm{E}-11$ & 0.2178 & $1.197 \mathrm{E}-11$ & 0.2483 & 0.1853 \\
\hline 19.66 & 217.14 & & & $8.547 \mathrm{E}-12$ & 0.1781 & $1.025 \mathrm{E}-11$ & 0.2126 & 0.1561 \\
\hline 21.48 & 218.96 & & & $6.749 \mathrm{E}-12$ & 0.1406 & $8.706 \mathrm{E}-12$ & 0.1805 & 0.1314 \\
\hline 23.30 & 220.78 & & & $5.017 \mathrm{E}-12$ & 0.1045 & $7.326 \mathrm{E}-12$ & 0.1519 & 0.1107 \\
\hline 24.84 & 222.33 & & & & & $6.222 \mathrm{E}-12$ & 0.1290 & \\
\hline 26.27 & 223.76 & & & & & $5.267 \mathrm{E}-12$ & 0.1092 & \\
\hline 27.86 & 225.35 & & & & & $4.242 \mathrm{E}-12$ & 0.0880 & \\
\hline 29.46 & 226.94 & & & & & $3.229 \mathrm{E}-12$ & 0.0670 & \\
\hline
\end{tabular}

${ }^{*} \mathrm{~d}=$ distance from PV inner (wetted) surface.

${ }^{* *} \mathrm{r}=$ distance from core vertical axis. 
Table 8 Dpa rate attenuation in the PV wall for different wall thicknesses. (Calculated with BUGLE-96 cross sections and ASTM dpa cross sections)

\begin{tabular}{|c|c|c|c|c|c|c|c|c|}
\hline \multirow[b]{2}{*}{$\mathrm{d}^{*}$} & \multirow[b]{2}{*}{$\mathrm{r}^{* *}$} & \multicolumn{2}{|c|}{$\begin{array}{l}\text { PV thickness } 18.75 \mathrm{~cm} \\
\text { PV outer radius } 216.235 \mathrm{~cm}\end{array}$} & \multicolumn{2}{|c|}{$\begin{array}{l}\text { PV thickness } 24.20 \mathrm{~cm} \\
\text { PV outer radius } 221.69 \mathrm{~cm}\end{array}$} & \multicolumn{2}{|c|}{$\begin{array}{l}\text { PV thickness } 30.25 \mathrm{~cm} \\
\text { PV outer radius } 227.74 \mathrm{~cm}\end{array}$} & \multirow{2}{*}{$\begin{array}{l}\text { RG } 1.99 \\
\text { Rev. 2 }\end{array}$} \\
\hline & & $\mathrm{dpa} / \mathrm{s}$ & Ratio & $\mathrm{dpa} / \mathrm{s}$ & Ratio & $\mathrm{dpa} / \mathrm{s}$ & Ratio & \\
\hline $\mathrm{cm}$ & $\mathrm{cm}$ & $\mathrm{s}^{-1}$ & & $\mathrm{~s}^{-1}$ & & $\mathrm{~s}^{-1}$ & & \\
\hline 0.00 & 197.49 & $4.779 \mathrm{E}-11$ & 1.0000 & $4.819 \mathrm{E}-11$ & 1.0000 & $4.841 \mathrm{E}-11$ & 1.0000 & 1.0000 \\
\hline 0.28 & 197.77 & $4.754 \mathrm{E}-11$ & 0.9948 & $4.799 \mathrm{E}-11$ & 0.9958 & $4.823 \mathrm{E}-11$ & 0.9964 & 0.9734 \\
\hline 1.47 & 198.96 & $4.419 \mathrm{E}-11$ & 0.9246 & $4.477 \mathrm{E}-11$ & 0.9290 & $4.509 \mathrm{E}-11$ & 0.9314 & 0.8700 \\
\hline 3.29 & 200.78 & $3.829 \mathrm{E}-11$ & 0.8011 & $3.906 \mathrm{E}-11$ & 0.8105 & $3.948 \mathrm{E}-11$ & 0.8156 & 0.7326 \\
\hline 5.11 & 202.60 & $3.235 \mathrm{E}-11$ & 0.6768 & $3.331 \mathrm{E}-11$ & 0.6912 & $3.384 \mathrm{E}-11$ & 0.6990 & 0.6170 \\
\hline 6.93 & 204.42 & $2.708 E-11$ & 0.5666 & $2.825 E-11$ & 0.5862 & $2.888 \mathrm{E}-11$ & 0.5965 & 0.5195 \\
\hline 8.75 & 206.23 & $2.260 \mathrm{E}-11$ & 0.4728 & $2.397 \mathrm{E}-11$ & 0.4974 & $2.471 \mathrm{E}-11$ & 0.5105 & 0.4375 \\
\hline 10.57 & 208.05 & $1.874 \mathrm{E}-11$ & 0.3920 & $2.034 \mathrm{E}-11$ & 0.4221 & $2.120 \mathrm{E}-11$ & 0.4380 & 0.3684 \\
\hline 12.38 & 209.87 & $1.534 \mathrm{E}-11$ & 0.3209 & $1.719 \mathrm{E}-11$ & 0.3567 & $1.818 \mathrm{E}-11$ & 0.3756 & 0.3103 \\
\hline 14.20 & 211.69 & $1.239 \mathrm{E}-11$ & 0.2592 & $1.452 \mathrm{E}-11$ & 0.3013 & $1.565 \mathrm{E}-11$ & 0.3233 & 0.2613 \\
\hline 16.02 & 213.51 & $9.674 \mathrm{E}-12$ & 0.2024 & $1.215 \mathrm{E}-11$ & 0.2521 & $1.344 \mathrm{E}-11$ & 0.2776 & 0.2201 \\
\hline 17.84 & 215.33 & $7.108 \mathrm{E}-12$ & 0.1487 & $1.008 \mathrm{E}-11$ & 0.2092 & $1.153 \mathrm{E}-11$ & 0.2381 & 0.1853 \\
\hline 19.66 & 217.14 & & & $8.223 \mathrm{E}-12$ & 0.1706 & $9.852 \mathrm{E}-12$ & 0.2035 & 0.1561 \\
\hline 21.48 & 218.96 & & & $6.485 \mathrm{E}-12$ & 0.1346 & $8.350 \mathrm{E}-12$ & 0.1725 & 0.1314 \\
\hline 23.30 & 220.78 & & & $4.818 \mathrm{E}-12$ & 0.1000 & $7.016 \mathrm{E}-12$ & 0.1449 & 0.1107 \\
\hline 24.84 & 222.33 & & & & & $5.953 \mathrm{E}-12$ & 0.1230 & \\
\hline 26.27 & 223.76 & & & & & $5.035 \mathrm{E}-12$ & 0.1040 & \\
\hline 27.86 & 225.35 & & & & & $4.053 \mathrm{E}-12$ & 0.0837 & \\
\hline 29.46 & 226.94 & & & & & $3.084 \mathrm{E}-12$ & 0.0637 & \\
\hline
\end{tabular}

${ }^{*} \mathrm{~d}=$ distance from PV inner (wetted) surface.

${ }^{* *} \mathrm{r}=$ distance from core vertical axis. 
Table 9 Flux $(E>0.1 \mathrm{MeV}$ ) attenuation in the PV wall for different wall thicknesses. PV inner radius was $197.49 \mathrm{~cm}$ in all the cases. (Calculations with BUGLE-96)

\begin{tabular}{|c|c|c|c|c|c|c|c|c|}
\hline \multirow[b]{2}{*}{$\mathrm{d}^{*}$} & \multirow[b]{2}{*}{$\mathrm{r}^{* *}$} & \multicolumn{2}{|c|}{$\begin{array}{c}\text { PV thickness } 18.75 \mathrm{~cm} \\
\text { PV outer radius } 216.235 \mathrm{~cm}\end{array}$} & \multicolumn{2}{|c|}{$\begin{array}{l}\text { PV thickness } 24.20 \mathrm{~cm} \\
\text { PV outer radius } 221.69 \mathrm{~cm}\end{array}$} & \multicolumn{2}{|c|}{$\begin{array}{l}\text { PV thickness } 30.25 \mathrm{~cm} \\
\text { PV outer radius } 227.74 \mathrm{~cm}\end{array}$} & \multirow[b]{2}{*}{$\begin{array}{l}\text { RG } 1.99 \\
\text { Rev. } 2\end{array}$} \\
\hline & & $\begin{array}{c}\text { Flux } \\
(\mathrm{E}>0.1 \mathrm{MeV}) \\
\end{array}$ & Ratio & $\begin{array}{c}\text { Flux } \\
(\mathrm{E}>0.1 \mathrm{MeV}) \\
\end{array}$ & Ratio & $\begin{aligned} & \text { Flux } \\
&(\mathrm{E}>0.1 \mathrm{MeV})\end{aligned}$ & Ratio & \\
\hline $\mathrm{cm}$ & $\mathrm{cm}$ & $\mathrm{cm}^{-2} \mathrm{~s}^{-1}$ & & $\mathrm{~cm}^{-2} \mathrm{~s}^{-1}$ & & $\mathrm{~cm}^{-2} \mathrm{~s}^{-1}$ & & \\
\hline 0.00 & 197.49 & $7.907 E+10$ & 1.0000 & $8.055 E+10$ & 1.0000 & $8.137 E+10$ & 1.0000 & 1.0000 \\
\hline 0.28 & 197.77 & $8.020 \mathrm{E}+10$ & 1.0144 & $8.188 \mathrm{E}+10$ & 1.0165 & $8.282 \mathrm{E}+10$ & 1.0178 & 0.9734 \\
\hline 1.47 & 198.96 & $7.946 \mathrm{E}+10$ & 1.0049 & $8.168 \mathrm{E}+10$ & 1.0141 & $8.293 E+10$ & 1.0192 & 0.8700 \\
\hline 3.29 & 200.78 & $7.484 \mathrm{E}+10$ & 0.9466 & $7.778 \mathrm{E}+10$ & 0.9657 & $7.945 \mathrm{E}+10$ & 0.9764 & 0.7326 \\
\hline 5.11 & 202.60 & $6.791 \mathrm{E}+10$ & 0.8589 & $7.156 \mathrm{E}+10$ & 0.8884 & $7.362 E+10$ & 0.9047 & 0.6170 \\
\hline 6.93 & 204.42 & $6.054 \mathrm{E}+10$ & 0.7657 & $6.490 \mathrm{E}+10$ & 0.8058 & $6.738 E+10$ & 0.8281 & 0.5195 \\
\hline 8.75 & 206.23 & $5.329 E+10$ & 0.6740 & $5.840 \mathrm{E}+10$ & 0.7250 & $6.130 \mathrm{E}+10$ & 0.7534 & 0.4375 \\
\hline 10.57 & 208.05 & $4.625 \mathrm{E}+10$ & 0.5850 & $5.215 \mathrm{E}+10$ & 0.6475 & $5.551 \mathrm{E}+10$ & 0.6822 & 0.3684 \\
\hline 12.38 & 209.87 & $3.938 \mathrm{E}+10$ & 0.4980 & $4.611 \mathrm{E}+10$ & 0.5725 & $4.995 \mathrm{E}+10$ & 0.6139 & 0.3103 \\
\hline 14.20 & 211.69 & $3.280 \mathrm{E}+10$ & 0.4149 & $4.046 \mathrm{E}+10$ & 0.5024 & $4.480 \mathrm{E}+10$ & 0.5506 & 0.2613 \\
\hline 16.02 & 213.51 & $2.624 \mathrm{E}+10$ & 0.3318 & $3.499 \mathrm{E}+10$ & 0.4344 & $3.989 \mathrm{E}+10$ & 0.4903 & 0.2201 \\
\hline 17.84 & 215.33 & $1.957 \mathrm{E}+10$ & 0.2475 & $2.983 \mathrm{E}+10$ & 0.3704 & $3.531 \mathrm{E}+10$ & 0.4339 & 0.1853 \\
\hline 19.66 & 217.14 & & & $2.489 \mathrm{E}+10$ & 0.3091 & $3.099 \mathrm{E}+10$ & 0.3808 & 0.1561 \\
\hline 21.48 & 218.96 & & & $1.997 \mathrm{E}+10$ & 0.2479 & $2.686 \mathrm{E}+10$ & 0.3301 & 0.1314 \\
\hline 23.30 & 220.78 & & & $1.498 \mathrm{E}+10$ & 0.1860 & $2.300 \mathrm{E}+10$ & 0.2826 & 0.1107 \\
\hline 24.84 & 222.33 & & & & & $1.979 \mathrm{E}+10$ & 0.2433 & \\
\hline 26.27 & 223.76 & & & & & $1.690 \mathrm{E}+10$ & 0.2077 & \\
\hline 27.86 & 225.35 & & & & & $1.373 E+10$ & 0.1688 & . \\
\hline 29.46 & 226.94 & & & & & $1.050 \mathrm{E}+10$ & 0.1290 & \\
\hline
\end{tabular}

* $\mathrm{d}=$ distance from PV inner (wetted) surface.

${ }^{* *} \mathrm{r}=$ distance from core vertical axis. 
Table 10 Flux ( $E>1 \mathrm{MeV}$ ) attenuation in the PV wall, calculated with the BUGLE-96 and the SAILOR cross-section libraries. The HBR-2 nominal geometry was used in both calculations. SAILOR calculation used the ENDF/B-IV fission spectra

\begin{tabular}{|c|c|c|c|c|c|c|}
\hline \multirow[b]{2}{*}{$\mathrm{d}^{*}$} & \multirow[b]{2}{*}{$\mathrm{r}^{* *}$} & \multicolumn{2}{|c|}{ SAILOR } & \multicolumn{2}{|c|}{ BUGLE-96 } & \multirow[b]{2}{*}{$100 *(\mathrm{~B}-\mathrm{A}) / \mathrm{A}$} \\
\hline & & Flux & Ratio & Flux & Ratio & \\
\hline $\mathrm{cm}$ & $\mathrm{cm}$ & $\mathrm{cm}^{-2} \mathrm{~s}^{-1}$ & $\mathrm{~A}$ & $\mathrm{~cm}^{-2} \mathrm{~s}^{-1}$ & $\mathrm{~B}$ & \\
\hline 0.00 & 197.49 & $2.873 E+10$ & 1.0000 & $3.042 \mathrm{E}+10$ & 1.0000 & 0.0 \\
\hline 0.28 & 197.77 & $2.846 \mathrm{E}+10$ & 0.9908 & $3.014 \mathrm{E}+10$ & 0.9908 & 0.0 \\
\hline 1.47 & 198.96 & $2.576 \mathrm{E}+10$ & 0.8968 & $2.745 \mathrm{E}+10$ & 0.9023 & 0.6 \\
\hline 3.29 & 200.78 & $2.108 \mathrm{E}+10$ & 0.7339 & $2.273 E+10$ & 0.7472 & 1.8 \\
\hline 5.11 & 202.60 & $1.659 \mathrm{E}+10$ & 0.5773 & $1.811 \mathrm{E}+10$ & 0.5953 & 3.1 \\
\hline 6.93 & 204.42 & $1.286 \mathrm{E}+10$ & 0.4478 & $1.421 \mathrm{E}+10$ & 0.4673 & 4.4 \\
\hline 8.75 & 206.23 & $9.937 \mathrm{E}+09$ & 0.3459 & $1.111 \mathrm{E}+10$ & 0.3653 & 5.6 \\
\hline 10.57 & 208.05 & $7.649 \mathrm{E}+09$ & 0.2662 & $8.657 \mathrm{E}+09$ & 0.2846 & 6.9 \\
\hline 12.38 & 209.87 & $5.840 \mathrm{E}+09$ & 0.2033 & $6.691 \mathrm{E}+09$ & 0.2200 & 8.2 \\
\hline 14.20 & 211.69 & $4.467 \mathrm{E}+09$ & 0.1555 & $5.180 \mathrm{E}+09$ & 0.1703 & 9.5 \\
\hline 16.02 & 213.51 & $3.389 \mathrm{E}+09$ & 0.1180 & $3.977 \mathrm{E}+09$ & 0.1307 & 10.8 \\
\hline 17.84 & 215.33 & $2.561 \mathrm{E}+09$ & 0.0892 & $3.044 \mathrm{E}+09$ & 0.1001 & 12.2 \\
\hline 19.66 & 217.14 & $1.921 \mathrm{E}+09$ & 0.0669 & $2.311 \mathrm{E}+09$ & 0.0760 & 13.7 \\
\hline 21.48 & 218.96 & $1.411 \mathrm{E}+09$ & 0.0491 & $1.721 \mathrm{E}+09$ & 0.0566 & 15.2 \\
\hline 23.30 & 220.78 & $9.897 \mathrm{E}+08$ & 0.0345 & $1.227 \mathrm{E}+09$ & 0.0403 & 17.1 \\
\hline
\end{tabular}

${ }^{*} \mathrm{~d}=$ distance from PV inner (wetted) surface.

${ }^{* *} \mathrm{r}=$ distance from core vertical axis. 
Table 11 Attenuation of the dpa rate in the PV wall. The ENDF/B-VI dpa cross section was used with BUGLE-96 and SAILOR calculations

\begin{tabular}{|c|c|c|c|c|c|c|c|c|c|}
\hline \multirow[b]{2}{*}{$d^{*}$} & \multirow[b]{2}{*}{$r^{* *}$} & \multicolumn{2}{|c|}{$\begin{array}{l}\text { SAILOR with } \\
\text { ENDF/B-VI dpa }\end{array}$} & \multicolumn{2}{|c|}{$\begin{array}{l}\text { BUGLE-96 with } \\
\text { ENDF/B-VI dpa }\end{array}$} & \multirow{2}{*}{$\begin{array}{l}\text { RG1.99 } \\
\text { Rev. } 2 \\
\end{array}$} & \multirow{2}{*}{$\begin{array}{c}100^{*} \\
(\mathrm{~A}-\mathrm{C}) / \mathrm{C}\end{array}$} & \multirow{2}{*}{$\begin{array}{c}100^{*} \\
(\mathrm{~B}-\mathrm{C}) / \mathrm{C}\end{array}$} & \multirow{2}{*}{$\begin{array}{c}100^{*} \\
(\mathrm{~B}-\mathrm{A}) / \mathrm{A}\end{array}$} \\
\hline & & dpa rate & Ratio & dpa rate & Ratio & & & & \\
\hline $\mathrm{cm}$ & $\mathrm{cm}$ & $\mathrm{s}^{-1}$ & $\mathrm{~A}$ & $\mathrm{~s}^{-1}$ & $\mathrm{~B}$ & $\mathrm{C}$ & $\%$ & $\%$ & $\%$ \\
\hline 0.00 & 197.49 & $4.592 \mathrm{E}-11$ & 1.0000 & $4.800 \mathrm{E}-11$ & 1.0000 & 1.0000 & 0.00 & 0.00 & 0.00 \\
\hline 0.28 & 197.77 & $4.560 \mathrm{E}-11$ & 0.9930 & $4.786 \mathrm{E}-11$ & 0.9970 & 0.9734 & 2.01 & 2.42 & 0.40 \\
\hline 1.47 & 198.96 & $4.228 \mathrm{E}-11$ & 0.9207 & $4.482 \mathrm{E}-11$ & 0.9338 & 0.8700 & 5.82 & 7.33 & 1.43 \\
\hline 3.29 & 200.78 & $3.663 \mathrm{E}-11$ & 0.7978 & $3.932 \mathrm{E}-11$ & 0.8192 & 0.7326 & 8.90 & 11.82 & 2.68 \\
\hline 5.11 & 202.60 & $3.110 \mathrm{E}-11$ & 0.6773 & $3.371 \mathrm{E}-11$ & 0.7023 & 0.6170 & 9.78 & 13.82 & 3.69 \\
\hline 6.93 & 204.42 & $2.628 \mathrm{E}-11$ & 0.5723 & $2.872 \mathrm{E}-11$ & 0.5983 & 0.5195 & 10.16 & 15.16 & 4.54 \\
\hline 8.75 & 206.23 & $2.223 \mathrm{E}-11$ & 0.4841 & $2.448 \mathrm{E}-11$ & 0.5100 & 0.4375 & 10.65 & 16.56 & 5.34 \\
\hline 10.57 & 208.05 & $1.879 \mathrm{E}-11$ & 0.4093 & $2.085 \mathrm{E}-11$ & 0.4344 & 0.3684 & 11.08 & 17.91 & 6.14 \\
\hline 12.38 & 209.87 & $1.582 \mathrm{E}-11$ & 0.3444 & $1.769 \mathrm{E}-11$ & 0.3685 & 0.3103 & 11.00 & 18.75 & 6.98 \\
\hline 14.20 & 211.69 & $1.329 \mathrm{E}-11$ & 0.2894 & $1.499 \mathrm{E}-11$ & 0.3122 & 0.2613 & 10.74 & 19.47 & 7.89 \\
\hline 16.02 & 213.51 & $1.105 \mathrm{E}-11$ & 0.2406 & $1.258 \mathrm{E}-11$ & 0.2620 & 0.2201 & 9.34 & 19.06 & 8.89 \\
\hline 17.84 & 215.33 & $9.079 \mathrm{E}-12$ & 0.1977 & $1.045 \mathrm{E}-11$ & 0.2178 & 0.1853 & 6.69 & 17.52 & 10.15 \\
\hline 19.66 & 217.14 & $7.320 \mathrm{E}-12$ & 0.1594 & $8.547 \mathrm{E}-12$ & 0.1781 & 0.1561 & 2.15 & 14.10 & 11.69 \\
\hline 21.48 & 218.96 & $5.681 \mathrm{E}-12$ & 0.1237 & $6.749 \mathrm{E}-12$ & 0.1406 & 0.1314 & -5.86 & 6.99 & 13.65 \\
\hline 23.30 & 220.78 & $4.103 \mathrm{E}-12$ & 0.0894 & $5.017 \mathrm{E}-12$ & 0.1045 & 0.1107 & -19.26 & -5.55 & 16.98 \\
\hline
\end{tabular}

${ }^{*} \mathrm{~d}=$ distance from PV inner (wetted) surface.

${ }^{* *} \mathrm{r}=$ distance from core vertical axis. 
Table 12 Flux $(E>1 \mathrm{MeV}$ ) and dpa rate attenuation in the PV wall. To determine the dpa rates the ENDF/B-VI dpa cross sections were used with BUGLE-96, while ASTM dpa cross sections were used with SAILOR. All calculations are for the HBR-2 geometry

\begin{tabular}{|c|c|c|c|c|c|c|c|c|c|c|c|}
\hline \multirow[b]{2}{*}{$\mathrm{d}^{*}$} & \multirow[b]{2}{*}{$\mathrm{r}^{* *}$} & \multicolumn{2}{|c|}{ BUGLE-96 } & \multicolumn{2}{|c|}{$\begin{array}{l}\text { SAILOR, } \\
\text { ASTM dpa }\end{array}$} & \multicolumn{2}{|c|}{$\begin{array}{l}\text { BUGLE-96, } \\
\text { ENDF/B-VI dpa }\end{array}$} & \multirow[b]{2}{*}{$\begin{array}{c}100^{*} \\
(\mathrm{~B}-\mathrm{A}) / \mathrm{A} \\
\end{array}$} & \multirow[b]{2}{*}{$\begin{array}{c}\text { RG } 1.99 \\
\text { Rev. } 2 \\
\end{array}$} & \multirow[b]{2}{*}{$\begin{array}{c}100^{*} \\
(\mathrm{~A}-\mathrm{C}) / \mathrm{C}\end{array}$} & \multirow[b]{2}{*}{$\begin{array}{c}100^{*} \\
(\mathrm{~B}-\mathrm{C}) / \mathrm{C}\end{array}$} \\
\hline & & Flux $(\mathrm{E}>1 \mathrm{MeV})$ & Ratio & dpa rate & Ratio & dpa rate & Ratio & & & & \\
\hline $\mathrm{cm}$ & $\mathrm{cm}$ & $\mathrm{cm}^{-2} \mathrm{~s}^{-1}$ & & $\mathrm{~s}^{-1}$ & A & $\mathrm{s}^{-1}$ & B & $\%$ & $\mathrm{C}$ & $\%$ & $\%$ \\
\hline 0.000 & 197.49 & $3.0420 \mathrm{E}+10$ & 1.0000 & $4.621 \mathrm{E}-11$ & 1.0000 & $4.800 \mathrm{E}-11$ & 1.0000 & 0.0 & 1.0000 & 0.0 & 0.0 \\
\hline 0.285 & 197.77 & $3.0142 \mathrm{E}+10$ & 0.9908 & $4.582 \mathrm{E}-11$ & 0.9916 & $4.786 \mathrm{E}-11$ & 0.9970 & 0.5 & 0.9734 & 1.9 & 2.4 \\
\hline 1.474 & 198.96 & $2.7449 \mathrm{E}+10$ & 0.9023 & $4.229 \mathrm{E}-11$ & 0.9152 & $4.482 \mathrm{E}-11$ & 0.9338 & 2.0 & 0.8700 & 5.2 & 7.3 \\
\hline 3.293 & 200.78 & $2.2731 \mathrm{E}+10$ & 0.7472 & $3.642 \mathrm{E}-11$ & 0.7882 & $3.932 \mathrm{E}-11$ & 0.8192 & 3.9 & 0.7326 & 7.6 & 11.8 \\
\hline 5.111 & 202.60 & $1.8108 \mathrm{E}+10$ & 0.5953 & $3.075 \mathrm{E}-11$ & 0.6655 & $3.371 \mathrm{E}-11$ & 0.7023 & 5.5 & 0.6170 & 7.9 & 13.8 \\
\hline 6.930 & 204.42 & $1.4215 \mathrm{E}+10$ & 0.4673 & $2.586 \mathrm{E}-11$ & 0.5596 & $2.872 \mathrm{E}-11$ & 0.5983 & 6.9 & 0.5195 & 7.7 & 15.2 \\
\hline 8.748 & 206.23 & $1.1113 \mathrm{E}+10$ & 0.3653 & $2.178 \mathrm{E}-11$ & 0.4713 & $2.448 \mathrm{E}-11$ & 0.5100 & 8.2 & 0.4375 & 7.7 & 16.6 \\
\hline 10.567 & 208.05 & $8.6568 \mathrm{E}+09$ & 0.2846 & $1.834 \mathrm{E}-11$ & 0.3968 & $2.085 \mathrm{E}-11$ & 0.4344 & 9.5 & 0.3684 & 7.7 & 17.9 \\
\hline 12.385 & 209.87 & $6.6911 \mathrm{E}+09$ & 0.2200 & $1.538 \mathrm{E}-11$ & 0.3327 & $1.769 \mathrm{E}-11$ & 0.3685 & 10.7 & 0.3103 & 7.2 & 18.7 \\
\hline 14.203 & 211.69 & $5.1802 \mathrm{E}+09$ & 0.1703 & $1.288 \mathrm{E}-11$ & 0.2787 & $1.499 \mathrm{E}-11$ & 0.3122 & 12.0 & 0.2613 & 6.7 & 19.5 \\
\hline 16.022 & 213.51 & $3.9774 \mathrm{E}+09$ & 0.1307 & $1.068 \mathrm{E}-11$ & 0.2311 & $1.258 \mathrm{E}-11$ & 0.2620 & 13.4 & 0.2201 & 5.0 & 19.1 \\
\hline 17.840 & 215.33 & $3.0436 \mathrm{E}+09$ & 0.1001 & $8.758 \mathrm{E}-12$ & 0.1895 & $1.045 \mathrm{E}-11$ & 0.2178 & 14.9 & 0.1853 & 2.3 & 17.5 \\
\hline 19.659 & 217.14 & $2.3115 \mathrm{E}+09$ & 0.0760 & $7.048 \mathrm{E}-12$ & 0.1525 & 8.547E-12 & 0.1781 & 16.7 & 0.1561 & -2.3 & 14.1 \\
\hline 21.477 & 218.96 & $1.7209 \mathrm{E}+09$ & 0.0566 & $5.462 \mathrm{E}-12$ & 0.1182 & $6.749 \mathrm{E}-12$ & 0.1406 & 19.0 & 0.1314 & -10.1 & 7.0 \\
\hline 23.296 & 220.78 & $1.2274 \mathrm{E}+09$ & 0.0403 & $3.942 \mathrm{E}-12$ & 0.0853 & $5.017 \mathrm{E}-12$ & 0.1045 & 22.5 & 0.1107 & -22.9 & -5.6 \\
\hline
\end{tabular}

${ }^{*} \mathrm{~d}=$ distance from PV inner (wetted) surface.

${ }^{* *} \mathrm{r}=$ distance from core vertical axis. 
Table 13 Flux $(E>1 \mathrm{MeV})$ attenuation in the PV, calculated with the BUGLE-96 crosssection library and the $P_{1}$ to $P_{3}$ approximations for the anisotropic scattering

\begin{tabular}{|c|c|c|c|c|c|c|c|c|}
\hline \multirow{2}{*}{$\mathrm{d}^{*}$} & \multicolumn{2}{|c|}{$\mathrm{P}_{3}$} & \multicolumn{3}{c|}{$\mathrm{P}_{2}$} & \multicolumn{2}{c|}{$\mathrm{P}_{1}$} & \\
\cline { 2 - 9 } & $\begin{array}{c}\text { Flux } \\
(\mathrm{E}>1 \mathrm{MeV})\end{array}$ & Ratio & $\begin{array}{c}\text { Flux } \\
(\mathrm{E}>1 \mathrm{MeV})\end{array}$ & Ratio & $\begin{array}{c}\text { Flux } \\
(\mathrm{E}>1 \mathrm{MeV})\end{array}$ & Ratio & $\begin{array}{c}\text { RG 1.99 } \\
\text { Rev. }\end{array}$ & $\begin{array}{c}100^{*} \\
(\mathrm{~A}-\mathrm{B}) / \mathrm{B}\end{array}$ \\
\hline $\mathrm{cm}$ & $\mathrm{cm}^{-2} \mathrm{~s}^{-1}$ & $\mathrm{~A}$ & $\mathrm{~cm}^{-2} \mathrm{~s}^{-1}$ & & $\mathrm{~cm}^{-2} \mathrm{~s}^{-1}$ & $\mathrm{~B}$ & & \\
0.00 & $3.042 \mathrm{E}+10$ & 1.0000 & $3.022 \mathrm{E}+10$ & 1.0000 & $2.527 \mathrm{E}+10$ & 1.0000 & 1.0000 & 0.00 \\
1.47 & $3.014 \mathrm{E}+10$ & 0.9908 & $2.996 \mathrm{E}+10$ & 0.9914 & $2.499 \mathrm{E}+10$ & 0.9890 & 0.9734 & 0.18 \\
3.29 & $2.745 \mathrm{E}+10$ & 0.9023 & $2.733 \mathrm{E}+10$ & 0.9042 & $2.255 \mathrm{E}+10$ & 0.8925 & 0.8700 & 1.10 \\
5.11 & $2.273 \mathrm{E}+10$ & 0.7472 & $2.261 \mathrm{E}+10$ & 0.7482 & $1.835 \mathrm{E}+10$ & 0.7261 & 0.7326 & 2.91 \\
6.93 & $1.811 \mathrm{E}+10$ & 0.5953 & $1.796 \mathrm{E}+10$ & 0.5944 & $1.436 \mathrm{E}+10$ & 0.5681 & 0.6170 & 4.78 \\
8.75 & $1.421 \mathrm{E}+10$ & 0.4673 & $1.406 \mathrm{E}+10$ & 0.4654 & $1.111 \mathrm{E}+10$ & 0.4395 & 0.5195 & 6.32 \\
10.57 & $1.111 \mathrm{E}+10$ & 0.3653 & $1.097 \mathrm{E}+10$ & 0.3629 & $8.569 \mathrm{E}+09$ & 0.3391 & 0.4375 & 7.73 \\
12.38 & $8.657 \mathrm{E}+09$ & 0.2846 & $8.526 \mathrm{E}+09$ & 0.2821 & $6.602 \mathrm{E}+09$ & 0.2613 & 0.3684 & 8.92 \\
14.20 & $6.691 \mathrm{E}+09$ & 0.2200 & $6.576 \mathrm{E}+09$ & 0.2176 & $5.044 \mathrm{E}+09$ & 0.1996 & 0.3103 & 10.19 \\
16.02 & $5.180 \mathrm{E}+09$ & 0.1703 & $5.084 \mathrm{E}+09$ & 0.1682 & $3.869 \mathrm{E}+09$ & 0.1531 & 0.2613 & 11.23 \\
17.84 & $3.977 \mathrm{E}+09$ & 0.1307 & $3.898 \mathrm{E}+09$ & 0.1290 & $2.942 \mathrm{E}+09$ & 0.1164 & 0.2201 & 12.29 \\
19.66 & $3.044 \mathrm{E}+09$ & 0.1001 & $2.979 \mathrm{E}+09$ & 0.0986 & $2.230 \mathrm{E}+09$ & 0.0883 & 0.1853 & 13.37 \\
21.48 & $2.311 \mathrm{E}+09$ & 0.0760 & $2.261 \mathrm{E}+09$ & 0.0748 & $1.680 \mathrm{E}+09$ & 0.0665 & 0.1561 & 14.30 \\
23.30 & $1.721 \mathrm{E}+09$ & 0.0566 & $1.683 \mathrm{E}+09$ & 0.0557 & $1.237 \mathrm{E}+09$ & 0.0490 & 0.1314 & 15.55 \\
\hline & $1.227 \mathrm{E}+09$ & 0.0403 & $1.200 \mathrm{E}+09$ & 0.0397 & $8.707 \mathrm{E}+08$ & 0.0345 & 0.1107 & 17.10 \\
\hline
\end{tabular}

${ }^{*} \mathrm{~d}=$ distance from PV inner (wetted) surface. 
Table 14 The attenuation of the dpa rate in the PV wall, calculated with the BUGLE-96 cross sections, the $P_{1}$ to $P_{3}$ approximations for anisotropic scattering, and with the ASTM dpa cross sections

\begin{tabular}{|c|c|c|c|c|c|c|c|c|}
\hline & $\mathrm{P}_{3}$ & & $\mathrm{P}_{2}$ & & $\mathrm{P}_{1}$ & & & \\
\cline { 2 - 8 } $\mathrm{d}^{*}$ & $\mathrm{dpa} / \mathrm{s}$ & Ratio & $\mathrm{dpa} / \mathrm{s}$ & Ratio & $\mathrm{dpa} / \mathrm{s}$ & Ratio & $\begin{array}{c}\text { RG 1.99 } \\
\text { Rev. } 2\end{array}$ & $\begin{array}{c}100^{*} \\
(\mathrm{~A}-\mathrm{B}) / \mathrm{B}\end{array}$ \\
\hline $\mathrm{cm}$ & $\mathrm{s}^{-1}$ & $\mathrm{~A}$ & $\mathrm{~s}^{-1}$ & & $\mathrm{~s}^{-1}$ & $\mathrm{~B}$ & & \\
\hline 0.00 & $4.819 \mathrm{E}-11$ & 1.0000 & $4.786 \mathrm{E}-11$ & 1.0000 & $4.002 \mathrm{E}-11$ & 1.0000 & 1.0000 & 0.00 \\
0.28 & $4.799 \mathrm{E}-11$ & 0.9958 & $4.768 \mathrm{E}-11$ & 0.9963 & $3.977 \mathrm{E}-11$ & 0.9937 & 0.9734 & 0.21 \\
1.47 & $4.477 \mathrm{E}-11$ & 0.9290 & $4.458 \mathrm{E}-11$ & 0.9315 & $3.684 \mathrm{E}-11$ & 0.9205 & 0.8700 & 0.93 \\
3.29 & $3.906 \mathrm{E}-11$ & 0.8105 & $3.890 \mathrm{E}-11$ & 0.8128 & $3.170 \mathrm{E}-11$ & 0.7920 & 0.7326 & 2.33 \\
5.11 & $3.331 \mathrm{E}-11$ & 0.6912 & $3.312 \mathrm{E}-11$ & 0.6919 & $2.668 \mathrm{E}-11$ & 0.6666 & 0.6170 & 3.70 \\
6.93 & $2.825 \mathrm{E}-11$ & 0.5861 & $2.803 \mathrm{E}-11$ & 0.5857 & $2.241 \mathrm{E}-11$ & 0.5600 & 0.5195 & 4.65 \\
8.75 & $2.397 \mathrm{E}-11$ & 0.4974 & $2.376 \mathrm{E}-11$ & 0.4964 & $1.889 \mathrm{E}-11$ & 0.4720 & 0.4375 & 5.37 \\
10.57 & $2.034 \mathrm{E}-11$ & 0.4220 & $2.014 \mathrm{E}-11$ & 0.4208 & $1.595 \mathrm{E}-11$ & 0.3987 & 0.3684 & 5.85 \\
12.38 & $1.719 \mathrm{E}-11$ & 0.3566 & $1.701 \mathrm{E}-11$ & 0.3554 & $1.343 \mathrm{E}-11$ & 0.3356 & 0.3103 & 6.26 \\
14.20 & $1.452 \mathrm{E}-11$ & 0.3012 & $1.436 \mathrm{E}-11$ & 0.3001 & $1.132 \mathrm{E}-11$ & 0.2828 & 0.2613 & 6.53 \\
16.02 & $1.215 \mathrm{E}-11$ & 0.2521 & $1.202 \mathrm{E}-11$ & 0.2511 & $9.452 \mathrm{E}-12$ & 0.2362 & 0.2201 & 6.75 \\
17.84 & $1.008 \mathrm{E}-11$ & 0.2091 & $9.965 \mathrm{E}-12$ & 0.2082 & $7.821 \mathrm{E}-12$ & 0.1954 & 0.1853 & 6.99 \\
19.66 & $8.223 \mathrm{E}-12$ & 0.1706 & $8.132 \mathrm{E}-12$ & 0.1699 & $6.372 \mathrm{E}-12$ & 0.1592 & 0.1561 & 7.16 \\
21.48 & $6.485 \mathrm{E}-12$ & 0.1346 & $6.414 \mathrm{E}-12$ & 0.1340 & $5.008 \mathrm{E}-12$ & 0.1251 & 0.1314 & 7.52 \\
23.30 & $4.818 \mathrm{E}-12$ & 0.1000 & $4.765 \mathrm{E}-12$ & 0.0996 & $3.702 \mathrm{E}-12$ & 0.0925 & 0.1107 & 8.07 \\
\hline
\end{tabular}

${ }^{*} \mathrm{~d}=$ distance from PV inner (wetted) surface. 
Table 15 Comparison of dpa rate attenuation in the PV wall, calculated with SAILOR library, $P_{1}$ approximation, and ASTM dpa cross sections with the dpa rate attenuation obtained with BUGLE-96 library, $P_{3}$ approximation, and ENDF/B-VI dpa cross sections. (Comparison with the RG 1.99, Rev. 2, attenuation formula is also given)

\begin{tabular}{|c|c|c|c|c|c|c|c|c|}
\hline & \multicolumn{2}{|c|}{$\begin{array}{c}\text { SAILOR, } \mathrm{P}_{1}, \\
\text { ASTM dpa }\end{array}$} & \multicolumn{2}{c|}{$\begin{array}{c}\text { BUGLE-96, } \mathrm{P}_{3}, \\
\text { ENDF/B-VI dpa }\end{array}$} & $\begin{array}{c}\text { RG } 1.99 \\
\text { Rev. }\end{array}$ & & \\
\cline { 2 - 8 } $\mathrm{d}^{*}$ & dpa rate & $\begin{array}{c}\text { Ratio } \\
\text { A }\end{array}$ & dpa rate & $\begin{array}{c}\text { Ratio } \\
\text { B }\end{array}$ & C & $\begin{array}{c}100^{*} \\
(\mathrm{~B}-\mathrm{A}) / \mathrm{A}\end{array}$ & $\begin{array}{c}100^{*} \\
(\mathrm{~A}-\mathrm{C}) / \mathrm{C}\end{array}$ & $\begin{array}{c}1 \\
(\mathrm{~B}-\mathrm{C}) / \mathrm{C}\end{array}$ \\
\hline $\mathrm{cm}$ & $\mathrm{s}^{-1}$ & & $\mathrm{~s}^{-1}$ & & & & & \\
\hline 0.00 & $3.833 \mathrm{E}-11$ & 1.0000 & $4.800 \mathrm{E}-11$ & 1.0000 & 1.0000 & 0.00 & 0.00 & 0.00 \\
0.28 & $3.791 \mathrm{E}-11$ & 0.9890 & $4.786 \mathrm{E}-11$ & 0.9970 & 0.9734 & 0.81 & 1.60 & 2.42 \\
1.47 & $3.470 \mathrm{E}-11$ & 0.9051 & $4.482 \mathrm{E}-11$ & 0.9338 & 0.8700 & 3.17 & 4.03 & 7.33 \\
3.29 & $2.944 \mathrm{E}-11$ & 0.7680 & $3.932 \mathrm{E}-11$ & 0.8192 & 0.7326 & 6.66 & 4.84 & 11.82 \\
5.11 & $2.453 \mathrm{E}-11$ & 0.6400 & $3.371 \mathrm{E}-11$ & 0.7023 & 0.6170 & 9.72 & 3.74 & 13.82 \\
6.93 & $2.044 \mathrm{E}-11$ & 0.5333 & $2.872 \mathrm{E}-11$ & 0.5983 & 0.5195 & 12.20 & 2.65 & 15.16 \\
8.75 & $1.710 \mathrm{E}-11$ & 0.4460 & $2.448 \mathrm{E}-11$ & 0.5100 & 0.4375 & 14.34 & 1.94 & 16.56 \\
10.57 & $1.433 \mathrm{E}-11$ & 0.3739 & $2.085 \mathrm{E}-11$ & 0.4344 & 0.3684 & 16.20 & 1.47 & 17.91 \\
12.38 & $1.197 \mathrm{E}-11$ & 0.3123 & $1.769 \mathrm{E}-11$ & 0.3685 & 0.3103 & 18.00 & 0.63 & 18.75 \\
14.20 & $1.000 \mathrm{E}-11$ & 0.2609 & $1.499 \mathrm{E}-11$ & 0.3122 & 0.2613 & 19.67 & -0.17 & 19.47 \\
16.02 & $8.275 \mathrm{E}-12$ & 0.2159 & $1.258 \mathrm{E}-11$ & 0.2620 & 0.2201 & 21.37 & -1.90 & 19.06 \\
17.84 & $6.769 \mathrm{E}-12$ & 0.1766 & $1.045 \mathrm{E}-11$ & 0.2178 & 0.1853 & 23.34 & -4.72 & 17.52 \\
19.66 & $5.437 \mathrm{E}-12$ & 0.1418 & $8.547 \mathrm{E}-12$ & 0.1781 & 0.1561 & 25.54 & -9.12 & 14.10 \\
21.48 & $4.198 \mathrm{E}-12$ & 0.1095 & $6.749 \mathrm{E}-12$ & 0.1406 & 0.1314 & 28.41 & -16.68 & 6.99 \\
23.30 & $3.011 \mathrm{E}-12$ & 0.0786 & $5.017 \mathrm{E}-12$ & 0.1045 & 0.1107 & 33.06 & -29.02 & -5.55 \\
\hline
\end{tabular}

${ }^{*} \mathrm{~d}=$ distance from PV inner (wetted) surface. 
Table 16 Comparison of the dpa rate attenuation in the PV wall, calculated with ENDF/BVI and ASTM dpa cross sections. Neutron fluxes are from the BUGLE-96 calculation. The HBR-2 "nominal" geometry was used.

\begin{tabular}{|c|c|c|c|c|c|c|}
\hline \multirow[b]{2}{*}{$\mathrm{d}^{*}$} & \multirow[b]{2}{*}{$\mathrm{r}^{* *}$} & \multicolumn{2}{|c|}{$\begin{array}{l}\text { dpa rate } \\
\text { ASTM }\end{array}$} & \multicolumn{2}{|c|}{$\begin{array}{c}\text { dpa rate } \\
\text { ENDF/B-VI }\end{array}$} & \multirow{2}{*}{$\begin{array}{c}100^{*} \\
(\mathrm{~B}-\mathrm{A}) / \mathrm{A}\end{array}$} \\
\hline & & Value & Ratio & Value & Ratio & \\
\hline $\mathrm{cm}$ & $\mathrm{cm}$ & $\mathrm{s}^{-1}$ & A & $\mathrm{s}^{-1}$ & B & $\%$ \\
\hline 0.000 & 197.485 & $4.82 \mathrm{E}-11$ & 1.0000 & $4.80 \mathrm{E}-11$ & 1.0000 & 0.00 \\
\hline 0.285 & 197.770 & $4.799 \mathrm{E}-11$ & 0.9958 & $4.786 \mathrm{E}-11$ & 0.9970 & 0.12 \\
\hline 1.474 & 198.959 & $4.477 \mathrm{E}-11$ & 0.9290 & $4.482 \mathrm{E}-11$ & 0.9338 & 0.51 \\
\hline 3.293 & 200.778 & $3.906 \mathrm{E}-11$ & 0.8105 & $3.932 \mathrm{E}-11$ & 0.8192 & 1.07 \\
\hline 5.111 & 202.596 & $3.331 \mathrm{E}-11$ & 0.6912 & $3.371 \mathrm{E}-11$ & 0.7023 & 1.60 \\
\hline 6.930 & 204.415 & $2.825 \mathrm{E}-11$ & 0.5861 & $2.872 \mathrm{E}-11$ & 0.5983 & 2.09 \\
\hline 8.748 & 206.233 & $2.397 \mathrm{E}-11$ & 0.4974 & $2.448 \mathrm{E}-11$ & 0.5100 & 2.54 \\
\hline 10.567 & 208.052 & $2.034 \mathrm{E}-11$ & 0.4220 & $2.085 \mathrm{E}-11$ & 0.4344 & 2.95 \\
\hline 12.385 & 209.870 & $1.719 \mathrm{E}-11$ & 0.3566 & $1.769 \mathrm{E}-11$ & 0.3685 & 3.32 \\
\hline 14.203 & 211.688 & $1.452 \mathrm{E}-11$ & 0.3012 & $1.499 \mathrm{E}-11$ & 0.3122 & 3.64 \\
\hline 16.022 & 213.507 & $1.215 \mathrm{E}-11$ & 0.2521 & $1.258 \mathrm{E}-11$ & 0.2620 & 3.92 \\
\hline 17.840 & 215.325 & $1.008 \mathrm{E}-11$ & 0.2091 & $1.045 \mathrm{E}-11$ & 0.2178 & 4.16 \\
\hline 19.659 & 217.144 & $8.223 \mathrm{E}-12$ & 0.1706 & $8.547 \mathrm{E}-12$ & 0.1781 & 4.35 \\
\hline 21.477 & 218.962 & $6.485 \mathrm{E}-12$ & 0.1346 & $6.749 \mathrm{E}-12$ & 0.1406 & 4.50 \\
\hline 23.296 & 220.781 & $4.818 \mathrm{E}-12$ & 0.1000 & $5.017 \mathrm{E}-12$ & 0.1045 & 4.56 \\
\hline
\end{tabular}

${ }^{*} \mathrm{~d}=$ distance from PV inner (wetted) surface.

${ }^{* *} \mathrm{r}=$ distance from core vertical axis. 
Table 17 Summary of the changes in dpa attenuation at $-5 \mathrm{~cm}$ and $15 \mathrm{~cm}$ from the PV inner surface, for a $24.20-\mathrm{cm}-$ thick PV wall

\begin{tabular}{|c|c|c|c|c|c|}
\hline \multirow[b]{2}{*}{$\mathrm{d}^{*}$} & \multicolumn{4}{|c|}{$\begin{array}{l}\text { Change in dpa extrapolation factor } \mathrm{dpa}(\mathrm{d}) / \mathrm{dpa}(\mathrm{d}=0) \text { due to } \\
\text { change from }\end{array}$} & \multirow{2}{*}{$\begin{array}{l}\text { Difference in the dpa extrapolation } \\
\text { factor calculated with } \\
\text { BUGLE- } 96, \mathrm{P}_{3}, \text { ENDF/B-VI dpa } \\
\text { cross sections } \\
\text { and } \\
\text { RG } 1.99, \text { Rev. } 2, \\
\text { extrapolation formula }\end{array}$} \\
\hline & $\begin{array}{c}\text { library from } \\
\text { SAILOR, } P_{1} \\
\text { to } \\
\text { BUGLE-96, } \\
\mathbf{P}_{1}\end{array}$ & $\begin{array}{c}\text { BUGLE-96, } \\
\text { from } P_{1} \\
\text { to } P_{3}\end{array}$ & $\begin{array}{c}\text { dpa cross sections } \\
\text { from } \\
\text { ENDF/B-IV (ASTM) } \\
\text { to } \\
\text { ENDF/B-VI }\end{array}$ & $\begin{array}{l}\text { Total } \\
\text { change }\end{array}$ & \\
\hline $\mathrm{cm}$ & $\%$ & $\%$ & $\%$ & $\%$ & $\%$ \\
\hline$\sim 5$ & 4.2 & 3.7 & 1.6 & 9.8 & 13.8 \\
\hline$\sim 15$ & 8.9 & 6.6 & 3.8 & 19.7 & 19.5 \\
\hline
\end{tabular}

${ }^{*} \mathrm{~d}=$ distance from PV inner (wetted) surface. 
Table 18 Flux $(E>1 \mathrm{MeV})$ attenuation in the PV wall. The ratios of the fast flux at a given depth to the fast flux at the PV inner radius are given. The column "average" gives the ratio, at the depth, " $d, "$ in the vessel wall, calculated as the arithmetic average over all azimuthal intervals. The columns "maximum" and "minimum" give the maximum and minimum ratio, respectively, over all azimuthal intervals. The deviations (in percent) of the maximum and minimum from the average are also given

\begin{tabular}{|c|c|c|c|c|c|c|}
\hline \multirow[b]{2}{*}{$\mathrm{d}^{*}$} & \multirow{2}{*}{$\begin{array}{c}\text { Average } \\
\mathrm{F}^{* *}(\mathrm{~d}) / \mathrm{F}(\mathrm{d}=0) \\
\end{array}$} & \multicolumn{2}{|c|}{ Maximum } & \multicolumn{2}{|c|}{ Minimum } & \multirow{2}{*}{$\begin{array}{r}\text { RG } 1.99 \\
\text { Rev. } 2\end{array}$} \\
\hline & & $F(d) / F(d=0)$ & $100 *(\mathrm{~B}-\mathrm{A}) / \mathrm{A}$ & $F(d) / F(d=0)$ & $100^{*}(\mathrm{C}-\mathrm{A}) / \mathrm{A}$ & \\
\hline $\mathrm{cm}$ & A & $\mathrm{B}$ & $\%$ & $\mathrm{C}$ & $\%$ & \\
\hline 0.00 & 1.0000 & 1.0000 & 0.0 & 1.0000 & 0.0 & 1.0000 \\
\hline 0.28 & 0.9915 & 1.0043 & 1.3 & 0.9837 & -0.8 & 0.9734 \\
\hline 1.47 & 0.9057 & 0.9218 & 1.8 & 0.8868 & -2.1 & 0.8700 \\
\hline 3.29 & 0.7531 & 0.7664 & 1.8 & 0.7419 & -1.5 & 0.7326 \\
\hline 5.11 & 0.6028 & 0.6163 & 2.2 & 0.5924 & -1.7 & 0.6170 \\
\hline 6.93 & 0.4765 & 0.4888 & 2.6 & 0.4647 & -2.5 & 0.5195 \\
\hline 8.75 & 0.3743 & 0.3850 & 2.9 & 0.3635 & -2.9 & 0.4375 \\
\hline 10.57 & 0.2923 & 0.3022 & 3.4 & 0.2815 & -3.7 & 0.3684 \\
\hline 12.38 & 0.2277 & 0.2356 & 3.5 & 0.2187 & -4.0 & 0.3103 \\
\hline 14.20 & 0.1766 & 0.1837 & 4.0 & 0.1670 & -5.4 & 0.2613 \\
\hline 16.02 & 0.1369 & 0.1421 & 3.8 & 0.1303 & -4.8 & 0.2201 \\
\hline 17.84 & 0.1054 & 0.1100 & 4.4 & 0.0975 & -7.5 & 0.1853 \\
\hline 19.66 & 0.0808 & 0.0848 & 5.0 & 0.0756 & -6.4 & 0.1561 \\
\hline 21.48 & 0.0611 & 0.0644 & 5.4 & 0.0560 & -8.3 & 0.1314 \\
\hline 23.30 & 0.0447 & 0.0480 & 7.4 & 0.0400 & -10.5 & 0.1107 \\
\hline
\end{tabular}

${ }^{*} \mathrm{~d}=$ distance from PV inner (wetted) surface.

${ }^{* *} \mathrm{~F}=$ flux. 
Table 19 Dpa rate (ASTM) attenuation in the PV wall. The ratios of the dpa rate at a given depth to the dpa rate at the PV inner radius are given. The column "average" gives the ratio, at the given depth, "d," in the vessel wall, calculated as the arithmetic average over all azimuthal intervals. The columns "maximum" and "minimum" give the maximum and minimum ratio over all azimuthal intervals, respectively. The deviations of the maximum and minimum from the average are also given

\begin{tabular}{|c|c|c|c|c|c|c|}
\hline \multirow[b]{2}{*}{$d^{*}$} & \multirow{2}{*}{$\begin{array}{c}\text { Average } \\
\mathrm{dpa}(\mathrm{d}) / \mathrm{dpa}(\mathrm{d}=0)\end{array}$} & \multicolumn{2}{|c|}{ Maximum } & \multicolumn{2}{|c|}{ Minimum } & \multirow{2}{*}{$\begin{array}{c}\text { RG } 1.99 \\
\text { Rev. } 2 \\
\end{array}$} \\
\hline & & $\mathrm{dpa}(\mathrm{d}) / \mathrm{dpa}(\mathrm{d}=0)$ & $100 *(\mathrm{~B}-\mathrm{A}) / \mathrm{A}$ & $\mathrm{dpa}(\mathrm{d}) / \mathrm{dpa}(\mathrm{d}=0)$ & $100^{*}(\mathrm{C}-\mathrm{A}) / \mathrm{A}$ & \\
\hline $\mathrm{cm}$ & A & B & $\%$ & $\mathrm{C}$ & $\%$ & \\
\hline 0.00 & 1.0000 & 1.0000 & 0.0 & 1.0000 & 0.0 & 1.0000 \\
\hline 0.28 & 0.9966 & 1.0094 & 1.3 & 0.9904 & -0.6 & 0.9734 \\
\hline 1.47 & 0.9328 & 0.9487 & 1.7 & 0.9194 & -1.4 & 0.8700 \\
\hline 3.29 & 0.8176 & 0.8358 & 2.2 & 0.8081 & -1.2 & 0.7326 \\
\hline 5.11 & 0.7010 & 0.7237 & 3.2 & 0.6904 & -1.5 & 0.6170 \\
\hline 6.93 & 0.5986 & 0.6228 & 4.0 & 0.5857 & -2.2 & 0.5195 \\
\hline 8.75 & 0.5112 & 0.5355 & 4.8 & 0.4965 & -2.9 & 0.4375 \\
\hline 10.57 & 0.4363 & 0.4607 & 5.6 & 0.4195 & -3.9 & 0.3684 \\
\hline 12.38 & 0.3725 & 0.3958 & 6.3 & 0.3553 & -4.6 & 0.3103 \\
\hline 14.20 & 0.3171 & 0.3390 & 6.9 & 0.2986 & -5.8 & 0.2613 \\
\hline 16.02 & 0.2690 & 0.2893 & 7.5 & 0.2516 & -6.5 & 0.2201 \\
\hline 17.84 & 0.2262 & 0.2447 & 8.2 & 0.2074 & -8.3 & 0.1853 \\
\hline 19.66 & 0.1879 & 0.2043 & 8.7 & 0.1699 & -9.6 & 0.1561 \\
\hline 21.48 & 0.1525 & 0.1674 & 9.8 & 0.1344 & -11.9 & 0.1314 \\
\hline 23.30 & 0.1180 & 0.1309 & 10.9 & 0.0994 & -15.8 & 0.1107 \\
\hline
\end{tabular}

${ }^{*} \mathrm{~d}=$ distance from PV inner (wetted) surface. 
Table 20 The attenuation of the flux $(\mathrm{E}>1 \mathrm{MeV})$, flux $(\mathrm{E}>0.1 \mathrm{MeV})$, and dpa rate calculated with the ASTM and ENDF/B-VI dpa cross sections, respectively, inside the PV wall. The calculations were done with the BUGLE-96 library. A two-Ioop plant of Westinghouse design with a 17.16-cm-thick PV wall was analyzed

\begin{tabular}{|c|c|c|c|c|c|c|c|c|c|c|}
\hline \multirow[b]{2}{*}{$d^{*}$} & \multirow[b]{2}{*}{$\mathrm{r}^{* * *}$} & \multicolumn{2}{|c|}{ ASTM dpa } & \multicolumn{2}{|c|}{ ENDF/B-VI dpa } & \multicolumn{2}{|c|}{$\begin{array}{c}\text { Flux } \\
(\mathrm{E}>0.1 \mathrm{MeV})\end{array}$} & \multicolumn{2}{|c|}{$\begin{array}{c}\text { Flux } \\
(E>1 \mathrm{MeV})\end{array}$} & \multirow{2}{*}{$\begin{array}{c}\text { RG } 1.99 \\
\text { Rev. } 2\end{array}$} \\
\hline & & Value & Ratio & Value & Ratio & Value & Ratio & Value & Ratio & \\
\hline $\mathrm{cm}$ & $\mathrm{cm}$ & $\mathrm{s}^{-1}$ & & $\mathrm{~s}^{-1}$ & & $\mathrm{~cm}^{-2} \mathrm{~s}^{-1}$ & & $\mathrm{~cm}^{-2} \mathrm{~s}^{-1}$ & & \\
\hline 0.00 & 67.64 & $8.596 \mathrm{E}-11$ & 1.0000 & $8.570 \mathrm{E}-11$ & 1.0000 & $1.480 \mathrm{E}+11$ & 1.0000 & $5.174 \mathrm{E}+10$ & 1.0000 & 1.0000 \\
\hline 0.60 & 168.24 & $8.280 \mathrm{E}-11$ & 0.9632 & $8.277 \mathrm{E}-11$ & 0.9658 & $1.487 \mathrm{E}+11$ & 1.0044 & $4.974 \mathrm{E}+10$ & 0.9613 & 0.9448 \\
\hline 1.80 & 169.44 & $7.582 \mathrm{E}-11$ & 0.8821 & $7.614 \mathrm{E}-11$ & 0.8884 & $1.457 \mathrm{E}+11$ & 0.9847 & $4.472 \mathrm{E}+10$ & 0.8643 & 0.8433 \\
\hline 3.01 & 170.65 & $6.850 \mathrm{E}-11$ & 0.7969 & $6.905 \mathrm{E}-11$ & 0.8057 & $1.392 \mathrm{E}+11$ & 0.9407 & $3.907 \mathrm{E}+10$ & 0.7550 & 0.7527 \\
\hline 4.21 & 171.85 & $6.151 \mathrm{E}-11$ & 0.7156 & $6.222 \mathrm{E}-11$ & 0.7261 & $1.313 \mathrm{E}+11$ & 0.8871 & $3.369 \mathrm{E}+10$ & 0.6511 & 0.6718 \\
\hline 5.41 & 173.05 & $5.508 \mathrm{E}-11$ & 0.6408 & $5.589 \mathrm{E}-11$ & 0.6522 & $1.228 \mathrm{E}+11$ & 0.8298 & $2.885 \mathrm{E}+10$ & 0.5575 & 0.5996 \\
\hline 6.62 & 174.26 & $4.922 \mathrm{E}-11$ & 0.5726 & $5.009 \mathrm{E}-11$ & 0.5845 & $1.142 \mathrm{E}+11$ & 0.7713 & $2.458 \mathrm{E}+10$ & 0.4751 & 0.5352 \\
\hline 7.82 & 175.46 & $4.391 \mathrm{E}-11$ & 0.5108 & $4.481 \mathrm{E}-11$ & 0.5229 & $1.055 \mathrm{E}+11$ & 0.7132 & $2.088 \mathrm{E}+10$ & 0.4036 & 0.4777 \\
\hline 9.02 & 176.66 & $3.909 \mathrm{E}-11$ & 0.4548 & $3.999 \mathrm{E}-11$ & 0.4667 & $9.705 \mathrm{E}+10$ & 0.6557 & $1.768 \mathrm{E}+10$ & 0.3418 & 0.4264 \\
\hline 10.22 & 177.86 & $3.470 \mathrm{E}-11$ & 0.4037 & $3.558 \mathrm{E}-11$ & 0.4152 & $8.870 \mathrm{E}+10$ & 0.5993 & $1.493 E+10$ & 0.2885 & 0.3806 \\
\hline 11.43 & 179.07 & $3.070 \mathrm{E}-11$ & 0.3571 & $3.154 \mathrm{E}-11$ & 0.3680 & $8.053 \mathrm{E}+10$ & 0.5441 & $1.256 \mathrm{E}+10$ & 0.2428 & 0.3397 \\
\hline 12.63 & 180.27 & $2.701 \mathrm{E}-11$ & 0.3142 & $2.780 \mathrm{E}-11$ & 0.3244 & $7.249 \mathrm{E}+10$ & 0.4898 & $1.052 \mathrm{E}+10$ & 0.2034 & 0.3032 \\
\hline 13.83 & 181.47 & $2.357 \mathrm{E}-11$ & 0.2742 & $2.430 \mathrm{E}-11$ & 0.2836 & $6.453 E+10$ & 0.4360 & $8.765 E+09$ & 0.1694 & 0.2706 \\
\hline 15.04 & 182.68 & $2.031 \mathrm{E}-11$ & 0.2363 & $2.097 \mathrm{E}-11$ & 0.2447 & $5.649 E+10$ & 0.3817 & $7.220 \mathrm{E}+09$ & 0.1395 & 0.2415 \\
\hline 16.24 & 183.88 & $1.710 \mathrm{E}-11$ & 0.1989 & $1.765 \mathrm{E}-11$ & 0.2060 & $4.797 \mathrm{E}+10$ & 0.3241 & $5.803 \mathrm{E}+09$ & 0.1121 & 0.2156 \\
\hline
\end{tabular}

${ }^{*} \mathrm{~d}=$ distance from PV inner (wetted) surface.

${ }^{* *} \mathrm{r}=$ distance from core vertical axis. 
Table 21 The attenuation of the flux $(\mathrm{E}>1 \mathrm{MeV})$, flux $(\mathrm{E}>0.1 \mathrm{MeV})$, and dpa rate calculated with the ASTM and the ENDF/B-VI dpa cross sections, respectively, inside the PV wall. The calculations were done with the SAILOR library. A two-loop plant of Westinghouse design with a 17.16-cm-thick PV wall was analyzed

\begin{tabular}{|c|c|c|c|c|c|c|c|c|c|c|}
\hline \multirow{2}{*}{$\mathrm{d}^{*}$} & \multirow{2}{*}{$\mathrm{r}^{* *}$} & \multicolumn{2}{|c|}{ ASTM dpa } & \multicolumn{2}{c|}{ ENDF/B-VI dpa } & \multicolumn{2}{c|}{$\begin{array}{c}\text { Flux } \\
(\mathrm{E}>0.1 \mathrm{MeV})\end{array}$} & \multicolumn{2}{c|}{$\begin{array}{c}\text { Flux } \\
(\mathrm{E}>1 \mathrm{MeV})\end{array}$} \\
\cline { 2 - 10 } $\mathrm{cm}$ & $\mathrm{cm}$ & $\mathrm{s}^{-1}$ & & $\mathrm{~s}^{-1}$ & & $\mathrm{~cm}^{-2} \mathrm{~s}^{-1}$ & & $\mathrm{~cm}^{-2} \mathrm{~s}^{-1}$ & & \\
\hline 0.00 & 167.64 & $7.778 \mathrm{E}-11$ & 1.0000 & $7.755 \mathrm{E}-11$ & 1.0000 & $1.348 \mathrm{E}+11$ & 1.0000 & $4.701 \mathrm{E}+10$ & 1.0000 & 1.0000 \\
0.60 & 168.24 & $7.478 \mathrm{E}-11$ & 0.9615 & $7.477 \mathrm{E}-11$ & 0.9642 & $1.357 \mathrm{E}+11$ & 1.0064 & $4.507 \mathrm{E}+10$ & 0.9587 & 0.9448 \\
1.80 & 169.44 & $6.820 \mathrm{E}-11$ & 0.8769 & $6.852 \mathrm{E}-11$ & 0.8836 & $1.331 \mathrm{E}+11$ & 0.9872 & $4.023 \mathrm{E}+10$ & 0.8557 & 0.8433 \\
3.01 & 170.65 & $6.132 \mathrm{E}-11$ & 0.7884 & $6.184 \mathrm{E}-11$ & 0.7975 & $1.267 \mathrm{E}+11$ & 0.9401 & $3.485 \mathrm{E}+10$ & 0.7413 & 0.7527 \\
4.21 & 171.85 & $5.479 \mathrm{E}-11$ & 0.7045 & $5.545 \mathrm{E}-11$ & 0.7151 & $1.191 \mathrm{E}+11$ & 0.8831 & $2.980 \mathrm{E}+10$ & 0.6339 & 0.6718 \\
5.41 & 173.05 & $4.882 \mathrm{E}-11$ & 0.6277 & $4.956 \mathrm{E}-11$ & 0.6391 & $1.109 \mathrm{E}+11$ & 0.8226 & $2.530 \mathrm{E}+10$ & 0.5382 & 0.5996 \\
6.62 & 174.26 & $4.340 \mathrm{E}-11$ & 0.5580 & $4.419 \mathrm{E}-11$ & 0.5698 & $1.026 \mathrm{E}+11$ & 0.7611 & $2.138 \mathrm{E}+10$ & 0.4549 & 0.5352 \\
7.82 & 175.46 & $3.851 \mathrm{E}-11$ & 0.4951 & $3.932 \mathrm{E}-11$ & 0.5070 & $9.437 \mathrm{E}+10$ & 0.7000 & $1.801 \mathrm{E}+10$ & 0.3832 & 0.4777 \\
9.02 & 176.66 & $3.408 \mathrm{E}-11$ & 0.4382 & $3.489 \mathrm{E}-11$ & 0.4499 & $8.625 \mathrm{E}+10$ & 0.6398 & $1.513 \mathrm{E}+10$ & 0.3217 & 0.4264 \\
10.22 & 177.86 & $3.006 \mathrm{E}-11$ & 0.3866 & $3.084 \mathrm{E}-11$ & 0.3977 & $7.828 \mathrm{E}+10$ & 0.5806 & $1.266 \mathrm{E}+10$ & 0.2693 & 0.3806 \\
11.43 & 179.07 & $2.640 \mathrm{E}-11$ & 0.3395 & $2.714 \mathrm{E}-11$ & 0.3500 & $7.049 \mathrm{E}+10$ & 0.5228 & $1.056 \mathrm{E}+10$ & 0.2247 & 0.3397 \\
12.63 & 180.27 & $2.304 \mathrm{E}-11$ & 0.2962 & $2.373 \mathrm{E}-11$ & 0.3060 & $6.284 \mathrm{E}+10$ & 0.4661 & $8.770 \mathrm{E}+09$ & 0.1866 & 0.3032 \\
13.83 & 181.47 & $1.992 \mathrm{E}-11$ & 0.2561 & $2.055 \mathrm{E}-11$ & 0.2650 & $5.531 \mathrm{E}+10$ & 0.4102 & $7.236 \mathrm{E}+09$ & 0.1539 & 0.2706 \\
15.04 & 182.68 & $1.696 \mathrm{E}-11$ & 0.2181 & $1.752 \mathrm{E}-11$ & 0.2259 & $4.773 \mathrm{E}+10$ & 0.3540 & $5.899 \mathrm{E}+09$ & 0.1255 & 0.2415 \\
16.24 & 183.88 & $1.403 \mathrm{E}-11$ & 0.1803 & $1.449 \mathrm{E}-11$ & 0.1869 & $3.962 \mathrm{E}+10$ & 0.2939 & $4.680 \mathrm{E}+09$ & 0.0995 & 0.2156 \\
\hline
\end{tabular}

${ }^{*} \mathrm{~d}=$ distance from PV inner (wetted) surface.

${ }^{* *} \mathrm{r}=$ distance from core vertical axis. 


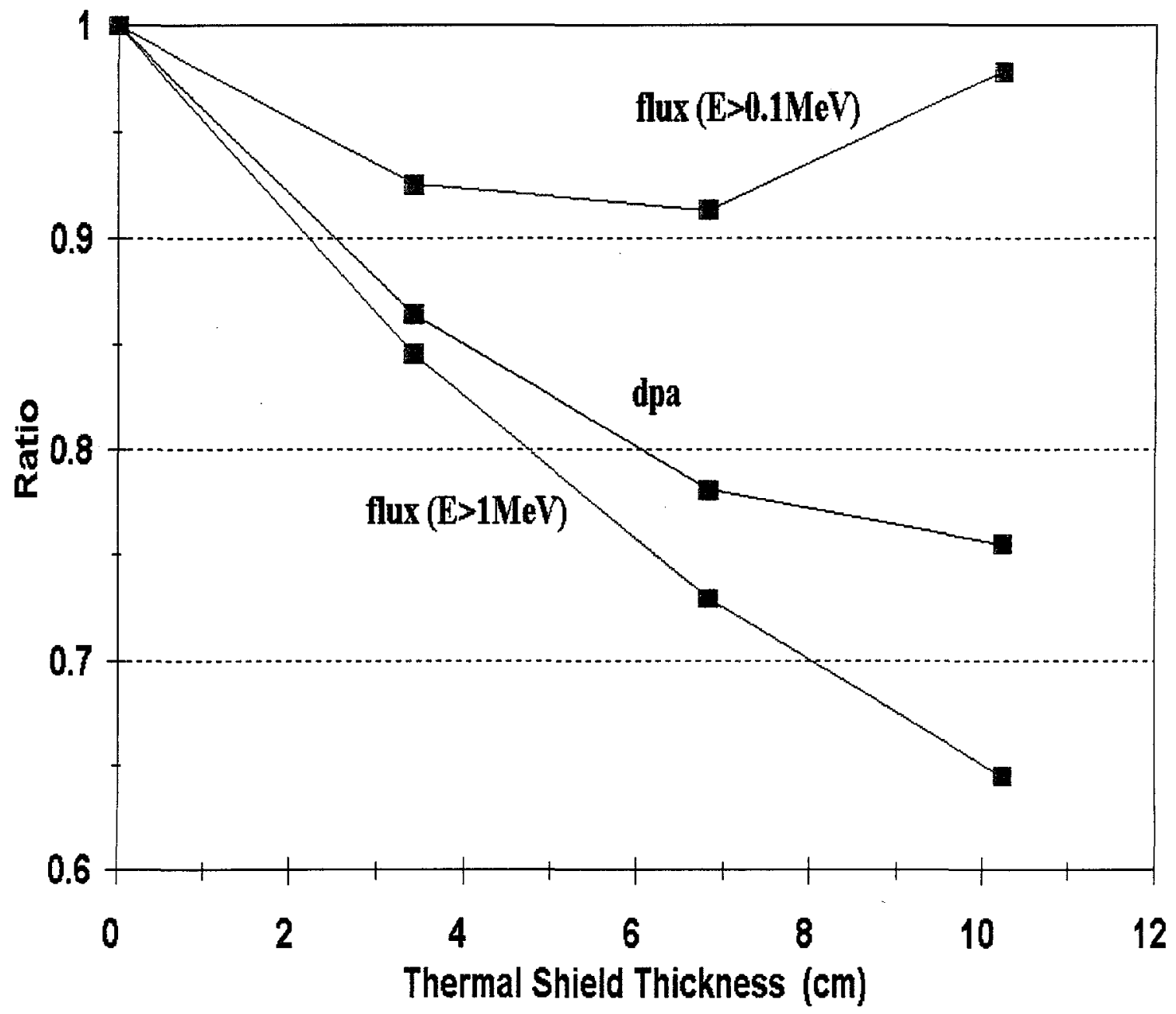

Figure 1 Flux $(\mathrm{E}>1 \mathrm{MeV})$, flux $(\mathrm{E}>0.1 \mathrm{MeV})$, and dpa rate (ENDF/B-VI dpa) at the PV inner wall as a function of the thermal shield thickness 


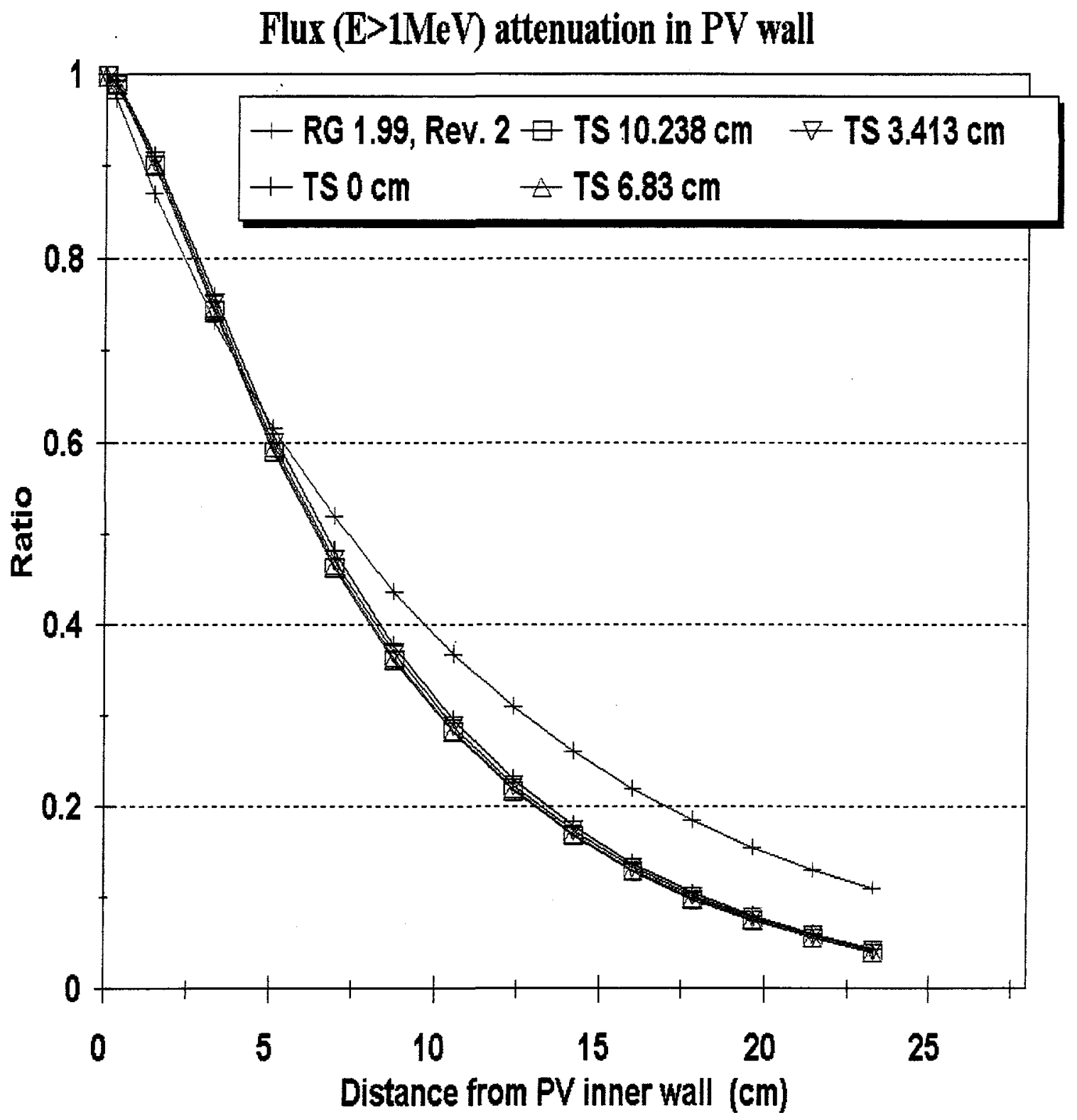

Figure 2 Flux ( $\mathrm{E}>1 \mathrm{MeV}$ ) attenuation in the $\mathrm{PV}$ wall for different thermal shield thicknesses. (Calculations were done with BUGLE-96 library) 


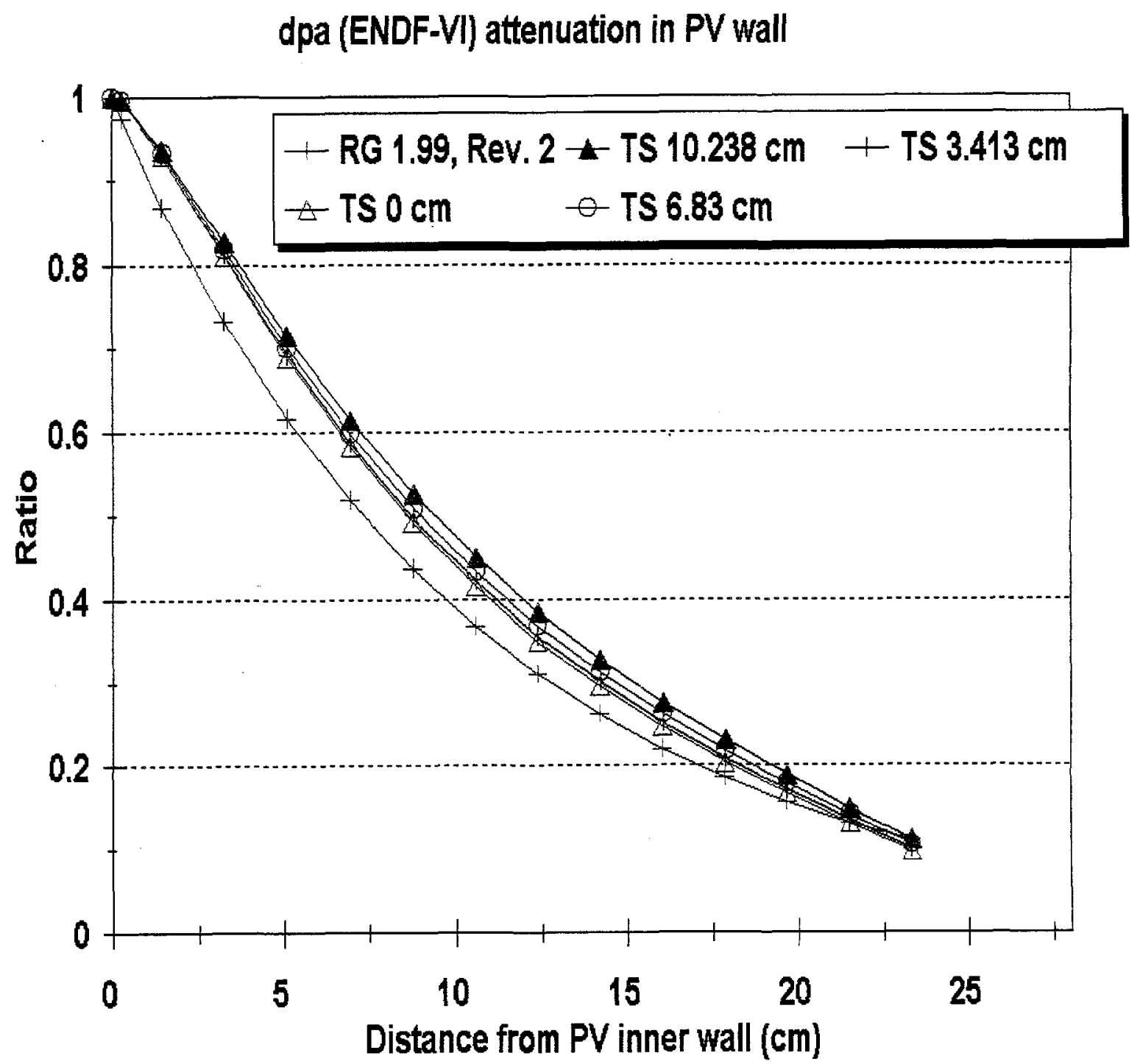

Figure 3 Dpa rate attenuation in the PV wall for different thicknesses of the thermal shield (TS). All values are normalized to 1.000 at the PV inner wall (wetted surface). Neutron fluxes are from the calculations with BUGLE-96. ENDF/B-VI dpa cross sections were used 
Flux $(E>0.1 \mathrm{MeV})$ attenuation in PV

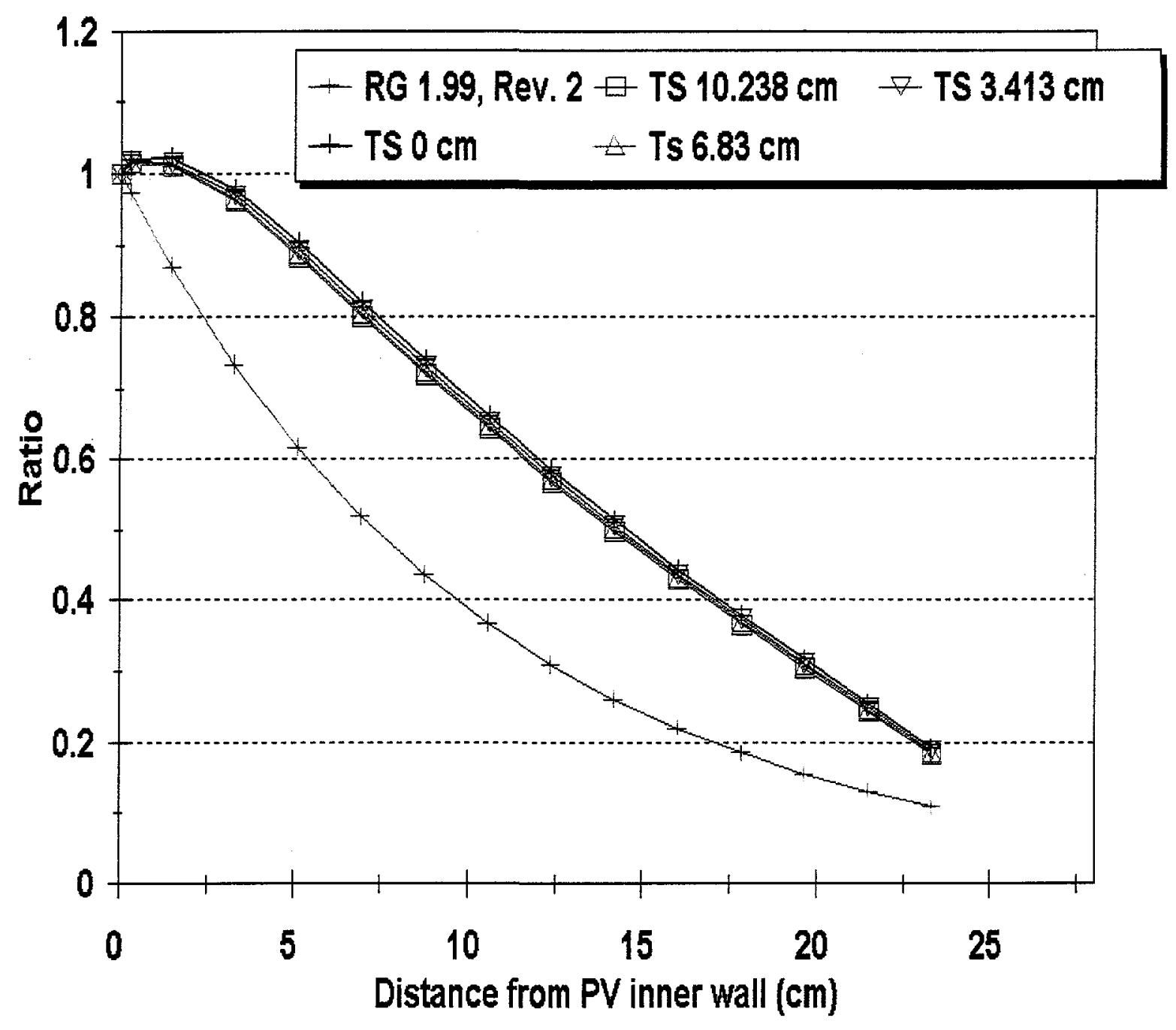

Figure 4 Flux $(\mathrm{E}>0.1 \mathrm{MeV})$ attenuation in the $P V$ wall for different thermal shield thicknesses. (Calculations were done with the BUGLE-96 library) 


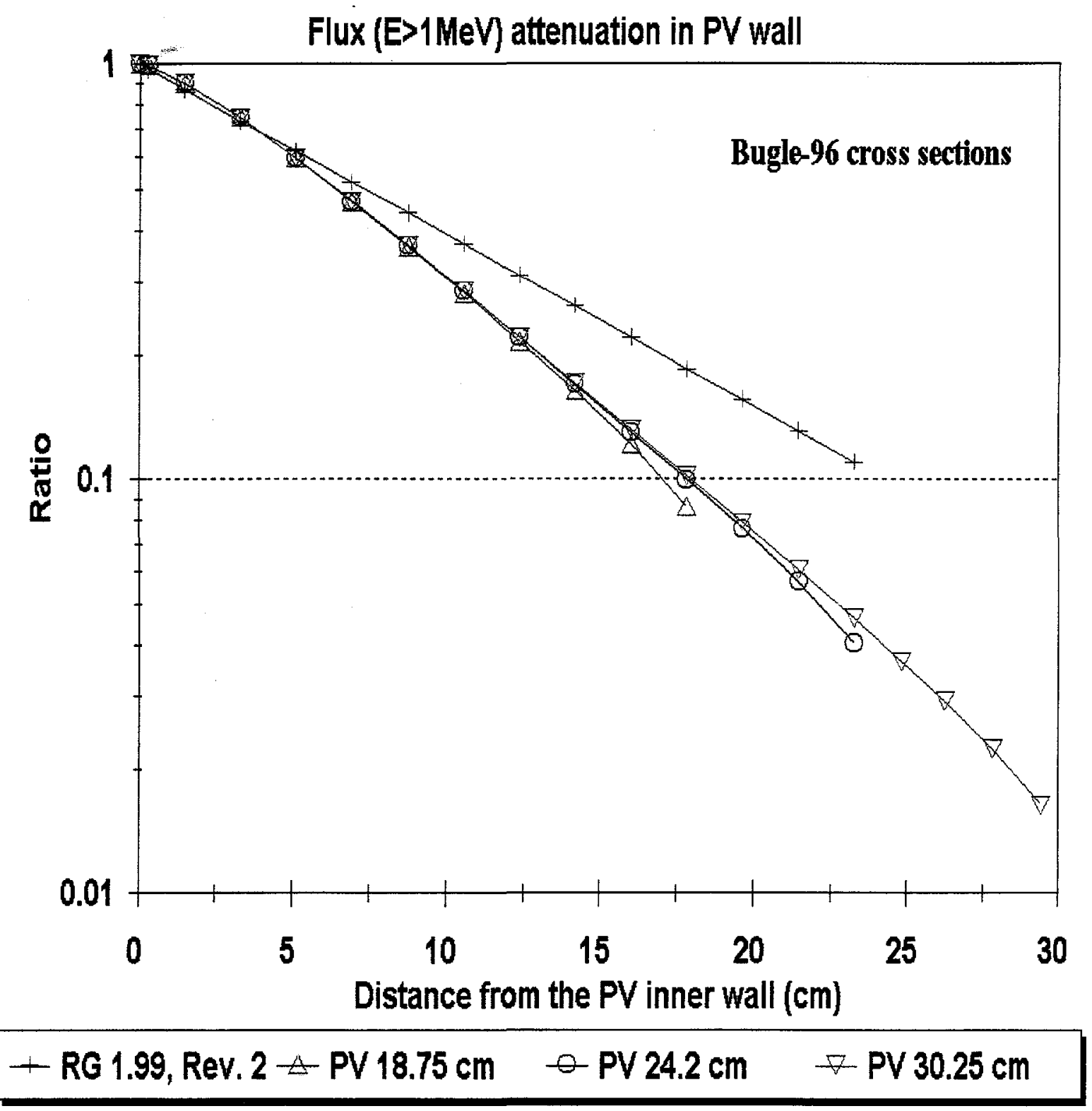

Figure 5 Flux (E $>1 \mathrm{MeV}$ ) attenuation in the PV wall for different PV wall thicknesses. The curve derived from the RG 1.99, Rev. 2 , formula is also shown 


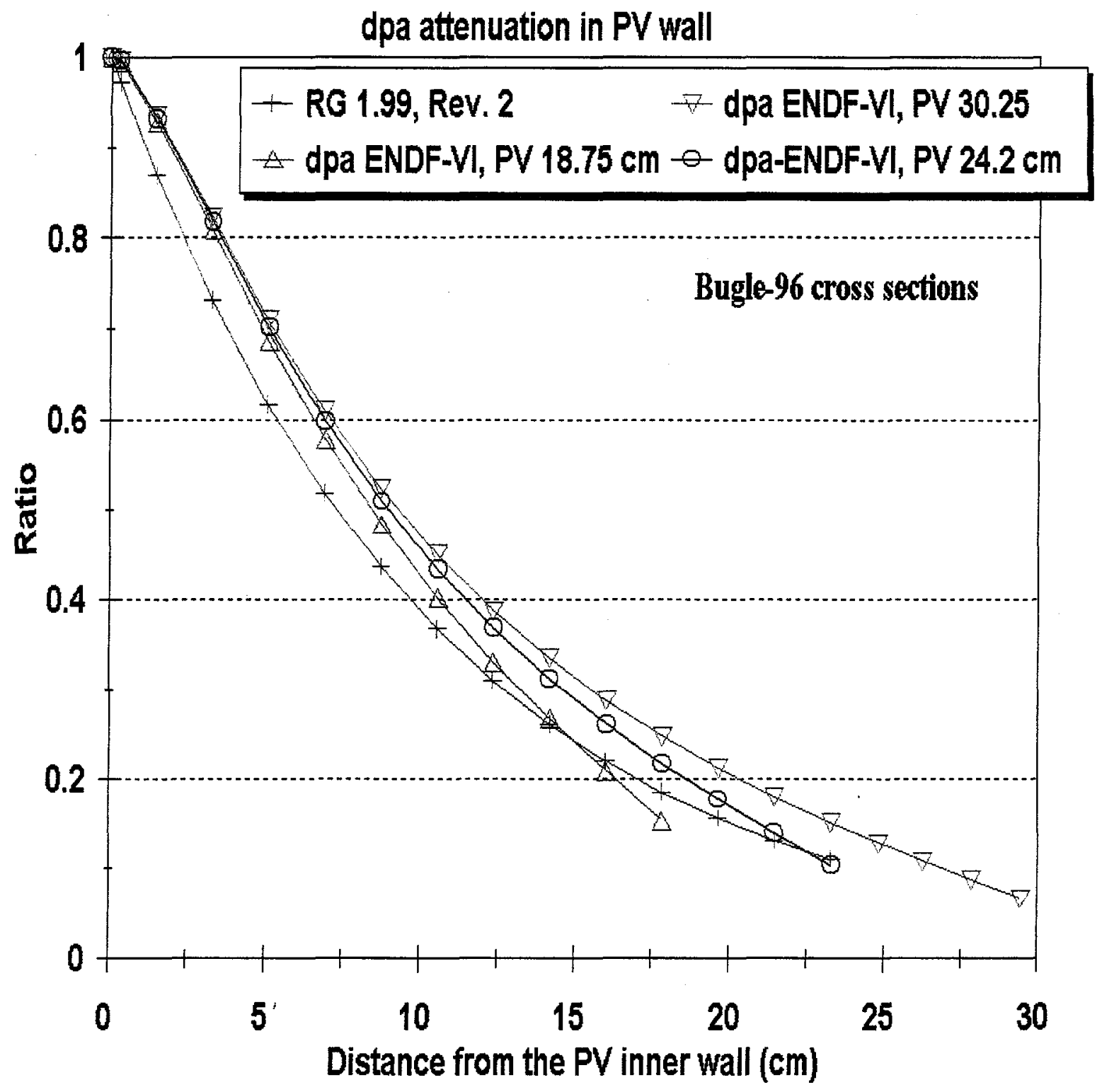

Figure 6 Dpa rate attenuation in the PV wall for different PV wall thicknesses. Calculations were done with the BUGLE-96 cross-section library and ENDF/B-VI dpa cross sections. The curve derived from the RG 1.99, Rev. 2, formula is also shown 


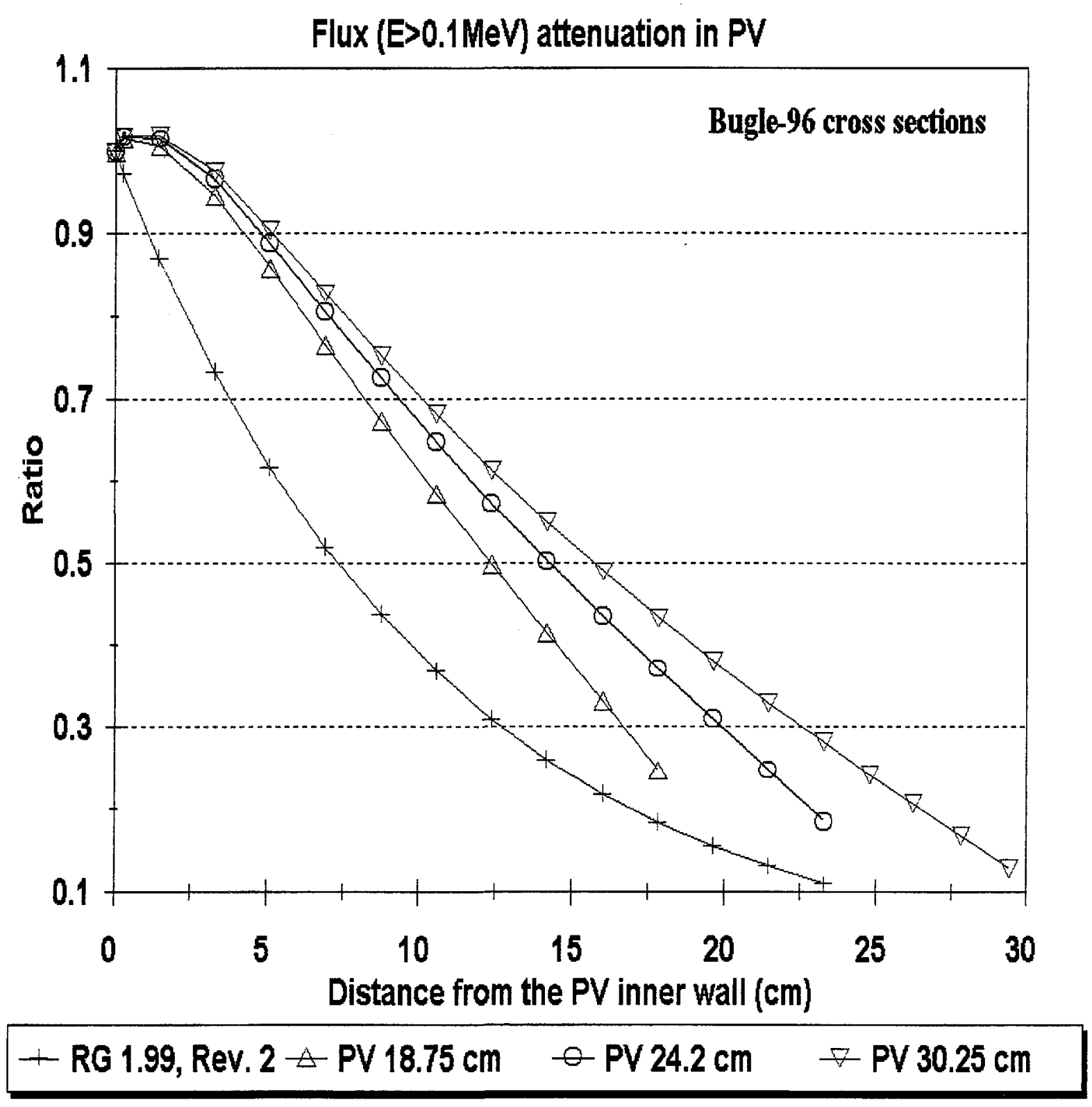

Figure 7 Flux (E $>0.1 \mathrm{MeV}$ ) attenuation in the PV wall for different PV wall thicknesses. Calculations were done with the BUGLE-96 cross-section library. The curve derived from the RG 1.99, Rev. 2, formula is also shown 


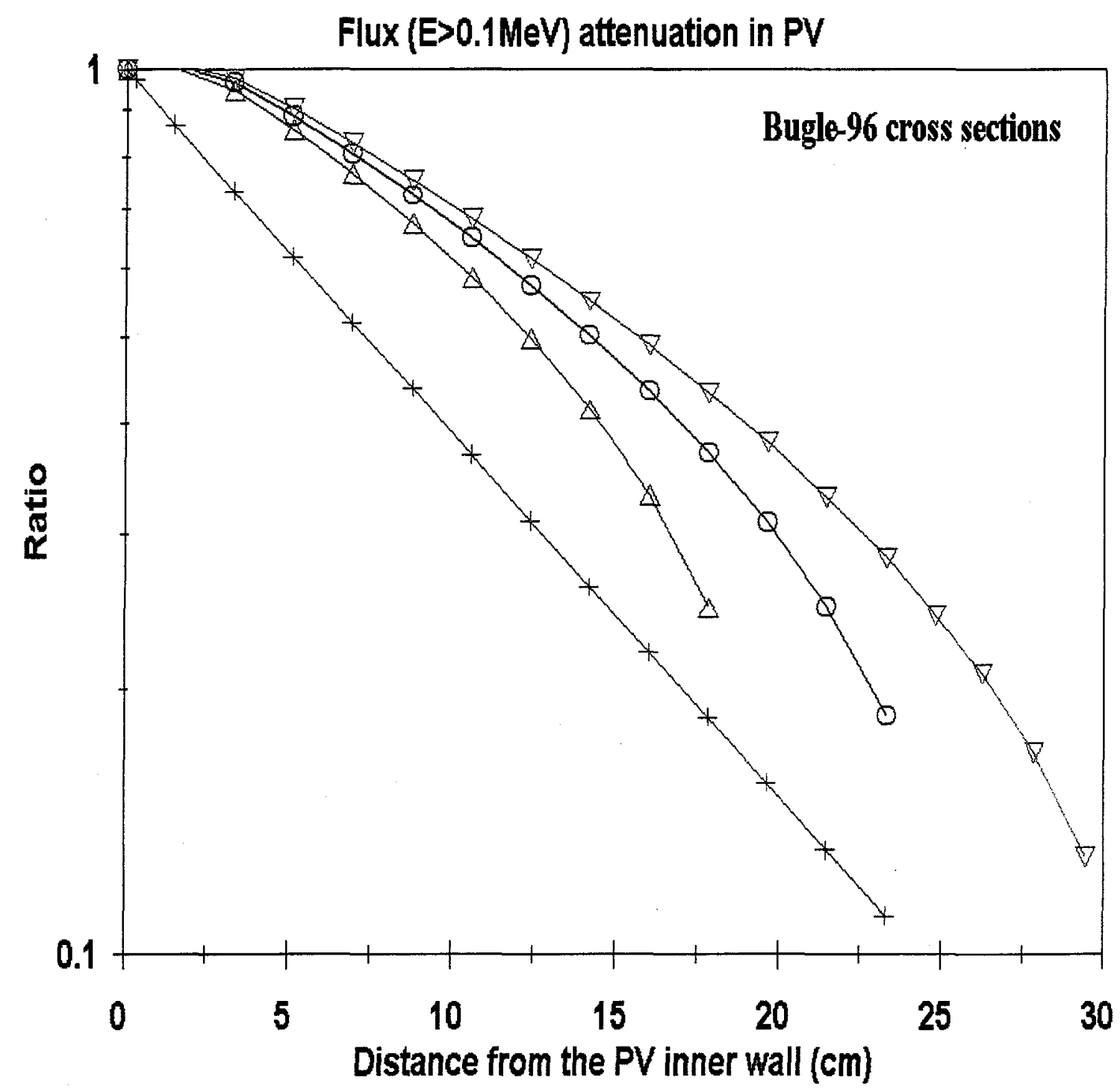

+ RG 1.99, Rev. $2 \triangle$ PV $18.75 \mathrm{~cm} \quad \frown \mathrm{PV} 24.2 \mathrm{~cm} \quad$ ₹ PV $30.25 \mathrm{~cm}$

Figure 8 Flux (E $>0.1 \mathrm{MeV}$ ) attenuation in the PV wall for different PV wall thicknesses. Calculations were done with the BUGLE-96 cross-section library. The curve derived from the RG 1.99, Rev. 2, formula is also shown 


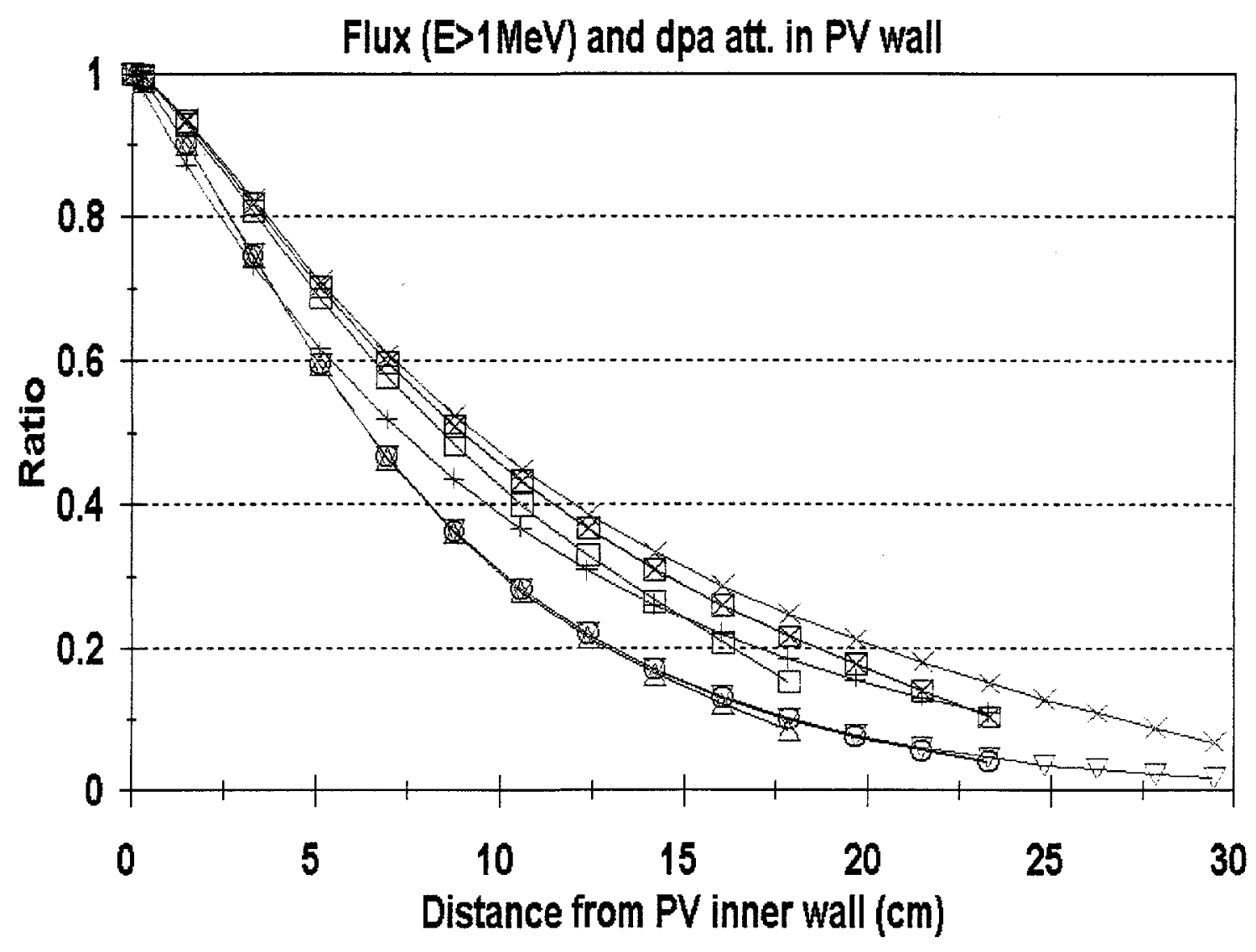

\begin{tabular}{|c|c|}
\hline$\ominus F>1, P V 24.2 \mathrm{~cm}$ & + RG 1.99, Rev. 2 \\
\hline$\triangle F>1, P V 18.75 \mathrm{~cm}$ & $\mp F>1, P V 30.25 \mathrm{~cm}$ \\
\hline * dpa ENDF-VI, PV 30.25 & $\because \mathrm{dpa}$ ENDF-VI, PV $18.75 \mathrm{~cm}$ \\
\hline dpa ENDF.VI, PV $24.2 \mathrm{~cm}$ & \\
\hline
\end{tabular}

Figure 9 Flux (E $>1 \mathrm{MeV}$ ) and dpa rate attenuation in the PV wall for different PV wall thicknesses. Calculations were done with the BUGLE-96 cross-section library and ENDF/B-VI dpa cross sections. The curve derived from the RG 1.99, Rev. 2, formula is also shown 


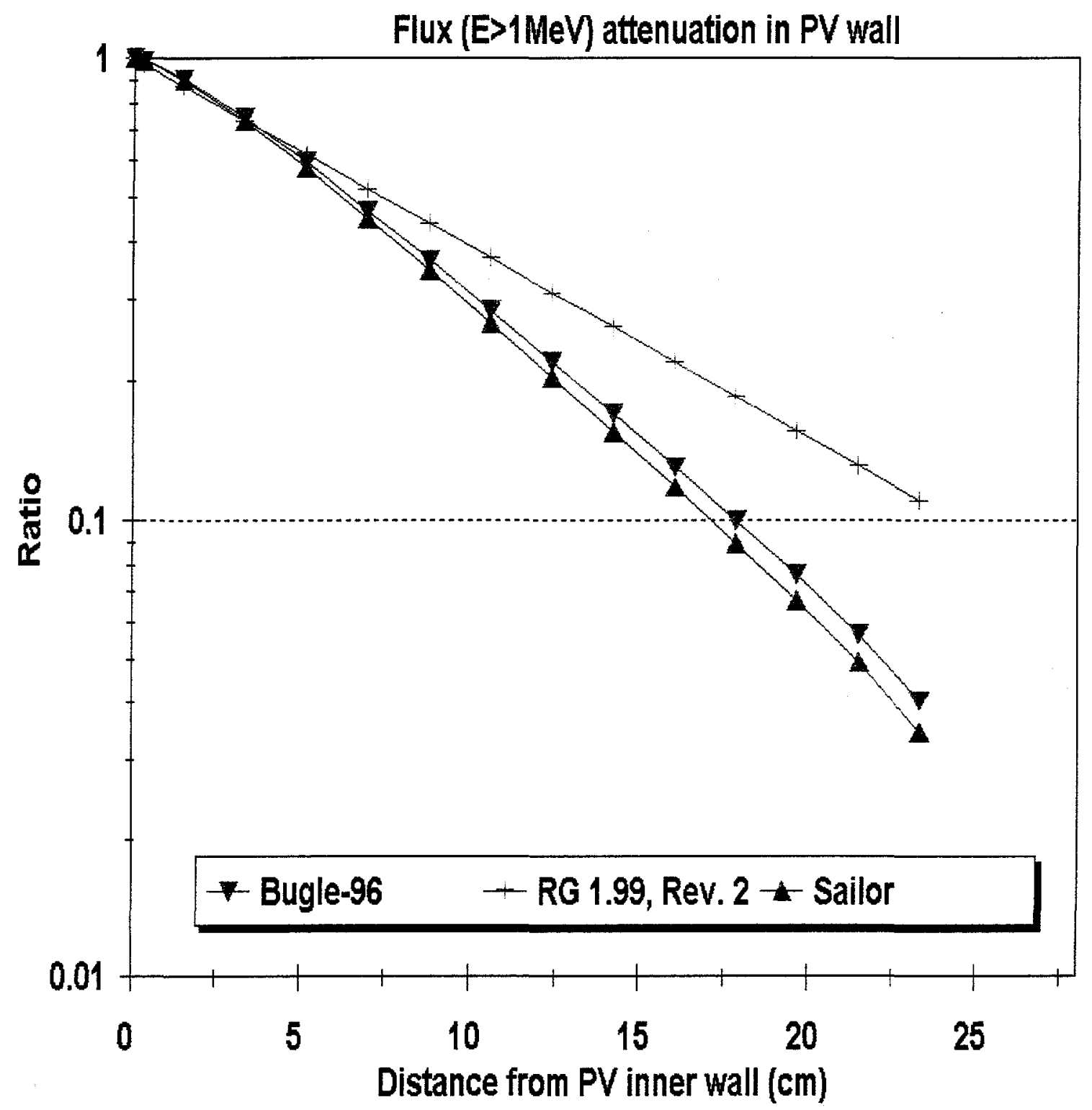

Figure 10 Flux (E $>1 \mathrm{MeV}$ ) attenuation in the PV wall calculated with BUGLE-96 and SAILOR cross-section libraries. SAILOR calculation used ENDF/B-IV fission spectra. The curve derived from the RG 1.99, Rev. 2, formula is also shown 


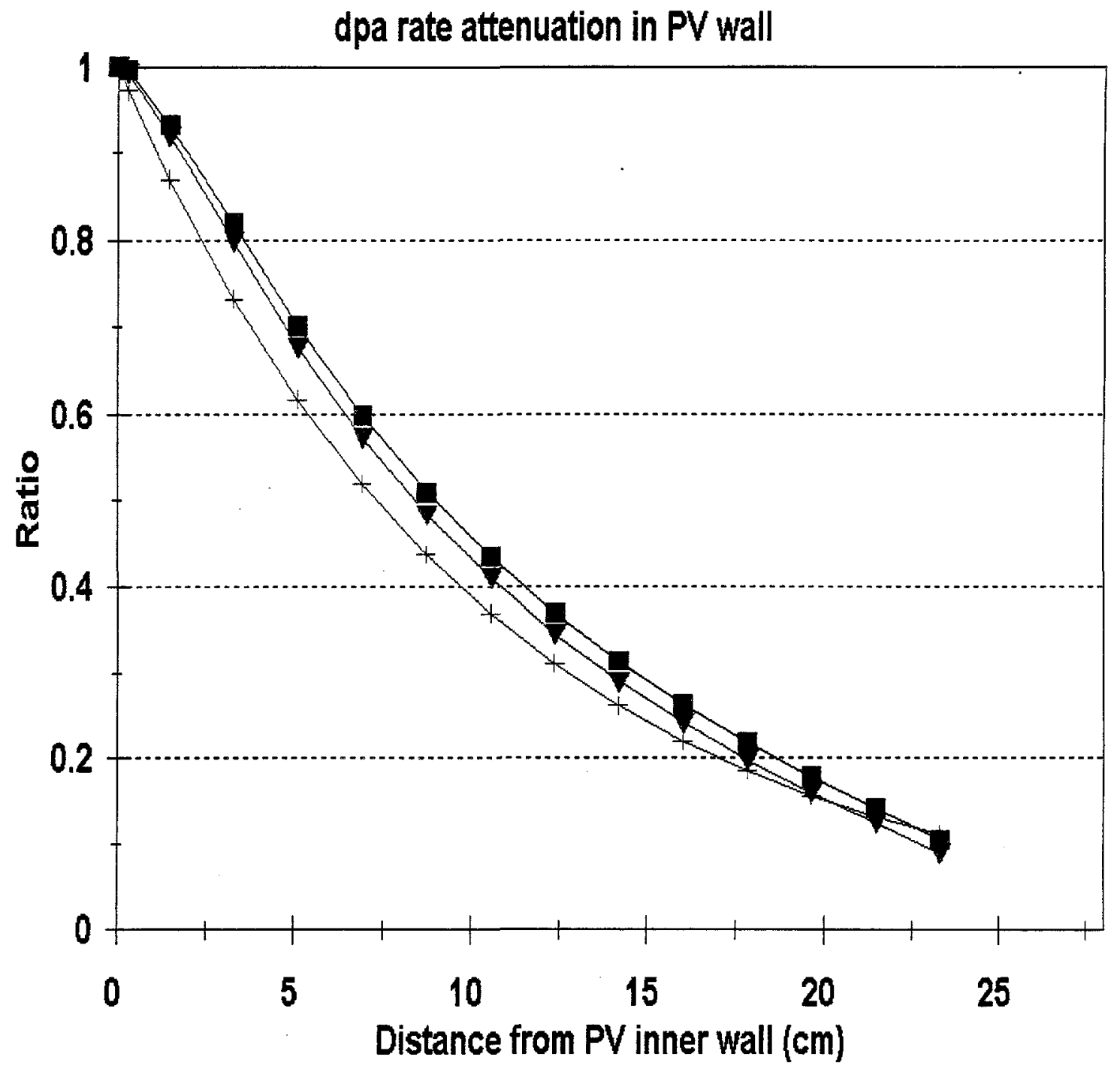

Figure 11 Comparison of dpa rate attenuation in the PV wall. The ENDF/B-VI dpa cross sections were used with both the BUGLE-96 and the SAILOR calculation. The curve derived from the RG 1.99, Rev. 2, attenuation formula is also shown 


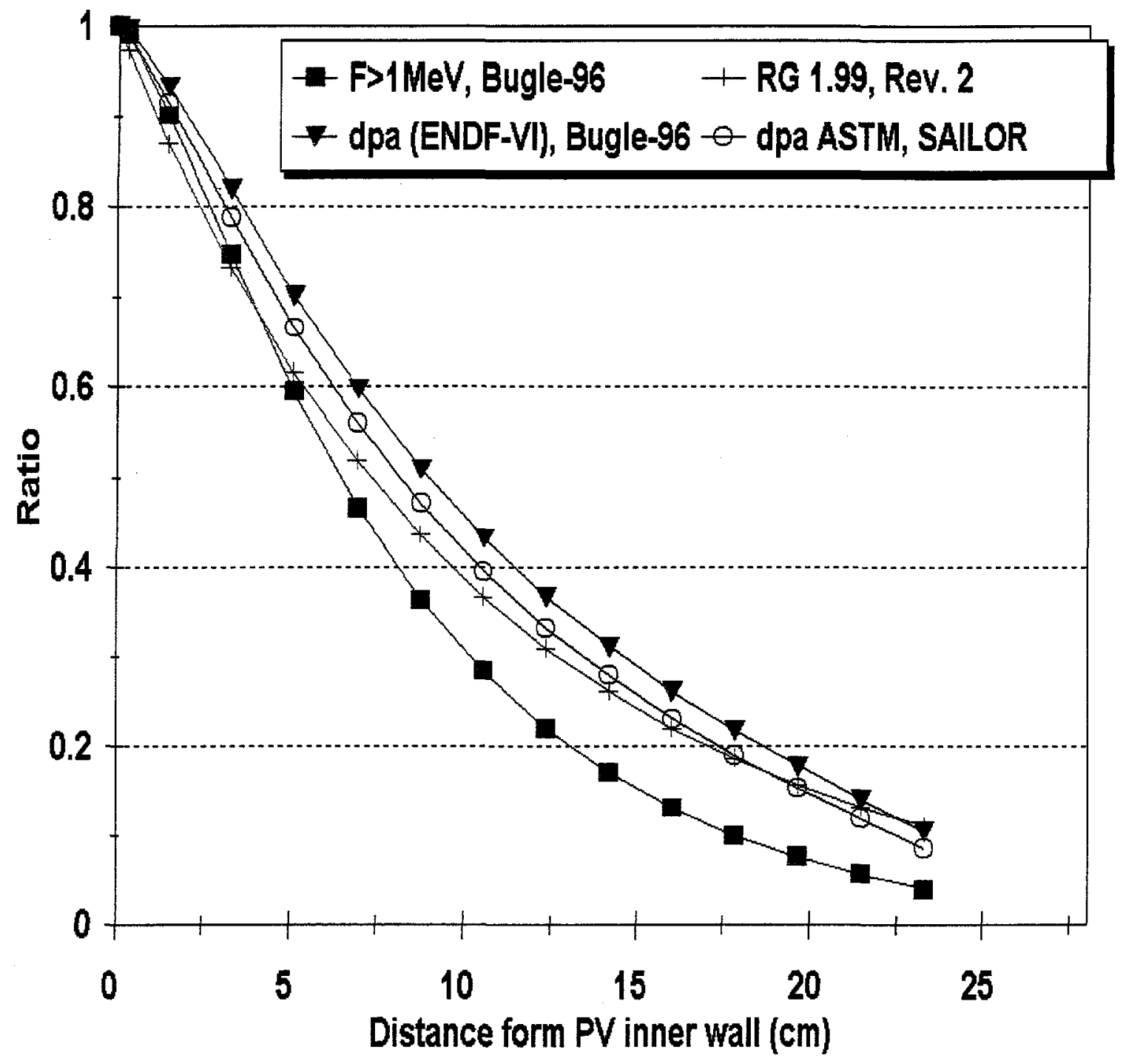

Figure 12 Flux (E $>1 \mathrm{MeV}$ ) and dpa rate attenuation in the PV wall calculated with BUGLE-96 and SAILOR cross-section libraries. SAILOR calculation used ENDF/B-IV fission spectra and ASTM dpa cross sections. The ENDF/B-VI dpa cross sections were used with BUGLE-96 calculations. The curve derived from the RG 1.99, Rev. 2 formula is also shown 


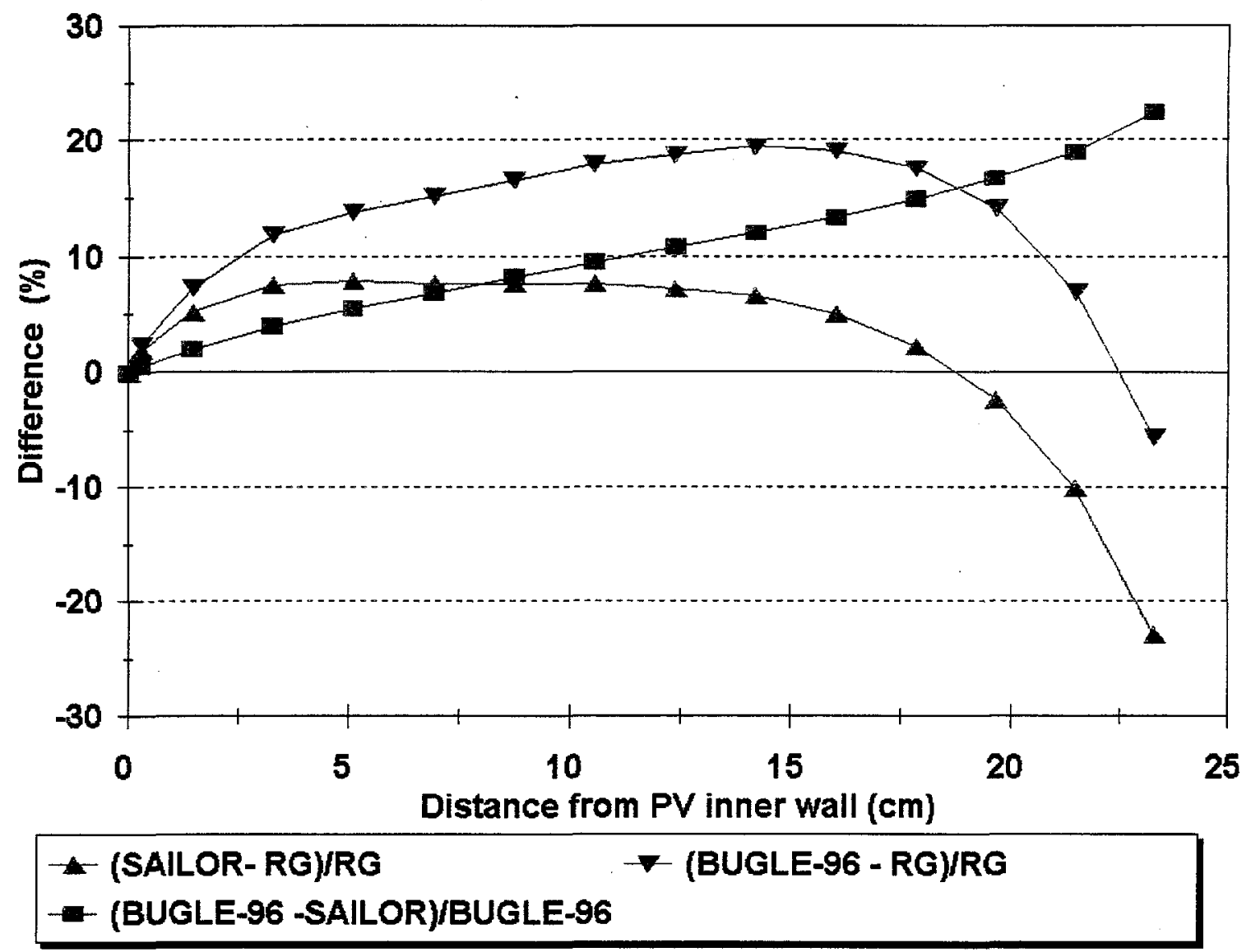

Figure 13 Comparison of dpa rate attenuation in the PV wall. The BUGLE-96 calculation with ENDF/B-VI dpa cross sections, and the SAILOR calculation with ASTM dpa cross sections are compared between themselves and with the RG 1.99, Rev. 2, attenuation formula 
Flux ( $\mathrm{E}>1 \mathrm{MeV}$ ) attenuation in PV wall

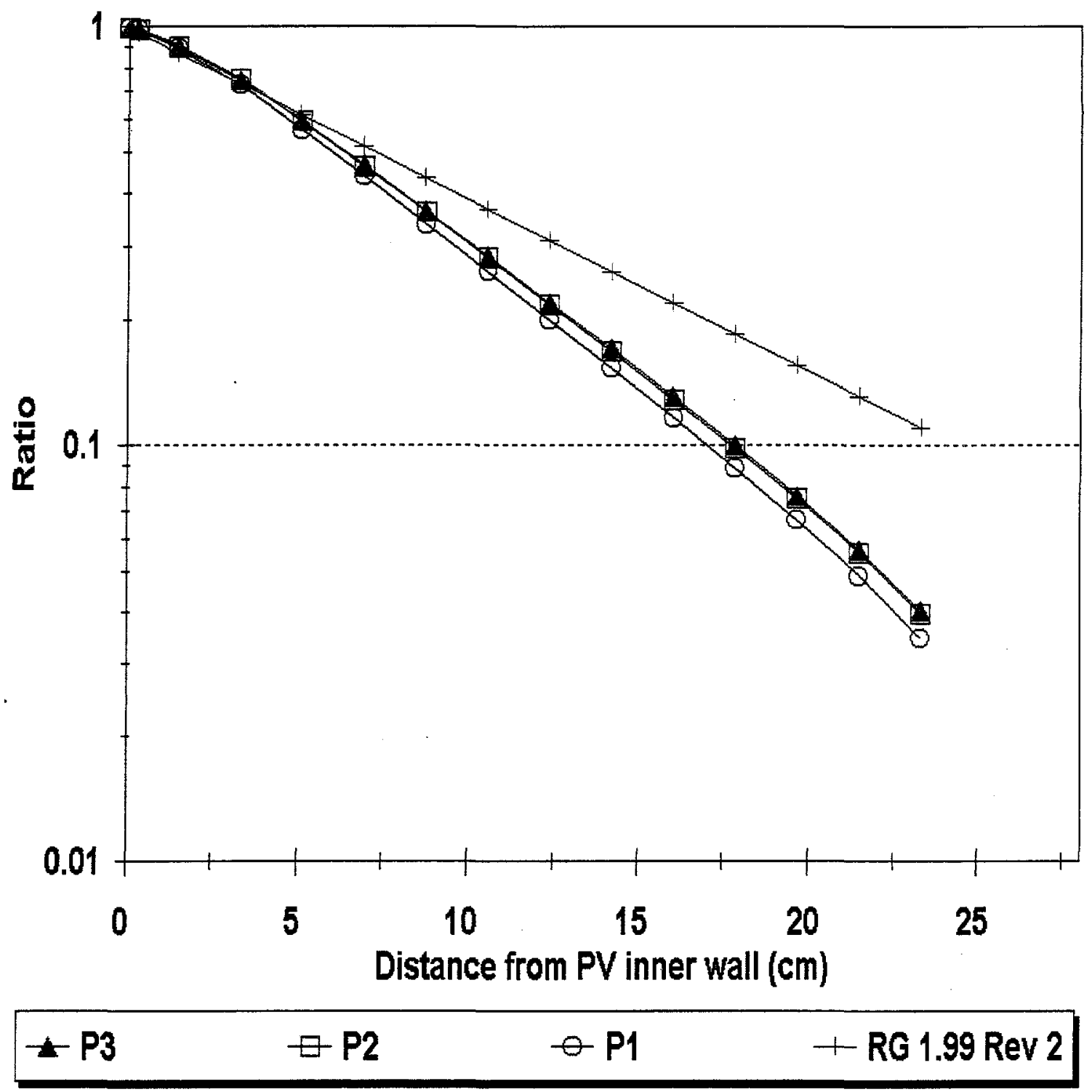

Figure 14 Flux ( $\mathrm{E}>1 \mathrm{MeV}$ ) attenuation in the PV wall, calculated with BUGLE-96 crosssection library, and the $P_{1}$ to $P_{3}$ approximations for the anisotropic scattering. Calculations were done for HBR-2 "nominal" dimensions 


\section{Dpa rate attenuation in PV wall}

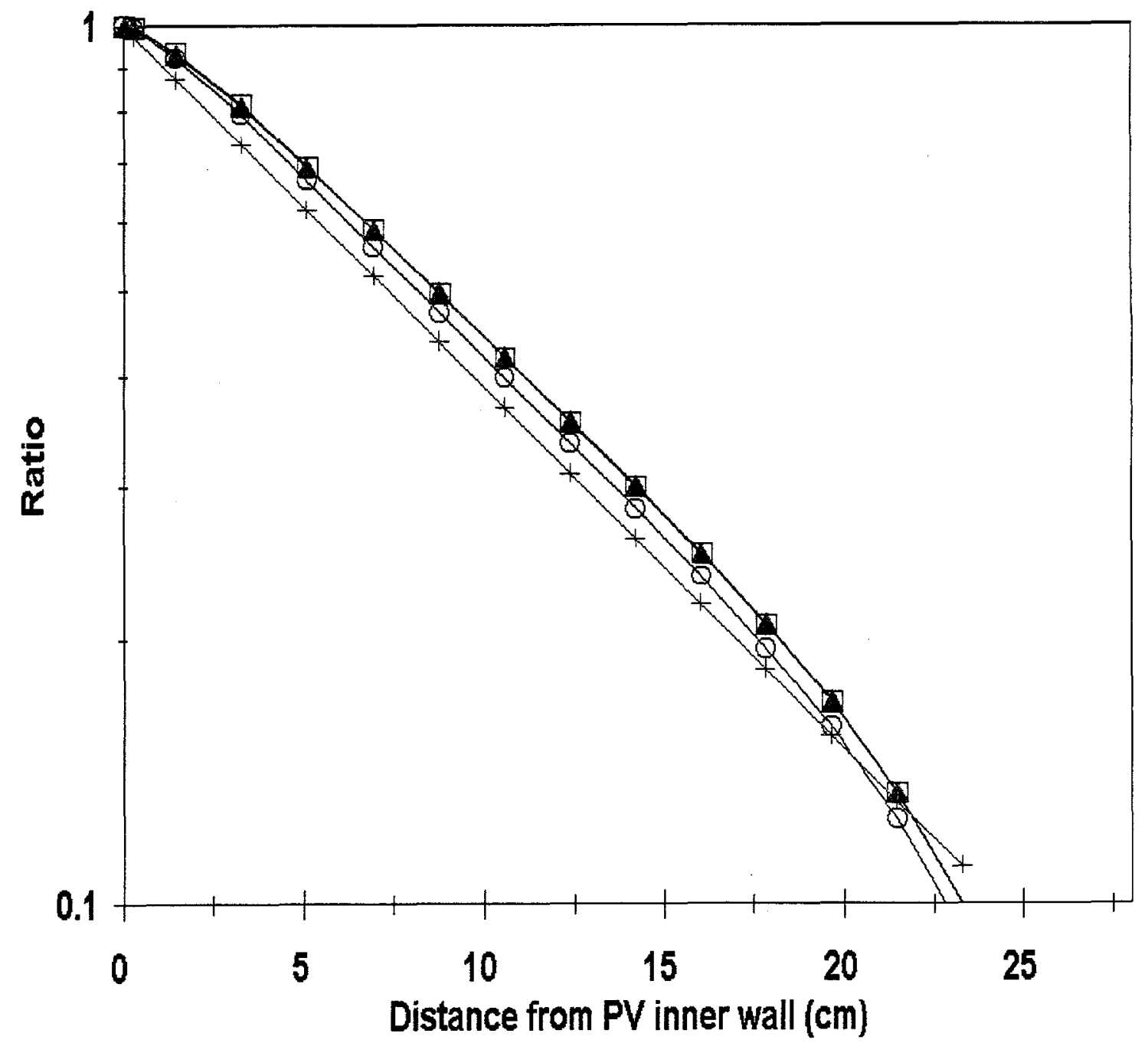

\begin{tabular}{llll}
\hline$-P 3$ & $\leftarrow P 1$ & $+R$ R $1.99 \operatorname{Rev} 2$ \\
\hline
\end{tabular}

Figure 15 Dpa rate attenuation in the PV wall, calculated with the BUGLE-96 cross-section library, the $P_{1}$ to $P_{3}$ approximations for anisotropic scattering, and ASTM dpa cross sections. Calculations were done for HBR-2 "nominal" dimensions 


\section{Dpa rate attenuation in PV wall}

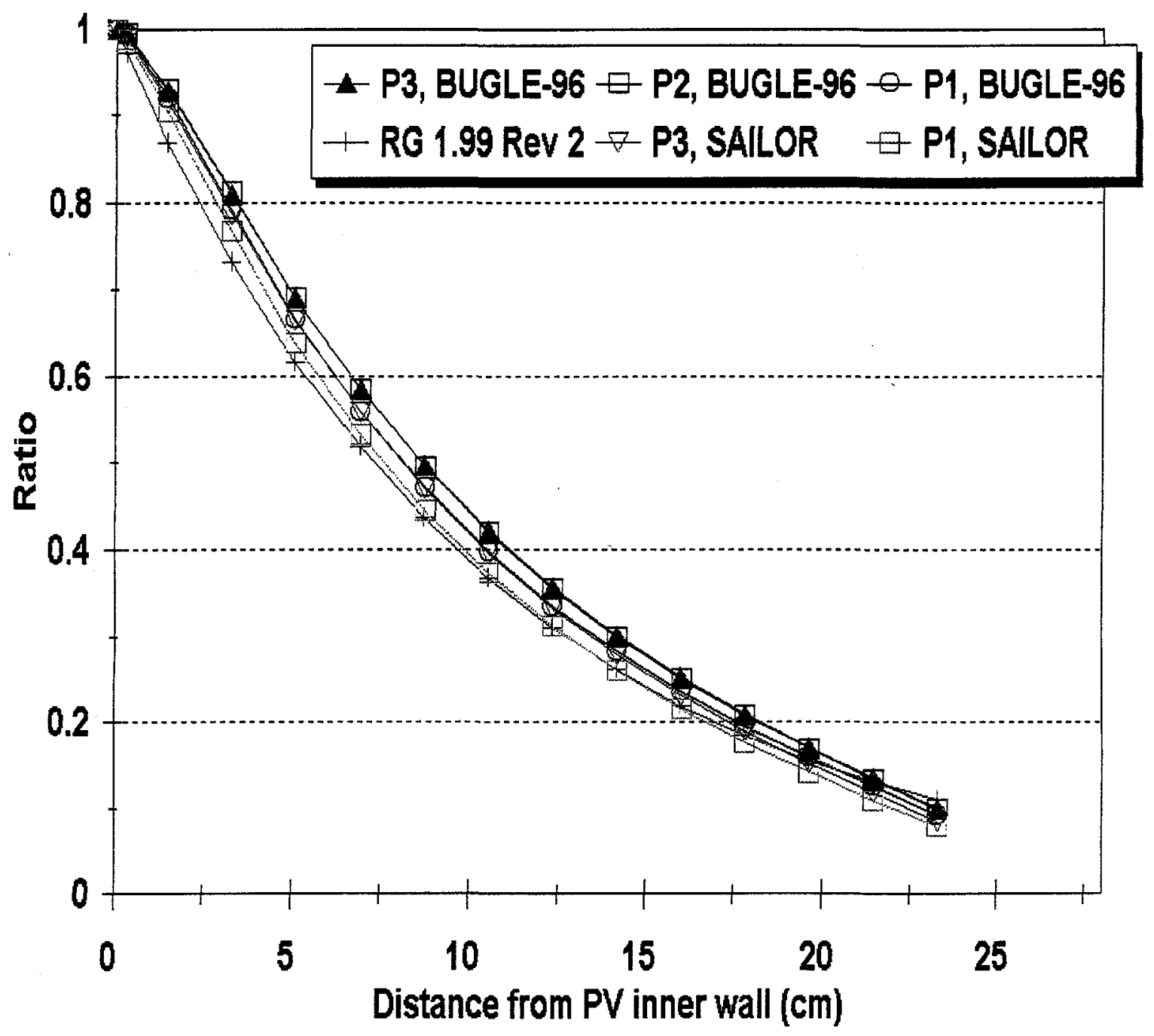

Figure 16 Dpa rate attenuation in the PV wall, calculated with the BUGLE-96 cross-section library, the $P_{1}$ to $P_{3}$ approximations for anisotropic scattering, and ASTM dpa cross sections. The results from the SAILOR calculation with $P_{1}$ and $P_{3}$ approximations, ENDF/B-IV fission spectra, and ASTM dpa cross sections are also shown. Calculations were done for HBR-2 "nominal" dimensions 


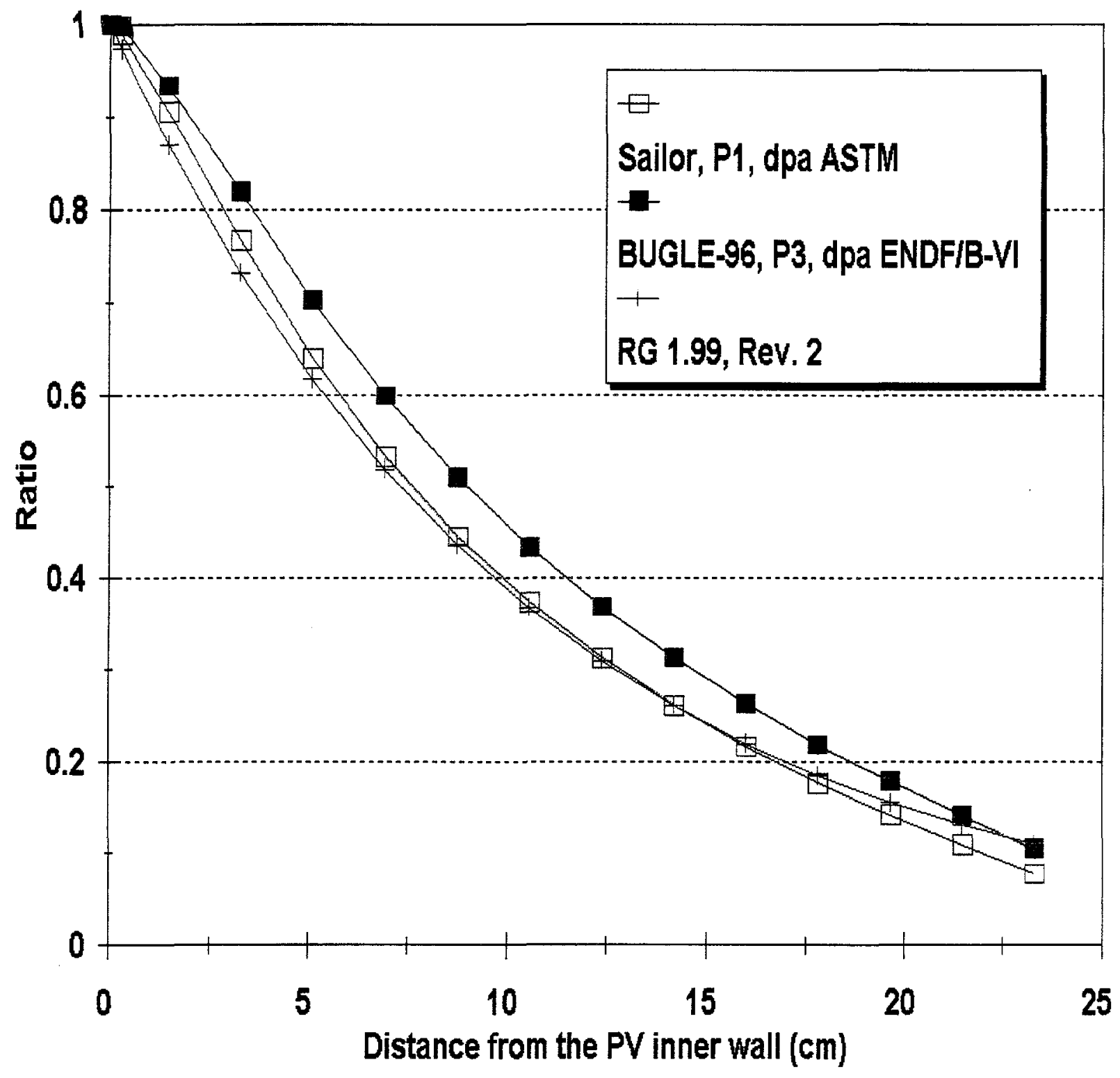

Figure 17 Comparison of the attenuation in the PV wall, as obtained from the BUGLE-96 calculation with $P_{3}$ approximation, and ENDF/B-VI dpa cross-sections; and SAILOR calculation with $P_{1}$ approximation and ASTM dpa cross sections. The curve derived from RG 1.99, Rev. 2, formula is also given 


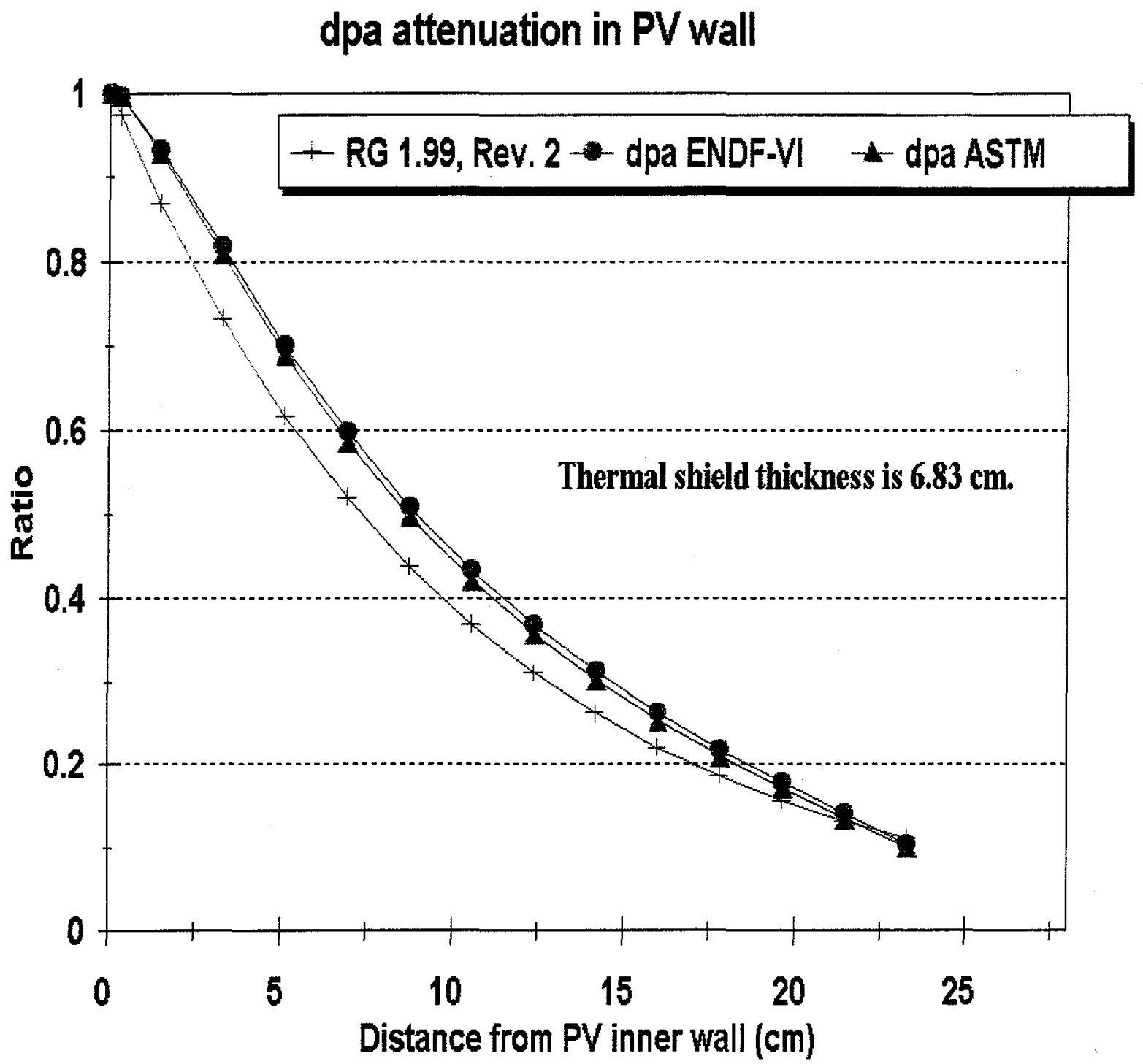

Figure 18 Comparison of the dpa rate attenuation in the PV wall, calculated with ENDF/B-VI and ASTM dpa cross sections. Neutron fluxes are from the BUGLE-96 calculation. HBR-2 "nominal" geometry was used 
Flux $(E>1 \mathrm{MeV})$ versus azimuthal angle

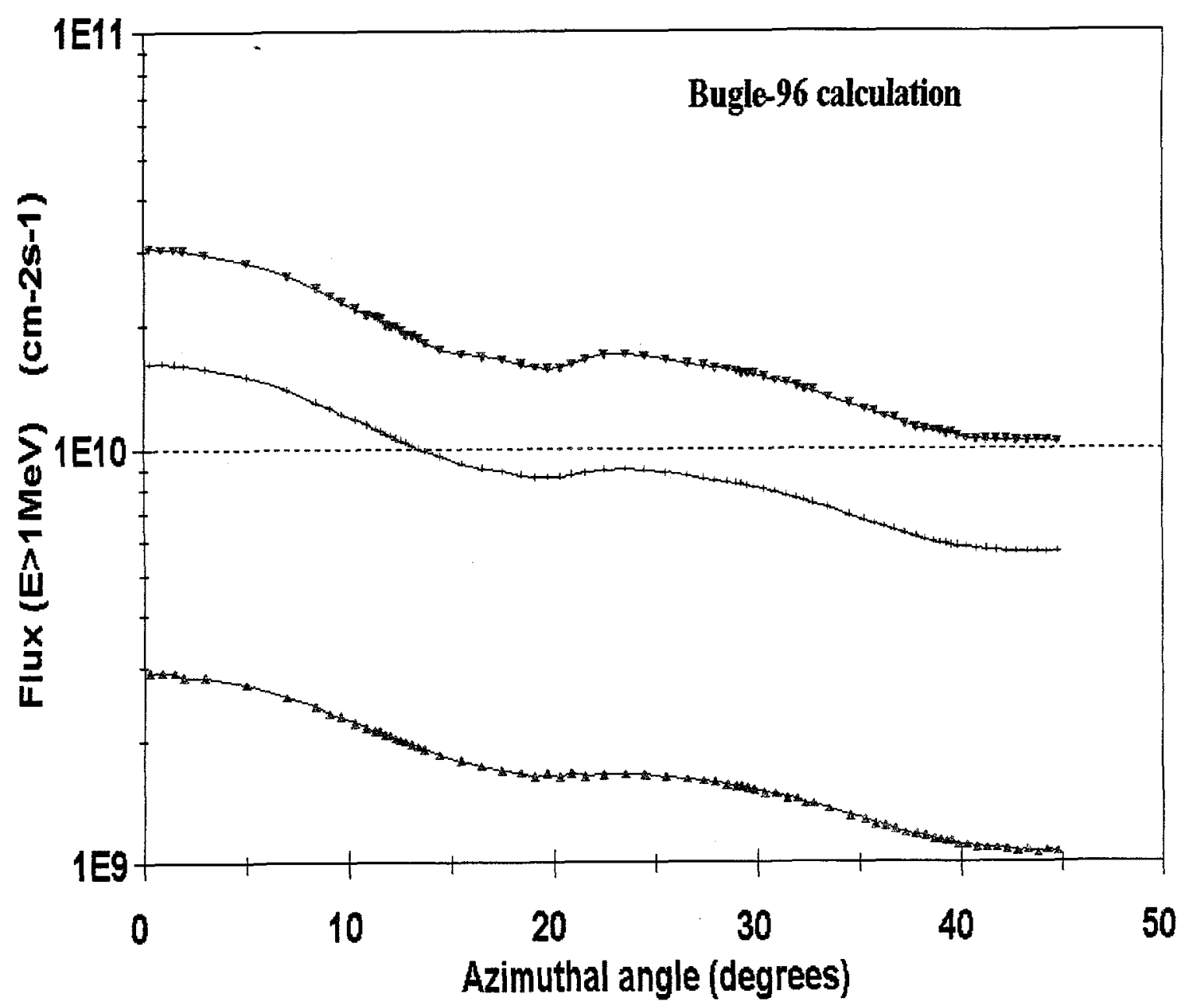

$\rightarrow$ Inner Radius $-1 / 4 \mathrm{~T} \quad-3 / 4 \mathrm{~T}$

Figure 19 Flux $(E>1 \mathrm{MeV})$ versus azimuthal angle, at the $P V$ inner radius, and at the $1 / 4$ and $3 / 4$ of the $P V$ wall thickness from the $P V$ inner surface. Calculations were done with BUGLE-96 cross-section library for "nominal" HBR-2 geometry 


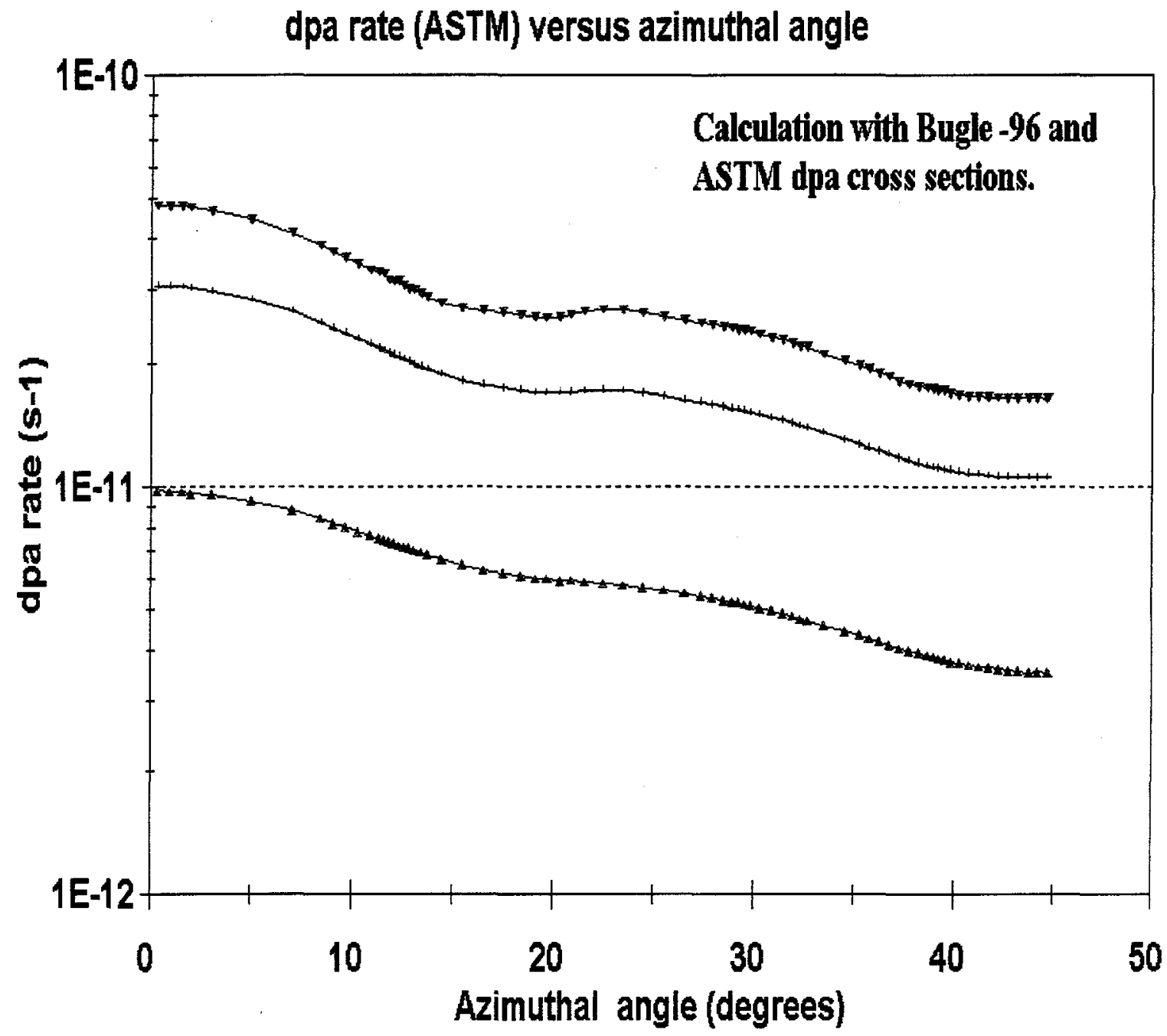

Figure 20 Dpa rate versus azimuthal angle, at the PV inner radius, and at the 1/4 and $3 / 4$ of the PV wall thickness from the $P V$ inner surface. Calculations were done with BUGLE-96 cross-section library and ASTM dpa cross sections, for "nominal" HBR-2 geometry 


\section{Flux (E>1MeV) attenuation in PV wall}

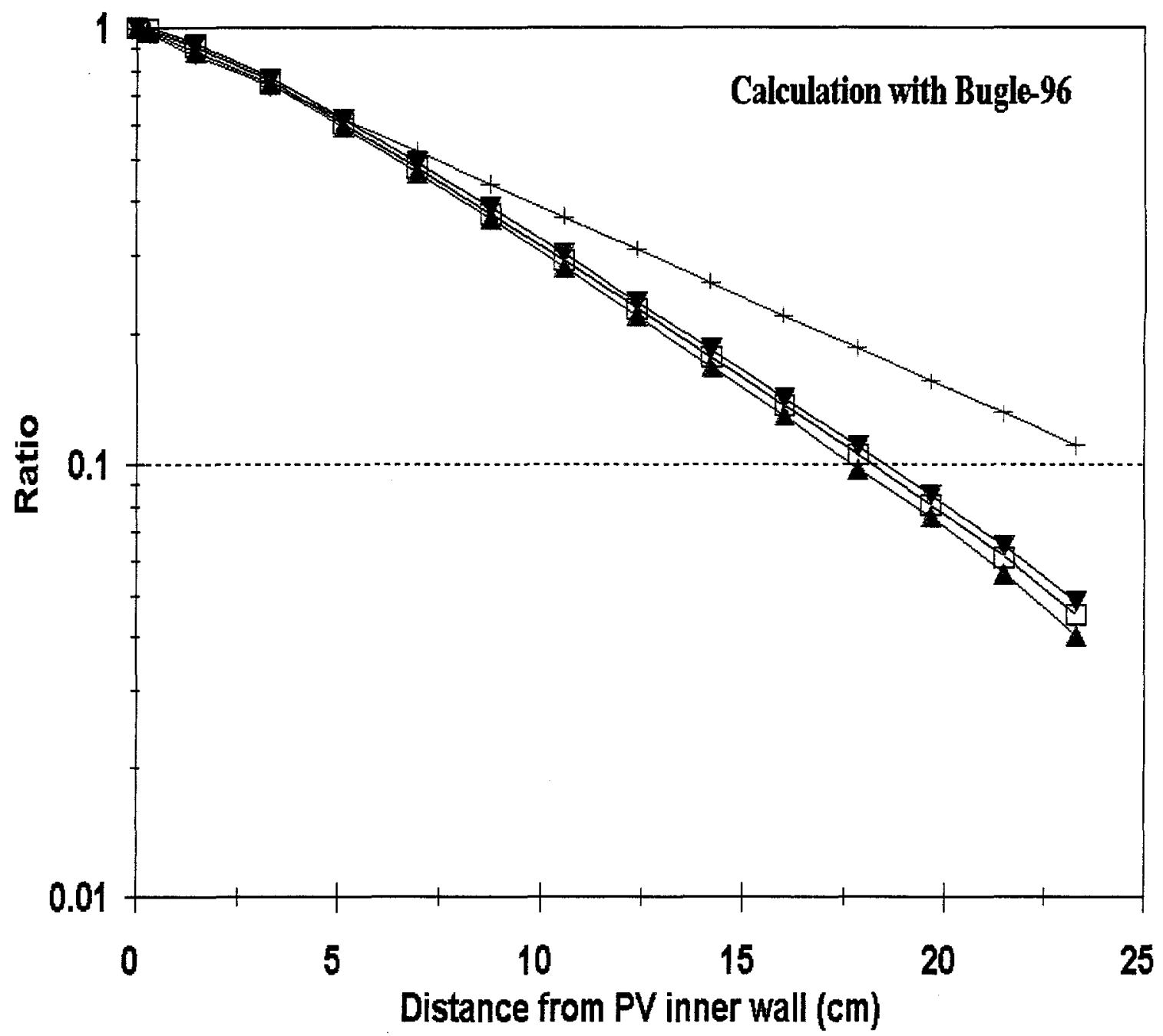

\section{RG 1.99 Rev $2 \square$ Average \\ $\rightarrow$ Maximum Minimum}

Figure 21 Flux (E $>1 \mathrm{MeV}$ ) attenuation in the PV wall. The curve labeled "average" gives the ratio of the flux at the given depth, "d," from the inner surface to the flux at the PV inner surface, averaged (arithmetic average) over all the azimuthal intervals. Curves labeled "maximum" and "minimum" give the maximum and minimum ratios over all the azimuthal intervals, respectively 


\section{dpa rate (ASTM) attenuation in PV wall}

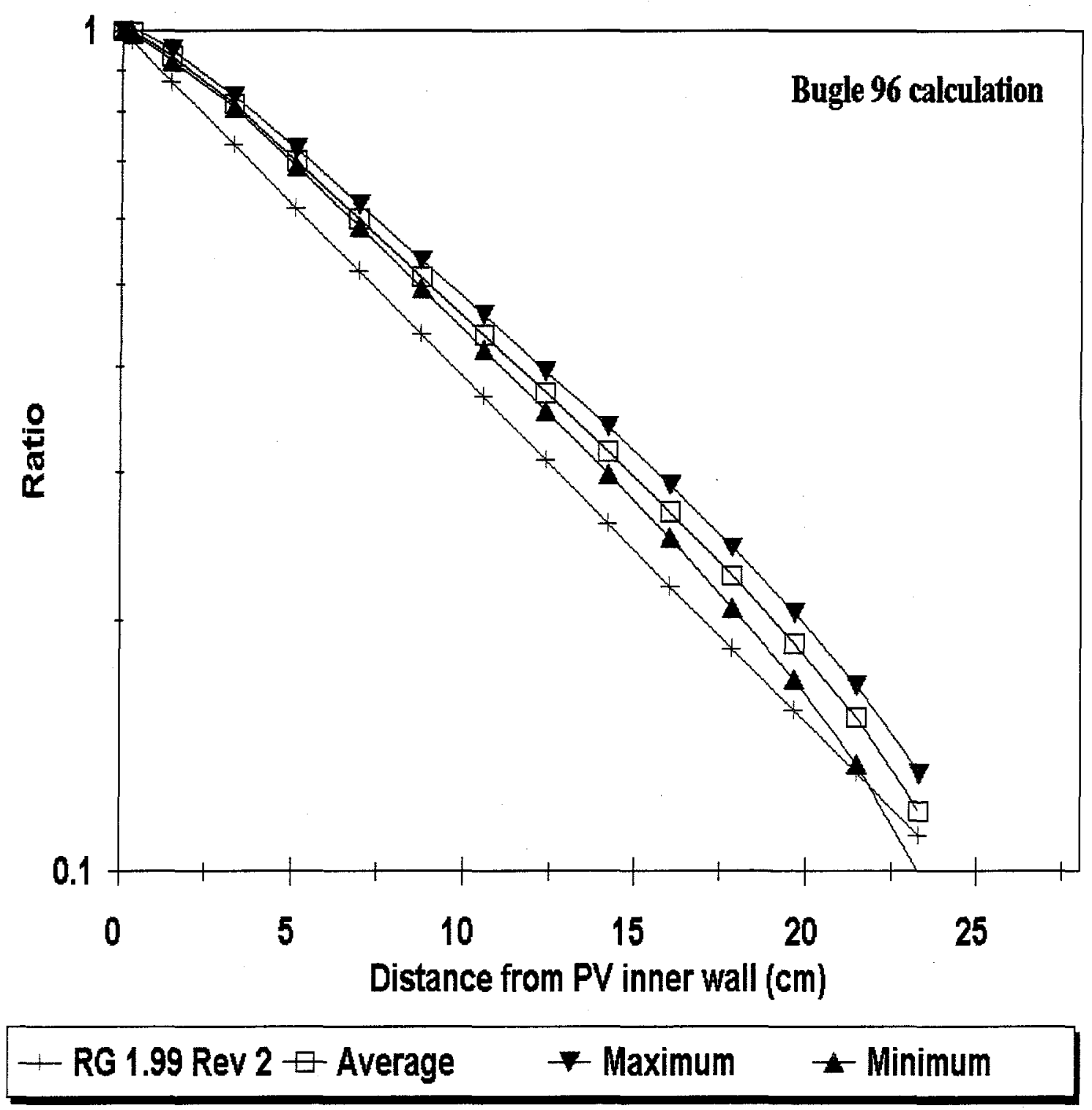

Figure 22 Dpa rate attenuation in the PV wall. The curve labeled "average" gives the ratio of the dpa rate at the given depth, " $d$," from the inner surface to the dpa rate at the PV inner surface, averaged (arithmetic average) over all the azimuthal intervals. The curves labeled "maximum" and "minimum" give the maximum and minimum ratios over all the azimuthal intervals, respectively. Dpa rates were obtained from the calculations with BUGLE-96 and ASTM dpa cross sections 
Flux (E > $1 \mathrm{MeV}$ ) attenuation

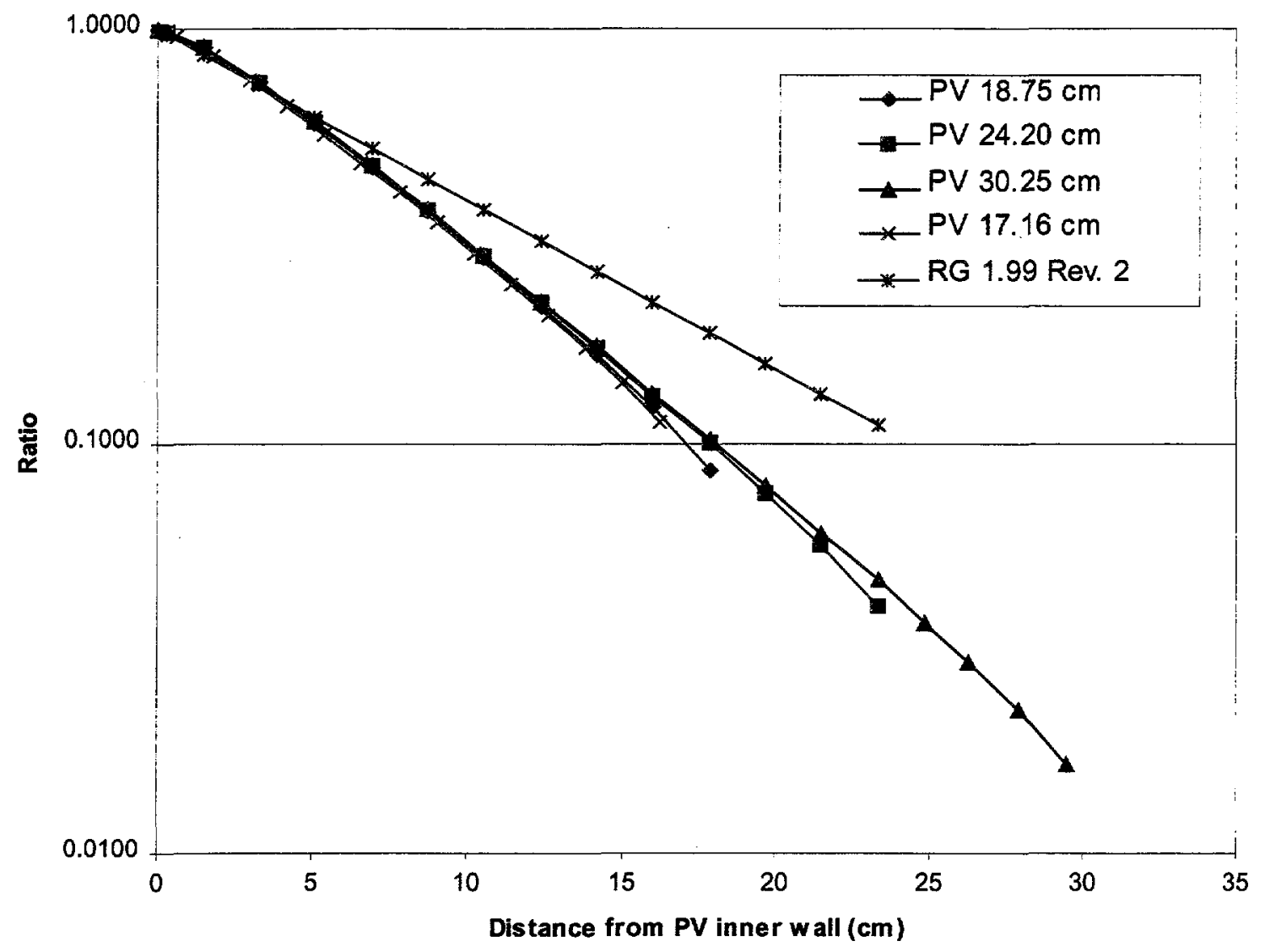

Figure 23 Flux ( $\mathrm{E}>1 \mathrm{MeV}$ ) attenuation in the PV wall, calculated with BUGLE-96 library, for different PV wall thicknesses. The calculations for the PV thickness of $17.16 \mathrm{~cm}$ were done for a two-loop plant. The other curves are those from Figure 5 
Flux $(E>0.1 \mathrm{MeV})$ attenuation in the PV wall

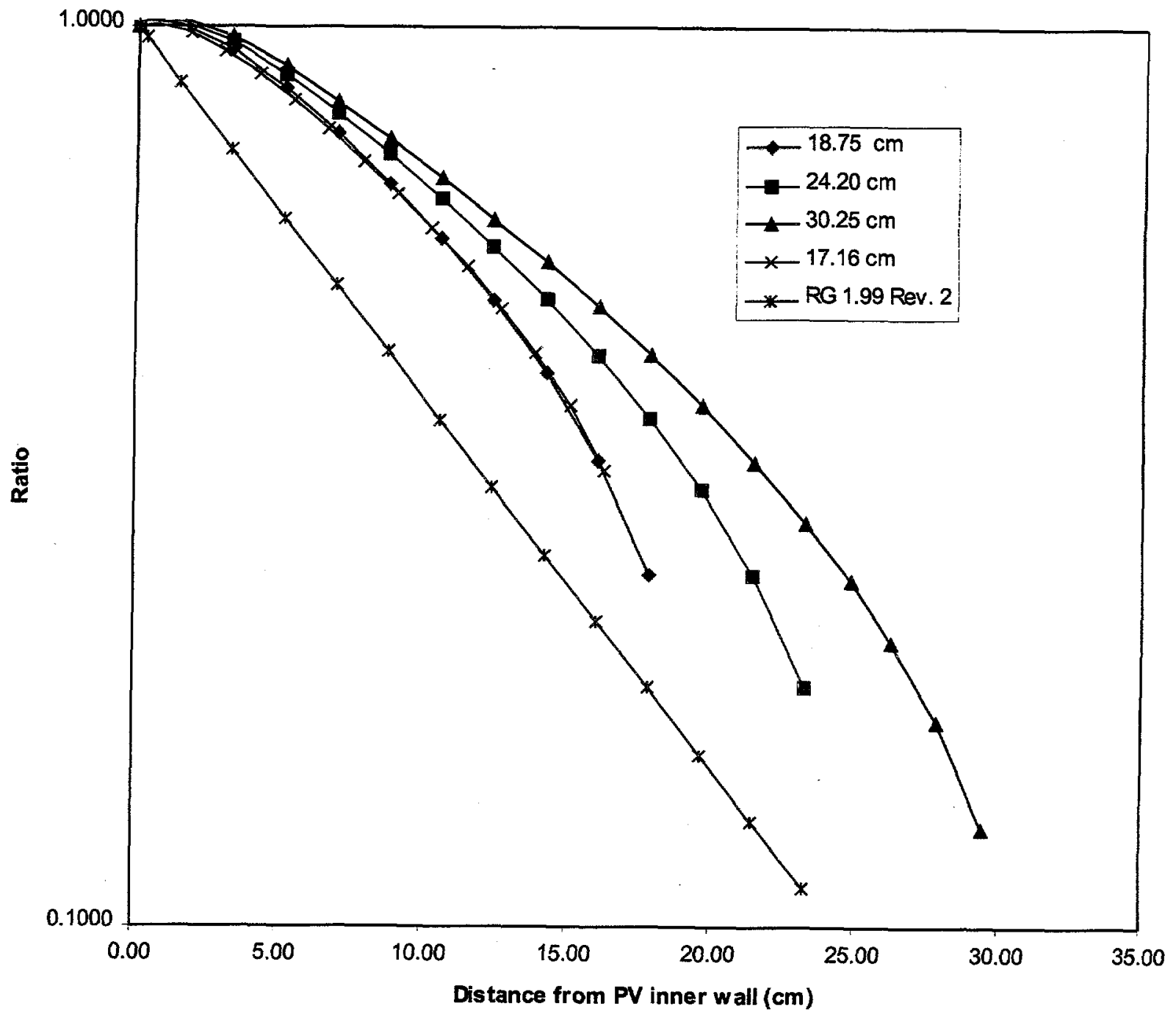

Figure 24 Flux (E $>0.1 \mathrm{MeV}$ ) attenuation in the PV wall, calculated with BUGLE-96 library, for different PV wall thicknesses. Calculations for the PV thickness of $17.16 \mathrm{~cm}$ were done for a two-loop plant. Other curves are from Figure 8 
Dpa rate (ASTM) attenuation in the PV wall

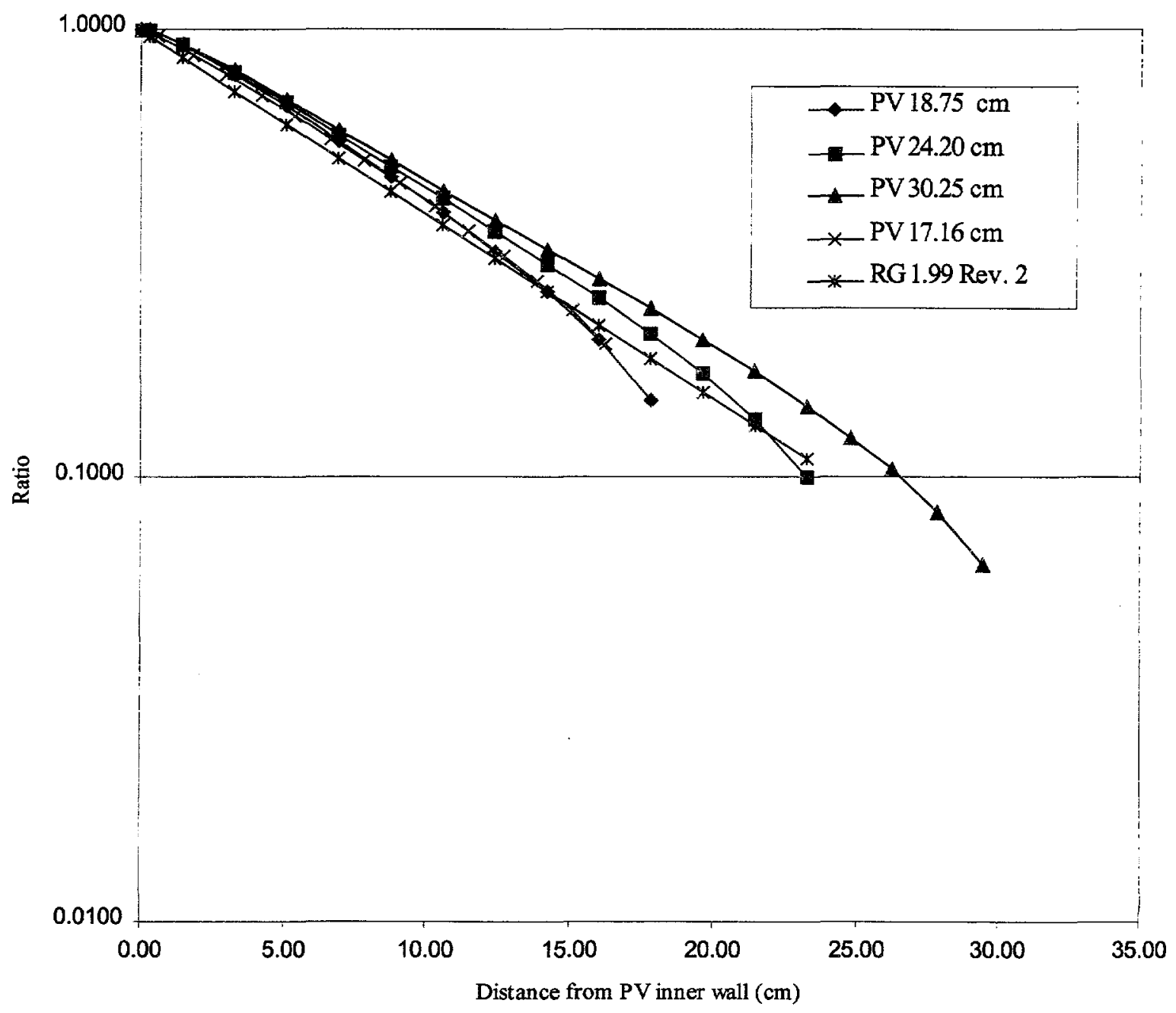

Figure 25 Dpa rate attenuation in the PV wall, calculated with BUGLE-96 library and the ASTM dpa cross sections, for different PV wall thicknesses. Calculations for the PV thickness of $17.16 \mathrm{~cm}$ were done for a two-loop plant. Other curves show data from Table 8 
Dpa rate ( $(N D F / B-V I)$ attenuation in the $P V$ w all

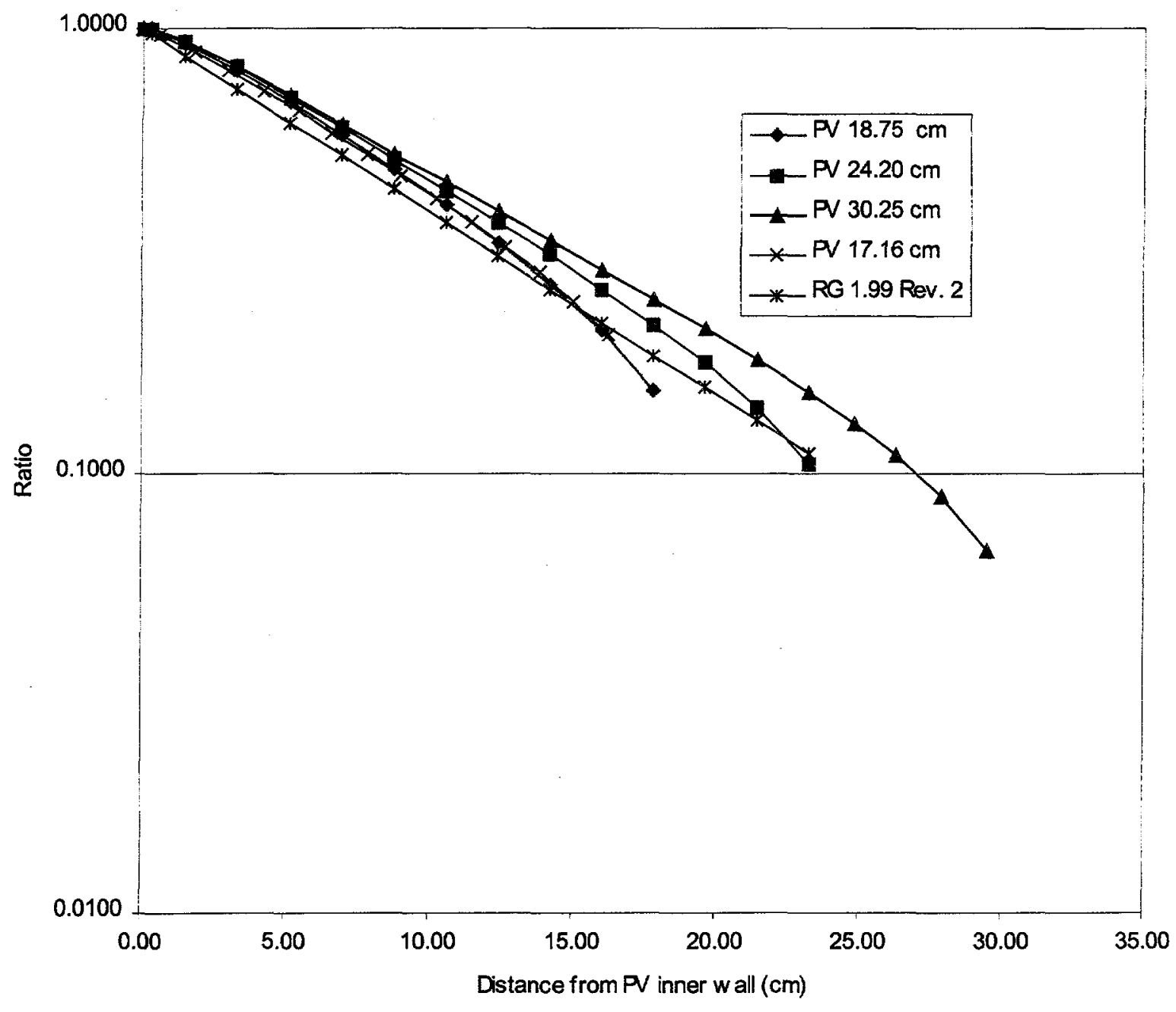

Figure 26 Dpa rate attenuation in the PV wall, calculated with BUGLE-96 library and ENDF/B-VI dpa cross sections, for different PV wall thicknesses. Calculations for the PV thickness of $17.16 \mathrm{~cm}$ were done for a two-loop plant. Other curves are from Figure 6 
(A) 
ORNL/NRC/LTR-99/5

\section{INTERNAL DISTRIBUTION}

1. K. J. Clayton

2. H. T. Hunter

3. D. T. Ingersoll

4. M. A. Kuliasha

5. J. V. Pace III

6. C. E. Pugh

7. I. Remec

8. C. H. Shappert

9. D. B. Simpson
10. J. A. Wang

11. R. M. Westfall

12. J. E. White

13. B. A. Worley

14. Central Research Library

15-16. Laboratory Records for Submission to OSTI

17. Laboratory Records - RC

\section{EXTERNAL DISTRIBUTION}

18. A. Abderrahim, SCK/CEN Fuel Research Unit, Boeretang 200, B-2400 MOL, Belgium

19. J. Adams, NIST, Bldg. 235, A-156, Gaithersburg, MD 20899-0001

20. A. F. Albornoz, National Atomic Energy Comm., Advanced Reactors Phys. Div., Ar. Ezequiel Bustillo 9500, 8400 San Carlos De Bariloche, Ris Negro, Argentine

21. S. L. Anderson, Radiation and Environmental Systems, Westinghouse Electric Corporation, Nuclear Energy Systems, Monroeville Nuclear Center, P.O. Box 355, Pittsburgh, PA 15230

22. J. F. Carew, Bldg. 130, Department of Nuclear Engineering, Brookhaven National Laboratory, Upton Long Island, New York 11973

23. J. W. Craig, U.S. Nuclear Regulatory Commission, Division of Engineering Technology, MS-T10D20, Washington, DC 20555-0001

24. I. Curl, AEA Technology plc, Reactor Physics, Shielding \& Criticality Dept., Winfrith, Dorchester, Dorset, DT28DH, United Kingdom

25. P. D'Hondt, SCK/CEN, Boeretang 200, B-2400 MOL, Belgium

26. C. J. Fairbanks, U.S. Nuclear Regulatory Commission, Materials Engineering Branch, Two White Flint North, MS-T10E10, 11545 Rockville Pike, N. Bethesda, MD 20852-2783

27. P. J. Griffin, Radiation Metrology Laboratory, MS 1172, Sandia National Laboratories, P.O. Box 5800, Albuquerque, NM 87112

28. E. M. Hackett, U.S. Nuclear Regulatory Commission, Materials Engineering Branch, MS-T 10 E10, Washington, DC 20555

29. A. Haghighat, The Pennsylvania State University, 231 Sackett Bldg., University Park, PA $16802-1408$

30. W. R. Jones, U.S. Nuclear Regulatory Commission, Reactor Analysis Branch, MS-T 4 A9, Washington, DC 20555

31. E. P. Lippincott, 1776 McClure Rd., Monroeville, PA 15146

32. L. Lois, Office of Nuclear Regulatory Research, Division of Systems Safety and Analysis, MS-ONFN8E23, Washington, DC 20555-0001 
33. M. E. Mayfield, U.S. Nuclear Regulatory Commission, Materials Engineering Branch, MST10E10, N. Bethesda, MD 20852-2783

34. M. A. Mitchell, U.S. Nuclear Regulatory Commission, Materials and Chemical Engineering Branch, MS-O 7 D4, Washington, DC 20555

35. B. C. Na, OECD Nuclear Energy Agency, Le Seine St-Germain, 12 boul.des Iles, 92130 Issy les Moulineaux, France

36. E. Polke, Siemens-KWU, Freyeslebenstr.1, D-91058 Erlangen, Germany

37. G. Reffo, Italian National Agency for New Technology, C.R.E. e. CLEMENTEL, Via Martiri di Monte Sole n.4, 40129 - Bologna Italy

38. M. Suzuki, Reactor Component Reliability, Dept. Of Reactor Safety Res., JAERI, Tokaimura, Ibaraki 319-11

39. R. D. Thompson, U.S. Nuclear Regulatory Commission, Property and Oversight Branch, Mail Stop T-7 I2, Washington, DC 20555-0001

40. W. T. Urban, Los Alamos National Laboratory, MS B 226 Los Alamos, New Mexico

41. J. G. Williams, University of Arizona, Nuclear Reactor Laboratory, Dept. of Nuclear \& Energy Engineering, Tucson, AZ 85721

42. M. L. Williams, LSU Nuclear Science Center, Louisiana State University, Baton Rouge, LA 70803

43. S. Zaritsky, Kurchatov Institute, Kurchatov Square, 123182 Moscow, Russia 